DARON ACEMOGLU Massachusetts Institute of Technology

SIMON JOHNSON

International Monetary Fund
PABLO QUERUBÍN

Massachusetts Institute of Technology

JAMES A. ROBINSON

Harvard University

\title{
When Does Policy Reform Work? The Case of Central Bank Independence
}

ABSTRACT Questions of the effectiveness of economic policy reform are inseparable from the political economy factors responsible for distortionary policies in the first place. Distortionary policies are more likely to be adopted where politicians face fewer constraints. Hence reform should have modest effects in societies where the political system already imposes strong constraints, and in societies with weak constraints, because it does not alter the underlying political economy. Reform should be most effective in societies with intermediate constraints. Furthermore, effective reform in one dimension may lead to deterioration in others, as politicians address the underlying demands through other means-a phenomenon we call the seesaw effect. We report evidence that central bank reforms reduced inflation in countries with intermediate constraints but had no or little effect where constraints were strong or weak. We also present evidence consistent with the seesaw effect: in countries where central bank reform reduces inflation, government expenditure tends to increase.

nstitutional and policy reforms are often promoted as a way to improve

economic performance and growth in poor countries. Reforms that have received substantial attention over the past decade or so include opening to trade, financial liberalization, judicial reform, privatization of state enterprises, reduction of entry barriers, tax reform, removal of targeted industrial subsidies, and central bank independence. The list thus includes not only those in the original Washington consensus, ${ }^{1}$ but also a range of other reforms.

1. Williamson (1990). 
Although there are sound economic theories suggesting why these reforms might be important in improving economic performance, the experience of the last decade shows that such reforms rarely seem to have the effects anticipated by their proponents. Nicolas van de Walle, for instance, summarizes the ineffectiveness of reform in sub-Saharan Africa by noting that "at the dawn of the twenty-first century, most of sub-Saharan Africa remains mired in economic crisis despite two decades of donor-sponsored reform efforts. ... Many if not most African countries are poorer today than they were twenty years ago."2 Similarly, Andrés Velasco, the current Chilean finance minister, articulates the widespread disillusion with the impact of reform in Latin America:

Reformers argued, persuasively, that growth was being held back by distortions. Many of the distortions were government induced, the result of poorly conceived policies. Change policy and the economy will fulfill its potential. . . . A decade later the view is less sanguine: with fewer bad-policy distortions, the Latin American economies grew in the 1990s at half the rate attained during precisely those decades when the allegedly distorting policies of import substitution reached their peak: the 1960s and 1970s. ${ }^{3}$

Why do seemingly sensible reforms fail to generate the benefits they promise? The critics of reform emphasize, among other things, the potential negative effects of international trade on infant industries, the instabilities that might be induced by financial liberalization, and the usefulness of a variety of regulations, government ownership, and industrial policy in less developed economies. ${ }^{4}$ Joseph Stiglitz, for example, argues that in many cases "the economic policies that evolved into the Washington Consensus and were introduced into developing countries were not appropriate for countries in the early stages of development or ... transition [from central planning]." ${ }^{5}$

This is not the only way to interpret the apparent failure of reform, however. In this paper we emphasize that to understand why reforms do or do not work, it is necessary to investigate the political economy of distortionary policies. Our general argument is that the analysis of whether and which reforms will lead to improved economic performance should start with an understanding of why distortionary policies were in place to start with. We show that this perspective leads to some simple, testable ideas

2. Van de Walle (2001, pp. 3-4).

3. Velasco (2005, p. 2).

4. See Rodrik (2005).

5. Stiglitz (2002, p. 16). 
about when policy reform will be more effective, and we provide preliminary evidence consistent with these ideas. ${ }^{6}$

Much of the economic literature on policy reform and most of the advice given by international institutions assume, implicitly or explicitly, that distortionary policies came about by accident. Either these policies were put in place long ago and remain as a historical legacy, or they are the outcome of some mistaken economic theory or shortsightedness on the part of policymakers. But this perspective is limited at best. Although one can undoubtedly find instances where mistaken economic theories led to disastrous policies, few policymakers create hyperinflations or large budget deficits because they think these are good for the economy.

What, then, might explain the presence of bad policies? The literature on political economy suggests that bad policies arise because the preferences of politicians or others holding power are not aligned with those of the rest of the society. The politically powerful may have an incentive to distort policies or institutions so as to redistribute income or power to themselves. ${ }^{7}$ Their ability to do so will depend on the constraints they face and, more generally, on the structure of political institutions. A potent source of policy failure is the absence of constraints on political officeholders, in the form of checks and balances on their actions and means of holding them accountable. ${ }^{8}$ This perspective emphasizes that policy reform takes place in an environment where existing policies serve political purposes, such as redistributing resources to groups with power and influence. This implies that those who expect to see their economic rents or privileges disappear as a result of policy reform are likely to use their political power to prevent its effective implementation.

Alternatively, political realities may make it impossible or impractical for those entrusted with the implementation of reform to carry it out. This implies a potentially large gap between de jure reform and de facto reform. In particular, only those policy reforms that the politically powerful beneficiaries of the distortionary policies cannot easily override, cir-

6. An alternative and complementary perspective is that reformers, aware of the political constraints underlying policy decisions, may push for reforms and emphasize their economic benefits as part of a bargaining process among political groups and policymakers. This perspective, although plausible, has not been developed in the literature and must also ultimately model the political economy of reform.

7. See, for example, Acemoglu (2006).

8. See, for example, North and Weingast (1989), Persson, Roland, and Tabellini (1997), Henisz (2000), and Acemoglu, Johnson, and Robinson (2005). 
cumvent, or ignore are likely to achieve their objectives. Whether or not these groups can thwart reform depends in turn on the constraints on politicians and on the policymaking process. This argument suggests that in societies such as many in sub-Saharan Africa, where politicians and politically powerful groups face only a few constraints on their power, policy reform is unlikely to be very effective. This is consistent with the case study evidence and argument presented by van de Walle, ${ }^{9}$ who illustrates that for African politicians, "restoring economic stability and growth has often taken a back seat in government motivations to preserving political power." ${ }^{10}$ In the context of structural adjustment, van de Walle argues,

Often, the policies have changed on paper, but in practice, something resembling the status quo ante continues to prevail. In some cases, the old policies were reinstated under a new name or with some new policy objective. ... In other cases, governments ignore the spirit of their own liberalization efforts by continuing to interfere in officially deregulated markets. ${ }^{11}$

Under these circumstances, the ineffectiveness of reform is not surprising; few people would expect privatization, financial liberalization, or central bank independence (CBI) to have fundamental effects in Zimbabwe as long as Robert Mugabe is in power, for example, or in Sudan as long as Omar al-Bashir's kleptocratic and genocidal regime remains in place. To illustrate, figure 1 plots the inflation rate in Zimbabwe; the vertical line at 1995 indicates when the Central Bank Act was modified to grant the Reserve Bank of Zimbabwe greater independence. ${ }^{12}$ Clearly, increased CBI did little to restrain Zimbabwe's subsequent monetary policy. This somewhat extreme example illustrates that a major reason why policy reform often fails is the absence of a functioning system of accountability and a lack of constraints and checks on politicians. ${ }^{13}$

9. Van de Walle $(1993,2001)$.

10. Van de Walle (2001, p. 13).

11. Van de Walle (2001, p. 76).

12. The 1995 Reserve Bank of Zimbabwe Act legislated a greater degree of autonomy for the central bank. After 1995 the bank had its own budget and could decide on its own finances. The act also established the control of inflation as the unique objective of monetary policy.

13. This example and our results below raise the question of why potentially ineffective reforms are implemented in the first place. One obvious answer is that they are partly a response to external pressures. For example, Jácome (2001) documents how an International Monetary Fund technical assistance mission to Zimbabwe exerted pressure for the reform of central bank laws in 1995. This perspective suggests that externally imposed policy reforms might be less successful and effective than those generated by internal dynamics. 
Figure 1. Inflation in Zimbabwe before and after Central Bank Independence, 1965-2007

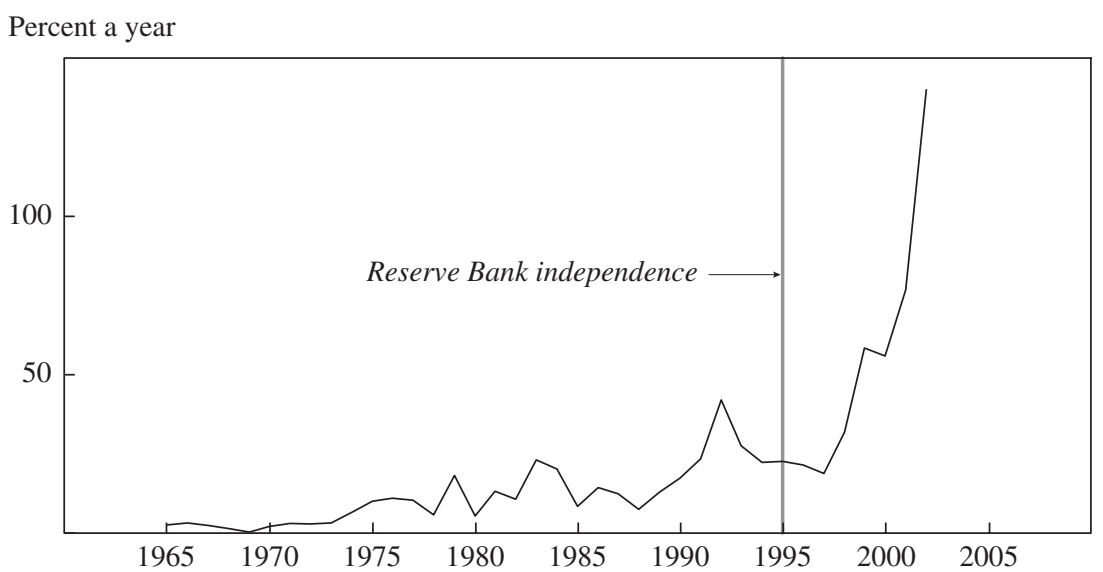

Sources: International Monetary Fund, International Financial Statistics; Polillo and Guillén (2005).

Does this imply that better political institutions and transparency will increase the impact of reforms? Not necessarily. Policy reform has its greatest potential effect when the prereform policies are highly distortionary. However, one would not expect a society with a functioning system of accountability and with checks on politicians to be pursuing highly distortionary policies in the first place. For example, inflation was already low in the United Kingdom in the 1990s, before the Bank of England became independent in 1998. ${ }^{14}$ Thus room for a large effect from CBI was limited. Rather, high inflation or even hyperinflation is much more likely in societies with weak institutions than in those where politicians are accountable, through elections or other means, to the population at large.

These arguments suggest that from a political economy perspective, policy reform should not be expected to be equally effective in every society; rather, the functioning and success of reform should depend on political institutions and political constraints. More specifically, these arguments suggest a potentially nonmonotonic relationship between the extent of

14. Inflation increased in the United Kingdom in the 1970s and early 1980s but never approached hyperinflationary levels. The desire to avoid a return of such episodes, as well as to realize the other benefits of CBI, such as greater credibility and transparency of monetary policy, might be among the reasons why countries with relatively good policies still prefer to implement central bank reform. 
constraints on politicians and the effectiveness of reform. The importance of political economy factors in understanding and evaluating the success of policy reform is this paper's main message.

We develop this perspective by investigating, both theoretically and empirically, the interplay between policy reform and institutional constraints on politicians. We first delineate the main issues using a simple theoretical model that illustrates how the relationship between constraints on power and the impact of reforms could be nonmonotonic. The model also highlights how effective reform may sometimes lead to the deterioration of other, unreformed policies-a phenomenon that in previous work we have called the seesaw effect. ${ }^{15}$

We then investigate the validity of these ideas by focusing on reforms related to central bank independence. CBI is a natural type of reform for us to study. Most other reforms, such as financial liberalization, judicial reform, or removal of targeted subsidies, have relatively broad mandates and try to improve, among other things, the overall functioning of the economy, investment, and growth. CBI, in contrast, has a much more clearly delineated target: inflation. We can thus judge the success of CBI by whether or not it has reduced inflation. Nevertheless, even this investigation is complicated by the fact that countries often introduce CBI not as a stand-alone policy reform, but as part of a broader anti-inflation package. ${ }^{16}$ In such cases, therefore, we interpret the regression evidence on the implications of $\mathrm{CBI}$ as corresponding to the effects of this broad package.

Our main empirical results are consistent with the hypothesis of a nonmonotonic relationship between political constraints and the effectiveness of policy reform. We create an index of the quality of general institutions by using constraints on the executive from Polity IV data. Although the highly serially correlated nature of data on inflation makes statistical inference difficult, the evidence is broadly consistent with a pattern in which CBI reduced inflation in countries with intermediate levels of constraints on the executive but appears to have had no effect in countries with the strongest institutions. For countries with the weakest institutions, the general pattern is likewise one of no effect, although some specifications show

15. Acemoglu and others (2003).

16. A clear example is Argentina, where, shortly before the introduction of CBI in 1992, a currency board was established to peg the exchange rate to the dollar. Figure B2 in appendix B also shows that, in a number of countries, inflation begins to decline a few years before the introduction of CBI. 
a statistically significant, but generally nonrobust, negative effect. Our empirical results reject the hypothesis that the effect of $\mathrm{CBI}$ is the same in countries with strong as in those with medium constraints, but we are generally unable to reject the hypothesis that the effect is the same in countries with medium and weak constraints.

Overall, our approach and empirical results suggest that reform of economic institutions will be effective only if the political context is right. If the context already provides political constraints and accountability mechanisms that produce a strong tendency to adopt good policies, there will be little room for reform to have major effects. If the context is poor, so that politics and policymaking are highly nonrepresentative, reform is likely to be irrelevant, because it can easily be undermined. It is in the intermediate situations that reform may have some bite: constraints in such cases are weak enough to generate bad policy, but not so weak that all reform can be undermined.

In this light, our findings point to a different interpretation of the apparent failure of the various reforms implemented throughout the 1990s and early 2000s than those argued by either the skeptics or the advocates of reform. First, contrary to the skeptics, it is not true that all reforms have failed. In the case of CBI, the empirical focus in this paper, it appears that policy reform is associated with a significant decline in inflation in societies with intermediate (and sometimes those with weak) constraints on politicians. Second, our results suggest that even in countries where reform has failed, it has not done so because it was inappropriate from an economic point of view. Rather, potentially sound economic reform may often be politically nonviable in certain societies, at least if it does not take into account the political context.

Nevertheless, we emphasize that all of the evidence provided in this paper corresponds to the conditional correlations in the data consistent with declines in inflation at the same time as or following central banking reform (and not to the causal effect of CBI on inflation). As we stress further below, policy reform in general and central bank reform in particular are endogenous, determined as part of the political economy equilibrium in the society. Consequently, one should be cautious about reaching strong conclusions on the basis of such evidence. Having said that, the fact that CBI is correlated with contemporaneous and future declines in inflation mostly in societies with intermediate levels of constraints on politicians is intriguing and, at the very least, requires further investigation. 
After reporting these basic findings, we go on to investigate whether there is any evidence of a seesaw effect following CBI. The seesaw effect suggests that when successful policy reform takes place in one dimension and the political equilibrium remains largely unchanged, politicians may try to use a different instrument to attain the goal previously targeted with the instrument now being reformed. In general, the seesaw effect implies that as policy gets better in one dimension, it may get worse in another. A natural candidate for the seesaw effect in the context of CBI is fiscal policy. We therefore investigate whether or not fiscal policy changes significantly after CBI is introduced. We provide some evidence that CBI is associated with greater government expenditure as a percentage of GDP in countries with intermediate constraints, and unrelated to government expenditure in countries with weak or strong constraints. This evidence is consistent with some worsening in other dimensions of policy in countries where CBI reform has been effective in reducing inflation, although the effect of CBI on government expenditure is less robust than its impact on inflation.

The recent economic history of Colombia and Argentina, depicted in figure 2, illustrates the seesaw effect. In both countries the introduction of CBI in 1991 was followed by both a significant fall in inflation and an increase in government expenditure as a percentage of GDP. In the Argentinean case, as in many other countries in our sample, inflation started falling before the central bank reform, which, as mentioned above, suggests that CBI is part of a broader package of reforms aimed at controlling and stabilizing inflation.

In Colombia it is widely alleged that, in the mid-1990s, President Ernesto Samper engaged in extensive clientelism in an effort to remain in power following the revelation that he had received large amounts of money from the Cali drug cartel. ${ }^{17}$ The situation somewhat resembled that in the 1970s, when President Misael Pastrana used clientelism to broaden his political support following a disputed election. ${ }^{18}$ But Pastrana was able to direct the central bank, which was not then independent, to give easy credit to various firms and sectors; this, in combination with increased expenditure financed by seigniorage, caused inflation to accelerate. ${ }^{19}$ Samper, in contrast, came to power after the central bank had become independent. As a consequence, he had to rely more heavily on increasing expenditure, largely in the form of wage increases for public

17. See, for example, Sierra Montoya (2004).

18. Jaramillo, Steiner, and Salazar (1997).

19. Cabrera Galvis and Ocampo (1980, p. 136). 
Figure 2. The Seesaw Effect in Colombia and Argentina
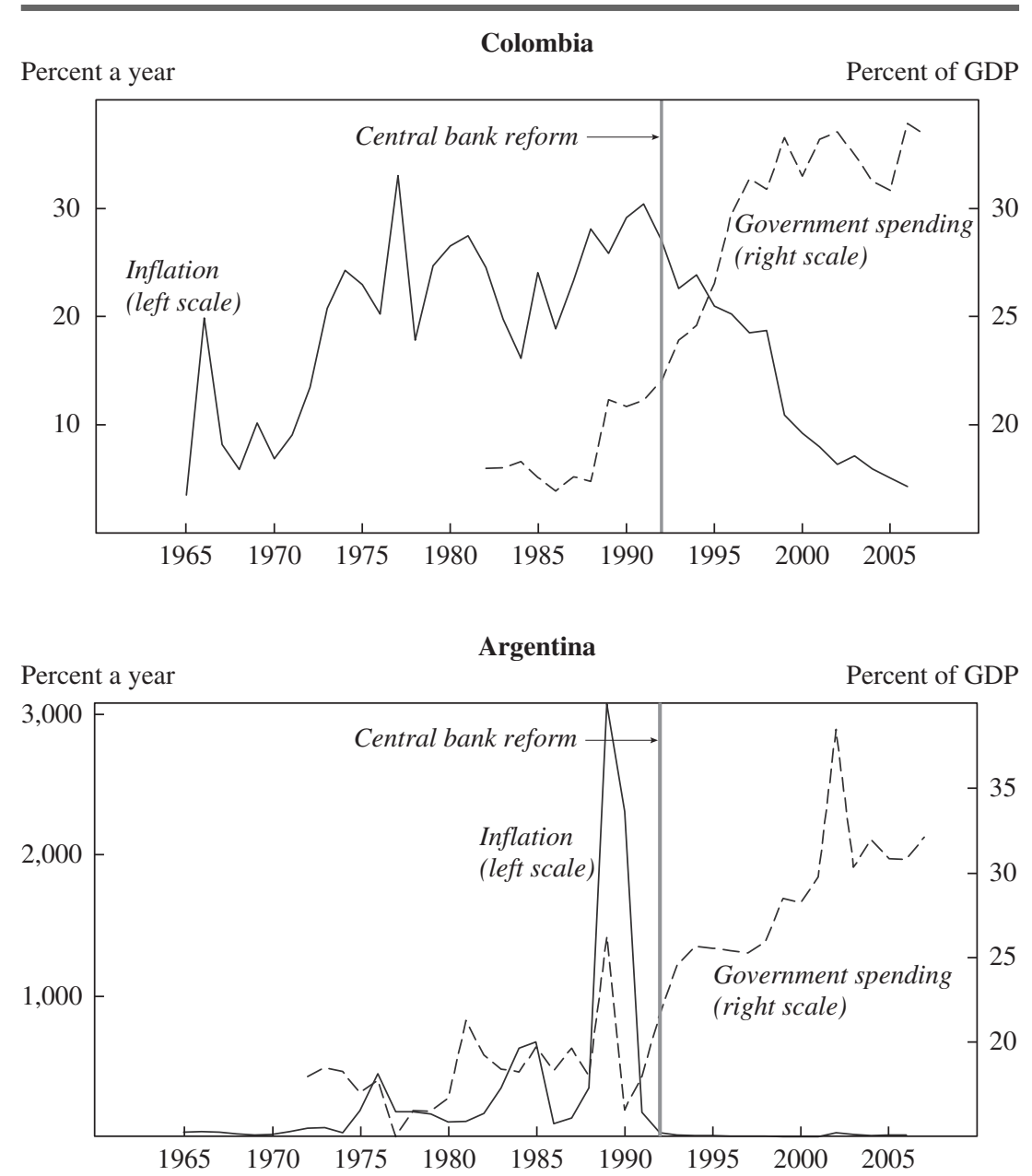

Source: International Monetary Fund, International Financial Statistics and World Economic Outlook; Jácome and Vásquez (2005).

employees and increased military spending. ${ }^{20}$ The central bank largely offset the inflationary effects of this expansionary fiscal policy with contractionary monetary policy. ${ }^{21}$

The rest of the paper is organized as follows. The next section discusses the relevant literature on the political economy of reform, on the

20. Echeverry (2002); Davila Ladron de Guevara and others (2000).

21. Reyes and others (1998). 
role of CBI in combating inflation, and on possible interactions between institutional factors and the effectiveness of policies. The following section presents a simple model illustrating why policy reform may be most influential in societies with intermediate levels of political constraints. We also use this model to show how policy reform in one sphere can lead to a deterioration of other dimensions of policy, creating a seesaw effect. The next section discusses our data sources and the construction of the CBI variable. The next presents our main empirical results, which suggest that, consistent with our theoretical expectations, CBI has little effect on inflation in societies with the strongest and the weakest constraints on politicians, but tends to reduce inflation in countries with intermediate levels of constraints. The penultimate section investigates the seesaw effect, looking for evidence, in societies where CBI has reduced inflation, of deterioration in other policies. The final section concludes.

\section{Related Literature}

Our paper is related to two broad areas of research, one on the political economy of reform in general and the other on the consequences of central bank independence. We now give a brief overview of these literatures and how our findings add to them.

\section{Political Economy of Reform}

A great deal of theoretical and case study work examines the political economy of reform. ${ }^{22}$ Most of the theoretical research focuses on developing explanations for why socially beneficial reforms do not occur or are delayed. ${ }^{23}$ Sharun Mukand and Dani Rodrik, however, develop a model in which policymakers adopt reforms they know to be inefficient in order to avoid being thought corrupt. ${ }^{24}$ Other work, taking political impediments to reform as given, discusses their implications for the sequencing of reforms, whether or not gradual or radical reform is desirable, and whether or not reform can be sustained. ${ }^{25}$ Most closely related to our paper are those by Maxim Boycko, Andrei Shleifer, and Robert Vishny, ${ }^{26}$ who examine the circumstances under which privatization increases effi-

22. See Rodrik (1996) and Drazen (2000) for overviews.

23. See, for example, Alesina and Drazen (1991) and Fernandez and Rodrik (1991).

24. Mukand and Rodrik (2005).

25. For example, Dewatripont and Roland (1997).

26. Shleifer and Vishny (1994); Boycko, Shleifer, and Vishny (1996). 
ciency. In their model, politicians derive political benefit from high employment, and even though the managers of a privatized firm may maximize profits with less employment, politicians can bribe them to employ more people. The same authors also study the circumstances under which employment falls after privatization. Stephen Coate and Stephen Morris, formalizing an intuition of George Stigler ${ }^{27}$ develop a model in which policy reform can reduce efficiency when politicians are initially using policy instruments to redistribute income in an optimal way. A key difference between our approach and Coate and Morris's is our emphasis on the role of political institutions. None of the papers mentioned above derive the nonmonotonic relationship between reform and outcomes that is at the heart of our model.

At a general level, the entire empirical literature on the impact of policy and policy reform on economic variables-for example, on economic growth — provides relevant and useful background to our work. That policy reform might be desirable is implied from regressions showing that variation in policies can account for variation in economic growth. Although certainly some papers argue this, the cross-country literature is far from a consensus. ${ }^{28}$ For instance, because policy variables exhibit multicollinearity, it is generally difficult to find robust relationships between particular policy measures and growth. Moreover, the empirical analysis in most of these papers is based on cross-sectional regressions, so that omitted-variable bias may be a significant concern. ${ }^{29}$

Most of the empirical work on reform focuses on specific instances of either failed or successful reforms. ${ }^{30}$ Among cross-national empirical studies, David Dollar and Jakob Svensson show that political factors, particularly whether or not a country has a democratic government and how long the government has been in power, are important for the success of World Bank programs. ${ }^{31}$ In the related context of the effectiveness of international aid, Craig Burnside and Dollar offer evidence that aid increases growth when combined with good institutions and policies, ${ }^{32}$ although William Easterly, Ross Levine, and David Roodman show that their results may not

27. Coate and Morris (2006); Stigler $(1971,1972)$.

28. See Easterly (2005) for a review.

29. There is also convincing microeconomic evidence that some specific types of reforms, such as privatization, can have large beneficial effects. See, for example, La Porta and Lopez-de-Silanes (1999) and Galiani, Gertler, and Schargrodsky (2005).

30. For example, Bates and Krueger (1993).

31. Dollar and Svensson (2000).

32. Burnside and Dollar (2000). 
be robust. ${ }^{33}$ The idea that the implications of policies or shocks depend on the institutional environment has also appeared in other empirical papers. For instance, Geert Bekaert, Campbell Harvey, and Christian Lundblad, and Halvar Mehlum, Karl-Ove Moene, and Ragnar Torvik, show that the effect of natural resource abundance on economic growth depends on the quality of institutions in the society. ${ }^{34}$

Our research is also related to the case study literature on Latin American politics, which has argued that the appearance and the reality of policy reform in Latin America may be very different. Several scholars have argued that the adoption of Washington consensus reforms in Latin America was accompanied by the continuation of populist policies and politics as usual. ${ }^{35}$ The adoption of these reforms did constrain which policies could be used, but politicians such as Carlos Menem in Argentina and Alberto Fujimori in Peru realized that even policy reform could be adjusted to the demands of clientelism: for example, government-owned firms could be privatized but sold relatively cheaply to those with political connections. Populism and clientelism persisted even though the instruments that they used changed, an argument clearly related to those we make in this paper.

\section{Central Bank Independence and Inflation}

One of the most studied types of policy reform is the introduction of CBI. Theoretical work in the early 1980s argued that when unanticipated changes in monetary policy can reduce the rate of unemployment, the government will be unable to commit to low inflation, and consequently inflation will be suboptimally high..$^{36}$ Kenneth Rogoff's proposed solution to this problem, namely, to delegate monetary policy to a conservative central banker, established a theoretical rationale for creating independent central banks. ${ }^{37}$

A large number of empirical studies over the past fifteen years have examined the impact of CBI on inflation, economic growth, and a variety of other variables. ${ }^{38}$ Some early studies used a measure of de jure CBI (we describe the construction of the various measures of CBI below) and exploited cross-sectional variation within OECD countries. ${ }^{39}$ Alberto

33. Easterly, Levine, and Roodman (2004).

34. Bekaert, Harvey, and Lundblad (2005); Mehlum, Moene, and Torvik (2006).

35. Notably, Roberts (1995, 2008), Gibson (1997), and Levitsky (2003).

36. Most notable in this literature is Barro and Gordon (1983).

37. Rogoff (1985).

38. See Eijffinger and de Haan (1996) for an overview.

39. Alesina (1988); Grilli, Masciandaro, and Tabellini (1991); Alesina and Summers (1993). 
Alesina and Lawrence Summers report a near perfect negative correlation between inflation and de jure CBI. ${ }^{40}$

This de jure index of CBI was further developed by Alex Cukierman, Steven Webb, and Bilin Neyapti and extended to seventy-two independent countries over the period 1950-89. ${ }^{41}$ Using their index in pooled time-series and cross-sectional regressions, that study and another by Cukierman show that the negative correlation between de jure CBI and inflation does not hold for a cross section of developing countries, although they confirm the earlier negative correlation for developed countries. ${ }^{42}$ They also show that their index of de facto CBI (based on the turnover of central bank governors) is negatively correlated with inflation in developing countries, but not significantly correlated with inflation in developed countries. ${ }^{43}$

Nevertheless, other studies find very different results. Using updated data, Christopher Crowe and Ellen Meade do not find the same correlations. ${ }^{44}$ Marta Campillo and Jeffrey Miron argue, as does Thomas Oatley, that the correlation between de jure CBI and inflation is not robust to the inclusion of various covariates, such as measures of openness or the government deficit. ${ }^{45}$ Oatley, Gabriel Mangano, James Forder, and King Banaian, Richard Burdekin, and Thomas Willett also document that the results depend on the subjectively coded details of CBI measures and are not generally robust. ${ }^{46}$

Philip Keefer and David Stasavage ${ }^{47}$ in work related to this paper, argue that CBI will be effective only if it cannot be reversed, and that this will happen only if there are political checks and balances. In their empirical work they interact a measure of checks and balances from Thorsten Beck and coauthors with CBI and find that introducing CBI increases inflation unless checks and balances are sufficiently strong..$^{48}$ Their work, like much of the rest of this literature, exploits only cross-sectional variation. This strategy makes omitted-variable bias potentially quite severe, since the

40. Alesina and Summers (1993, p. 154)

41. Cukierman, Webb, and Neyapti (1992).

42. Cukierman (1992).

43. Various other papers, such as Gutiérrez (2003) and Arnone and others (2007), report similar results.

44. Crowe and Meade (2007).

45. Campillo and Miron (1997); Oatley (1999).

46. Oatley (1999); Mangano (1998); Forder (1998); Banaian, Burdekin, and Willett (1998).

47. Keefer and Stasavage $(2002,2003)$.

48. Beck and others (2001). 
countries that have introduced CBI typically have different macroeconomic equilibria than the rest.

In contrast to almost all of this literature, we focus on within-country variation. Although not a panacea against omitted-variable bias, fixedeffects panel data regressions provide more convincing and more relevant conditional correlations, focusing on whether inflation declines following the introduction of CBI. Using such regressions, we will show that the introduction of CBI appears to be associated with declines in inflation in countries with intermediate political constraints. The benefits of CBI in more developed economies appear to be more limited. ${ }^{49}$

\section{The Motivating Theory}

In this section we use a simple model to clarify our approach to the political economy of reform, and we derive hypotheses concerning the circumstances under which CBI should have a significant impact on inflation. Our purpose is not to contribute to the theoretical literature on the political economy of reform, but rather to highlight why specific institutional reforms might have different effects depending on the constraints facing politicians. For this purpose we choose the simplest model possible to communicate the major forces rather than strive for generality. Our model is a simplified version of - and a slight variant on-Gene Grossman and Elhanan Helpman's model of lobbying. ${ }^{50}$ In this model a single organized lobby tries to convince a politician to choose distortionary policies, but underlying constraints and reform of specific institutions relating to this policy place limits on the lobby's influence on the politician and on policy choices. We first use this model to highlight the interactions between policy reform and constraints on politicians. We then use a simple extension of the model to show how successful policy reform in one sphere can lead to a deterioration in other dimensions of policy (the seesaw effect).

Our framework is chosen both for its simplicity and to emphasize the commonalities between CBI and other types of policy reform; it does not do justice to some aspects of the macroeconomic equilibrium leading to high inflation. For example, the time-inconsistency problems emphasized

49. This does not imply that CBI has no benefit in relatively developed countries. Given the lower inflation observed in OECD economies, the effect of CBI will be harder to detect, particularly if it is small. Moreover, CBI might create other benefits by introducing transparency and creating insurance against possible future relaxations of monetary policy.

50. Grossman and Helpman (1994). 
by Robert Barro and David Gordon and by Rogoff are absent. ${ }^{51}$ We provide some justification for why we think these time-inconsistency problems are not first-order in the context of high inflation in developing countries. The war-of-attrition aspect of the conflict over policy reform, emphasized by Alesina and Allan Drazen, is also absent in our setup. ${ }^{52}$ Although one could develop the same general insights using a war-of-attrition model, we prefer to use our simpler model to highlight the basic political economy factors affecting the effectiveness of policy reforms.

\section{Model and Main Result}

The economy consists of three actors: the citizenry, a politician, and an organized interest group or lobby. There is a single policy variable $\pi \geq 0$. To make the transition to the empirical work easier, this policy can be thought of as inflation policy, although nothing in this section depends on this interpretation. In addition to policy $\pi$, the variable $\rho \in\left\{0, \rho_{R}\right\}$, with $\rho_{R}>0$, denotes whether or not there has been policy reform ( $\rho=0$ if there has not) and parameterizes its intensity (see below). The large group of citizens has preferences given by

$$
u(\pi)=-\eta \pi
$$

where $\eta$ is a strictly positive constant. These preferences imply that the political bliss point of the citizens (that is, their most preferred policy) is $\pi=0$ (since $\pi \geq 0$ by assumption), and any increase in $\pi$ away from zero reduces citizens' welfare. Thus $\pi$ should be thought of throughout as a distortionary policy. We could also make $u$ directly depend on whether there has been policy reform, that is, on $\rho$. This has no effect on the major results we would like to emphasize. In addition, $u$ is made linear in $\pi$ only to simplify the exposition.

The second actor, the politician, has a utility function given by

$$
v(\pi, \rho, t)=\lambda u(\pi)+(1-\lambda) t-\rho \pi .
$$

Here $t \geq 0$ denotes a transfer from the lobby, which might consist of explicit bribes or campaign contributions. The variable $\lambda \in[0,1]$ captures how much weight the politician's utility function places on the welfare of the citizens. We think of $\lambda$ as a measure of general institutional constraints on the politician (such as those measured, in our empirical work, by con-

51. Barro and Gordon (1983); Rogoff (1985).

52. Alesina and Drazen (1991). 
straints on the executive or control of corruption). ${ }^{53}$ When $\lambda=1$, the politician must act as a perfect agent of the citizens, perhaps because any deviation from the policies preferred by the citizens will be punished by quick replacement. In contrast, when $\lambda$ is close to zero, there are few constraints on the politician's behavior, perhaps because he or she is not accountable to the citizens or because politicians are difficult to replace using elections or other means. In this case the politician can pursue with impunity policies that increase the transfers he or she receives.

The other important feature of the preferences in equation 2 is the dependence on $\rho \pi$. This captures the idea that policy reform makes distortionary policies more costly for the politician. For example, the politician may find it more difficult to provide credit to favored firms or groups, or to enact inflationary policies aimed at winning support. All else equal, this will discourage the use of distortionary policies by the politician. Making the use of such policies more costly for the politician is not the only way to model the effects of policy reform. ${ }^{54}$ An alternative would be to model policy reform as introducing a hard constraint, for example imposing $\pi \leq \bar{\pi}$ for some upper bound on policy $\bar{\pi}$. This is not a useful modeling strategy for understanding policy reform in societies with weak institutions, however, because such hard constraints would leave no room for pursuing distortionary policies after the reform, whereas our focus is on whether reform will prevent politicians from choosing distortionary policies.

The third actor is an organized lobby, which benefits from $\pi$. Suppose that the utility of the lobby is given by

$$
w(\pi, t)=\alpha \pi-\frac{\beta}{2} \pi^{2}-t,
$$

where $\alpha$ and $\beta$ are strictly positive constants. The quadratic form is again assumed for convenience, as is the specification that these preferences do

53. In a richer model, strong constraints might make lobbies more powerful, because a well-meaning politician might be unable to act decisively to reduce inflation. However, we believe that this consideration is second-order because well-meaning politicians are relatively rare.

54. Yet another alternative, which in fact gives even more stark results, is to assume that these reforms act as costly commitment devices, and thus that they make distortionary policies more costly for the citizens. In this case policy reform would discourage distortionary policies by increasing the costs that these policies impose on the society, and indirectly on the politician. In the context of CBI, for example, high inflation becomes both more costly to society and potentially more costly to implement for the government, both because it will destroy the beneficial reputation that monetary policy may have established and because workers' and firms' behavior would have been shaped by expectations of low inflation. The assumption adopted in the text may have wider applicability, motivating our choice here. 
not directly depend on $\rho$. These assumptions also have no effect on the qualitative results. These preferences immediately imply that the lobby's political bliss point is

$$
\pi^{*} \equiv \frac{\alpha}{\beta}>0,
$$

and so the lobby will try, using the only instrument available to it for this purpose, the transfer $t$, to shift policy toward higher levels of $\pi$ than preferred by the citizens. Examples of policies for which citizens and lobbies have conflicting preferences include industrial policy, tariffs, and agricultural subsidies. Inflation is another potential example, since it is often used as a means of generating funds (for example, through the inflation tax) for redistribution to politically powerful groups, such as public sector employees or companies receiving procurements or industrial subsidies, at the expense of the citizens at large; inflation may also result from the use of government credits for favored firms.

Although there are three actors in all, the citizens are passive, and the main interactions are between the lobby and the politician. We model this game as follows:

- The parameter $\lambda$ and the reform variable $\rho$ are given.

- The lobby makes an offer $(\hat{\pi}, \hat{t})$ to the politician. As in Grossman and Helpman's model, this implies that if the politician accepts the transfer $\hat{t}$, he or she has to implement policy $\hat{\pi}$. This is presumably supported by a continuation game with repeated interactions, but as in much of the literature, to simplify the analysis we do not model these.

-The politician chooses policy $\tilde{\pi}$. If $\tilde{\pi}=\hat{\pi}$, the politician also receives transfer $\hat{t}$. Otherwise, the politician receives $t=0$.

This is a simple game, and we characterize its subgame perfect equilibrium, as is usually done, by backward induction. In the last stage of the game, the politician will choose whichever policy maximizes his or her utility. Clearly, this will be either $\tilde{\pi}=\hat{\pi}$, so that the politician receives the transfer $\hat{t}$, obtaining a utility $\lambda u(\hat{\pi})+(1-\lambda) \hat{t}-\rho \hat{\pi}$, or $\tilde{\pi}=0$, in which case the politician receives zero transfers and obtains utility $\lambda u(0)$.

Therefore we can summarize the best response of the politician as follows: ${ }^{55}$

$$
\tilde{\pi}= \begin{cases}0 & \text { if } \lambda u(\hat{\pi})+(1-\lambda) \hat{t}-\rho \hat{\pi}<\lambda u(0) \\ \hat{\pi} & \text { if } \lambda u(\hat{\pi})+(1-\lambda) \hat{t}-\rho \hat{\pi} \geq \lambda u(0) .\end{cases}
$$

55. To simplify the notation, this expression already imposes the choice that will prevail in equilibrium when the politician is indifferent. 
If the lobby wishes to have its own policy preferences implemented, it must satisfy this incentive compatibility constraint (or respect the fact that the politician will play a best response in the last stage). This implies that when the lobby wishes to see implemented a policy close to its own preferences, it must choose $(\hat{\pi}, \hat{t})$ as a solution to the following program:

$$
\max _{\hat{\pi} \geq 0, t \geq 0} w(\hat{\pi}, \hat{t}) \quad \text { subject to equation } 4 \text {. }
$$

Let the solution to this maximization problem give the lobby utility $\hat{w}$. Since $(\hat{\pi}=0, \hat{t}=0)$ is a feasible strategy, we must have $\hat{w} \geq 0$. Moreover, it is also evident that this problem will lead to a solution with $\hat{w}>0$, when $\hat{\pi}>0$, and $\hat{t}>0$ will be chosen if and only if the solution to expression 5 also involves $\hat{\pi}>0$.

We next characterize the solution to this problem. The incentive compatibility constraint of the politician (equation 4 ) requires that if $\hat{\pi}>0$, then

$$
\hat{t}=\frac{\lambda \eta+\rho}{1-\lambda} \hat{\pi}
$$

Substituting this into the objective function of the lobby (equation 3), we have the problem faced by the lobby expressed as

$$
\max _{\hat{\pi} \geq 0} \alpha \hat{\pi}-\frac{\beta}{2} \hat{\pi}^{2}-\frac{\lambda \eta+\rho}{1-\lambda} \hat{\pi},
$$

whenever it wants to implement policy $\hat{\pi}>0$. Inspection of this maximization problem establishes our first result:

Result 1. If $\lambda \geq \bar{\lambda} \equiv \alpha /(\alpha+\eta)$, then the lobby prefers not to have an influence on policy regardless of whether $\rho=0$ or $\rho=\rho_{R}$.

This result follows immediately, since when $\lambda \geq \bar{\lambda}$, the utility-maximizing policy for the lobby is to choose $\hat{\pi}=0$. Since $\lambda$ corresponds to a measure of the quality of constraints on the politician, this result suggests that when these constraints are sufficiently strong, the political system will generate a policy choice that is not distortionary, regardless of whether there has been reform or not. In terms of our empirical work below, this result suggests that in societies that place significant constraints on politicians, reform should have relatively small effects. This can be understood by considering the example of inflation: although CBI might limit inflation in well-governed societies, one would not expect a very large decline in inflation to result from implementing CBI, since these societies would not have chosen highly distortionary policies to start with. 
More generally, the solution to the lobby's maximization problem in expression 6, and thus the (subgame perfect) equilibrium level of policy, is given by

$$
\tilde{\pi}=\max \left\{\frac{1}{\beta}\left(\alpha-\frac{\lambda \eta+\rho}{1-\lambda}\right) ; 0\right\} .
$$

This equation shows that the sensitivity of equilibrium policy $\tilde{\pi}$ to $\rho$ (policy reform) will be lower, the lower is $\lambda$. Intuitively, when there are no checks on the politician in power, the politician will do whatever maximizes his or her utility, and this will involve maximizing the transfers the politician receives. Consequently, transfers can outweigh the costs that policy reform imposes on the politician's use of distortionary policies. In terms of the inflation example, the politician in power can exert pressure or use other means to force the central bank to increase the money supply and inflation, even if choosing high inflation might have become more difficult or costly. ${ }^{56}$ Interpreted differently, equation 7 suggests that in societies with low $\lambda$, de jure reform may not translate into de facto reform, because despite the greater cost of $\pi$ to the politician, the political equilibrium will induce him or her to choose policies not so different from those before the reform.

The following result now readily follows from equation 7 :

Result 2. Suppose that $\lambda<\bar{\lambda}$. Then a reform that increases $\rho$ from 0 to $\rho_{R}$ will reduce $\tilde{\pi}$. Moreover, for $\lambda<\frac{\alpha-\rho_{R}}{\eta+\alpha}$, the greater is $\lambda$, the greater

the decline following policy reform.

This result therefore implies that when constraints are not so strong as to have avoided the use of distortionary policies in the first place, policy reform might be effective. How effective it will be is a function of the constraints on the politician. The greater is $\lambda$, the more transfers are necessary for the politician to adopt the distortionary policy after reform, and thus the lower will be the equilibrium distortionary policies following reform.

56. This will also be true when inflation or other distortionary policies also become more costly for the society as a whole after reform. For example, inflation might be disastrous for the future of the economy and ruin the potential benefits that might have resulted from credibly establishing CBI (this can be incorporated by including $\rho \pi$ in the utility function of the citizens), but when $\lambda$ is low, this still will not deter politicians from using distortionary policies. 
Putting these two results together, we conclude:

Result 3. Policy reform will have the largest effect on distortionary policies in societies with intermediate levels of constraints on politicians, and it will have no or only limited effects in societies with the strongest and the weakest constraints.

In the empirical work that follows, we investigate whether the effects of CBI reform on inflation are consistent with the predictions in Result 3.

\section{The Seesaw Effect}

We now use the model from the previous subsection to illustrate the seesaw effect, whereby successful policy reform might lead to a deterioration in other dimensions of policy. To do this, we augment the previous model with another policy dimension, denoted by $\theta \geq 0$, and modify citizen preferences to

$$
u(\pi, \theta)=-\eta \pi-\eta^{\prime} \theta,
$$

where $\eta^{\prime}$ is also a strictly positive constant. This implies that $\theta$ is another distortionary policy, and thus the political bliss point of the citizens now corresponds to $\pi=\theta=0$. In this instance policy reform is narrowly targeted at $\pi$ and thus only makes policy $\pi$ more costly for the politician. Some reforms, which involve the introduction of greater accountability for politicians, would not fit this pattern. CBI reform is a natural candidate in this context, since it is primarily focused on monetary policy and inflation.

The preferences of the lobby are modified to

$$
w(\pi, t)=\alpha \pi+\alpha^{\prime} \theta-\frac{\beta}{2}(\pi+\theta)^{2}-t,
$$

with again $\alpha^{\prime}>0$. The preferences of the politician are unchanged. We again look for a subgame perfect equilibrium.

The politician will choose $\hat{\pi}$ and $\hat{\theta}$ greater than zero if

$$
\hat{t}=\frac{\lambda \eta+\rho}{1-\lambda} \hat{\pi}+\frac{\lambda \eta^{\prime}}{1-\lambda} \hat{\theta}
$$

By reasoning identical to that in the previous subsection, the optimal policy-transfer combination for the lobby is then given by the solution to the following maximization problem:

$$
\max _{\hat{\pi} \geq 0, \hat{\theta} \geq 0} \alpha \hat{\pi}+\alpha^{\prime} \hat{\theta}-\frac{\beta}{2}(\hat{\pi}+\hat{\theta})^{2}-\left(\frac{\lambda \eta+\rho}{1-\lambda} \hat{\pi}+\frac{\lambda \eta^{\prime}}{1-\lambda} \hat{\theta}\right) .
$$


To simplify the discussion, let us impose the following assumption:

$$
\eta^{\prime}>\eta \text { and } \alpha^{\prime}<\alpha
$$

This assumption implies that policy $\theta$ is more costly for the citizens and less beneficial for the lobby than policy $\pi$. In view of this, the following result is immediate:

Result 4. Suppose expression 9 holds and there has been no policy reform; that is, $\rho=0$. Then $\tilde{\theta}=0$.

Intuitively, it is more economical for the lobby to receive policy favors through $\pi$, which is both more beneficial for the lobby and less costly for the citizens. Consequently, policy $\theta$ will never be used in equilibrium (either $\pi>0$ and $\theta=0$, or $\pi=\theta=0$ ). Result 4 is a consequence of the simplifying assumptions made in this subsection; in particular, it depends on the assumption that the two policies, $\pi$ and $\theta$, are perfect substitutes. Without this assumption, both policies might be used simultaneously before policy reform. Nevertheless, our main result, Result 5 below, would continue to apply even when these policies are not perfect substitutes.

Next suppose that policy reform is enacted, so that $\rho=\rho_{R}>0$. Our main result in this subsection is that following such policy reform, it may become beneficial to use the alternative distortionary policy $\theta$. The following result summarizes the conditions under which this will happen:

Result 5. Suppose expression 9 holds and consider policy reform increasing $\rho$ from 0 to $\rho_{R}$. If

$$
\alpha-\frac{\lambda \eta+\rho}{1-\lambda}<\alpha^{\prime}-\frac{\lambda \eta^{\prime}}{1-\lambda}
$$

and if

$$
\lambda<\tilde{\lambda} \equiv \frac{\alpha^{\prime}}{\alpha^{\prime}+\eta^{\prime}}
$$

then the equilibrium following policy reform involves $\tilde{\pi}^{\prime}=0$ and

$$
\tilde{\theta}^{\prime}=\frac{1}{\beta}\left(\alpha^{\prime}-\frac{\lambda \eta^{\prime}}{1-\lambda}\right)>0
$$

This result follows readily from the maximization problem in expression 8 , combined with expressions 9 and 10. Note that those two expressions are consistent with each other provided that $\rho_{R}$ is sufficiently large-meaning that reform is effective in making policy $\pi$ costly. Result 4 implies that before policy reform, the equilibrium involves $\widetilde{\theta}=0$. Moreover, given 
expressions 9 and 10, before policy reform the equilibrium involves $\tilde{\pi}>0$. Consequently, policy reform in this case creates a typical seesaw pattern: the policy that is regulated with the reform is used less intensively (moving from $\tilde{\pi}>0$ to $\tilde{\pi}^{\prime}=0$ ), but at the same time the political process generates rents for the still-powerful lobby by using an alternative policy instrument more intensively (moving from $\widetilde{\theta}=0$ to $\widetilde{\theta}^{\prime}>0$ ). This result highlights that when the political-economic interactions leading to distortionary policies remain unchanged, the imposition of a (specific or narrowly targeted) policy reform might change only the form of redistribution toward politically powerful groups, rather than eliminate policy distortions entirely.

An interesting implication of the specific configuration of parameters given by expressions 9 and 10 should also be noted: in the case discussed in Result 5, policy reform makes both citizens and the lobby worse off. Instead of redistribution being accomplished through the less costly instrument, it now uses the more costly instrument. This is not a general result: policy reform might improve the allocation of resources despite the presence of seesaw-like effects. Nevertheless, this result points out the potential pitfalls of specific policy reforms in societies where constraints on politicians are absent and political-economic interactions lead to dysfunctional policy choices.

\section{Discussion}

The model we have developed here is in the spirit of standard approaches to redistributive politics. In particular, as noted above, it does not include any element of time inconsistency. We do not believe that time-inconsistency issues play a major role in understanding high-inflation or hyperinflationary episodes in less developed economies. Most instances of high inflation are instead directly related to the inability of governments to fund their (often politically motivated) expenditure through taxation and borrowing. Such policies are much more likely to emerge when there is severe distributional conflict that the political system is unable to resolve, or when politicians have only limited instruments to use to distribute patronage. The increasing inflation in Zimbabwe, depicted in figure 1, is an example: President Mugabe turned to hyperinflation when he had no further resources left to redistribute as patronage to the military and to his key supporters.

Finally, although we have followed Grossman and Helpman in setting up the model with lobbies making offers to politicians, ${ }^{57}$ the model could be reformulated to allow politicians to make offers to lobbies or interest groups

57. Grossman and Helpman (1994). 
without affecting any of the results. This reformulation might be more in line with the political experiences of countries in sub-Saharan Africa or Latin America, where interest groups are as likely to be captured by politicians as vice versa. ${ }^{58}$ For instance, in his seminal study of economic policy in Ghana, Tony Killick notes that President Kwame Nkrumah succeeded in capturing the lobbies, making them dependent on him instead of himself on them. ${ }^{59}$ Argentina under Juan Perón illustrates the same pattern. ${ }^{60}$ First as minister of labor and then as president in the 1940s, Perón played an active role in creating the interest groups that then constituted his support base. Certain groups in society will have (political) resources that politicians need, and politicians will offer them redistribution in exchange for this support. The model above could be reformulated along these lines, so that policy reform would represent an increase in the cost to politicians of supplying policy favors to interest groups, possibly because they now have to use patronage to control those who run the independent central bank as well. Our major results, in particular Results 3 and 5, would continue to apply in this modified setup.

\section{Data Sources and Construction}

Throughout the paper we focus on the post-Bretton Woods period 1972-2005. From 1946 until 1971, when the United States suspended the convertibility of dollars to gold, countries under the Bretton Woods system agreed to coordinate monetary policy in order to fix their currencies with respect to gold. This naturally limited the discretion that both governments and central banks enjoyed in managing their monetary policies. This implies that the post-Bretton Woods era is a natural period for us to focus on in analyzing the relationship between CBI and inflation.

Several approaches have been used to measure CBI, and some controversy surrounds the advantages and disadvantages of each. ${ }^{61}$ The key question centers around whether one should use de jure measures, which capture how much independence the central bank has under the law, or de facto measures, which correspond to how much independence the central bank has in practice. Another distinction that has been made is between goal independence, in which the central bank is able to determine its own objectives, and operational independence, in which it does

58. See Acemoglu, Robinson, and Verdier (2004) for a discussion.

59. Killick (1978, p. 35).

60. See, for example, Collier and Collier (1991).

61. See Arnone, Laurens, and Segalotto (2006) for a comprehensive overview. 
not set its own goals but is free to achieve any goal set for it without interference.

Vittorio Grilli, Donato Masciandaro, and Guido Tabellini developed an index based on work by Hans Aufricht that emphasizes political independence, as measured by the procedures regarding the appointment of the central bank board, the relationship between the bank and the government in the formulation of monetary policy, and the formal responsibilities of the bank. ${ }^{62}$ They also measured economic independence, which focuses on whether or not the central bank must finance government debt. The current state of the art of measurement of de jure CBI stems from Cukierman and his collaborators, ${ }^{63}$ who constructed an index of de jure CBI for seventy-two countries over the period 1950-89, coding the variable for each of four ten-year periods, with the index remaining constant within a given period. Their index is a weighted average of sixteen different central bank characteristics. ${ }^{64}$

Each of the above indices has various drawbacks. Mangano argues that both the choice of criteria in the different indices and the interpretation of laws involve significant subjectivity ${ }^{65}$ It appears that these indices do not capture de jure CBI only but are, at least in part, informative about how monetary policy is being conducted in practice. Our focus on policy reform makes it important that we focus on de jure CBI. A related problem is that most existing work reports values for CBI indices computed at a

62. Grilli, Masciandaro, and Tabellini (1991); Aufricht (1967).

63. Cukierman (1992); Cukierman, Webb, and Neyapti (1992).

64. Eight characteristics assessed the extent of limitations on central bank lending to the government, and these collectively received half of the weight in the index. Four legal characteristics that concern the way governors are appointed or dismissed were given one-fifth of the weight, three other characteristics that determined the degree of independence of the bank's policymaking process were given 15 percent of the total weight, and a measure related to the objectives of the central bank was given the remaining 15 percent.

65. Mangano (1998). In particular, from a comparison of the Cukierman and GrilliMasciandaro-Tabellini (GMT) indices, Mangano (1998, pp. 476-77) concludes that "[there is] a significant degree of inconsistency between the two indices' valuation of their common criteria. In only one country out of seventeen and in the case of one criterion out of nine have Cukierman and GMT translated the legislation in exactly the same way: their interpretations of the laws governing the Italian central bank, and of the regulations concerning the central bank governors' terms of office in the countries sampled, exhibit no divergence. On the other hand, the average spread between their interpretations when examining Danish, French, Greek, and Japanese legislation is close to 50 percent, and they disagree in nearly 60 percent of countries when deciding whether the central bank is legally allowed to purchase government debt in the primary market. Overall, it appears that in the seventeen countries included in both [Cukierman's] and GMT's samples, virtually a third of the values attributed to their nine common criteria are subject to nonnegligible interpretation problems." 
specific point in time. However, within-country variation is essential for our empirical strategy based on panel fixed-effects regressions. ${ }^{66}$

To overcome these problems, we measure de jure CBI by a dummy variable that takes a value of one in every year after a major reform to the constitution or the central bank law leading to increased independence, and zero elsewhere. The advantage of this measure is that it does not incorporate information on the de facto conduct of monetary policy. A drawback is that this measure assumes that $\mathrm{CBI}$ increases by the same magnitude in every country following a reform, which we know is not true, because reforms in different countries have introduced different levels of independence. Nevertheless, it captures in a simple way the effect of central bank reform and changes in de jure CBI.

Our main sample consists of fifty-two countries for which information on changes in central bank legislation was reported by Luis Jácome and Francisco Vásquez, and by Simone Polillo and Mauro Guillén. ${ }^{67} \mathrm{We}$ exclude all former socialist countries, because data for these countries before CBI are limited, and many enacted CBI at the same time as many other reforms associated with the transition from planned to market economies. We also exclude Africa, since central bank reforms in these countries are hard to identify and interpret, and in most cases their reforms have fallen short of creating truly independent central banks. ${ }^{68}$

Our sample does, however, include almost every OECD and Latin American country and a sample of thirteen Asian countries. ${ }^{69}$ To construct our CBI dummy for Latin American countries, we used the dates of major central bank reforms provided by Jácome and Vásquez. ${ }^{70}$ For the remaining countries the CBI dummy takes a value equal to one starting in the year in which the Cukierman index constructed by Polillo and Guillén

66. Exceptions that construct and use time-varying indices are Polillo and Guillén (2005), who provide values of the Cukierman index for the period 1989-2000 for a sample of ninety countries; Jácome and Vasquez (2005) for Latin America; Cukierman, Miller, and Neyapti (2002) for a sample of former Soviet countries; Arnone and others (2007) for a sample of emerging market countries; and Crowe and Meade (2007) for a sample of 102 countries worldwide. Both Arnone and others (2007) and Crowe and Meade (2007) explore time-series variation in these indices by taking values of them at two points in time (the late 1980s and the early twenty-first century) and assume that the change from one value to another occurs in the year in which central bank reform takes place.

67. Jácome and Vásquez (2005); Polillo and Guillén (2005).

68. For example, the Cukierman index of central bank independence reported by Polillo and Guillén (2005) is very low for most African countries, and reforms to the central bank charters during the 1990s caused only very small increases in these indices.

69. See the online appendix at econ-www.mit.edu/faculty/acemoglu.

70. Jácome and Vásquez (2005). 
increases. ${ }^{71}$ Moreover, for every country we used information from Marco Arnone and coauthors, ${ }^{72}$ who report the years of major central bank reforms, to verify that a major reform did take place in the year in which the index constructed by Polillo and Guillén increases. Whenever there was disagreement between the two sources, we consulted additional sources (such as the central bank's website) to identify the year in which the most substantial reform toward CBI (if any) took place. Similarly, for countries for which the index constructed by Polillo and Guillén did not increase between 1989 and 2000, we used Arnone and coauthors and other sources to explore whether a central bank reform took place after 2000. A list of the countries included in our sample and the details of the coding, including the laws that have amended central bank charters, as well as additional sources used, can be found in the online appendix. Most central bank reforms in these countries took place during the 1990s.

We also examined the impact of CBI on the forty of these fifty-two countries whose degree of CBI changed over our sample period. Focusing on this sample enables us to obtain identification from differences in the timing of CBI; the countries in this sample might also be more homogeneous, since all have undergone the same policy reform.

Although we believe our CBI dummy provides a transparent way of investigating the relationship between CBI and inflation, we also study the robustness of our results by using the Cukierman index. Since these data are not in the form of an annual time series, and earlier data exhibit almost no variation, we take the value of the index in 1989 and assume that this value holds for all pre-CBI periods. We then use the 2003 value from Crowe and Meade for all post-CBI periods. ${ }^{73}$

Our main measure of political institutions is constraints on the executive, from the Polity IV dataset, which codes the extent of constitutional limits on the exercise of arbitrary power by the executive. ${ }^{74}$ The Polity dataset reports a qualitative score between 1 and 7 for every independent country. We computed the average of the constraints on the executive variable for the period 1972-2004 and then classified each country in our sample according to whether it has weak, medium, or strong constraints on the

71. Polillo and Guillén (2005).

72. Arnone and others (2007).

73. Crowe and Meade (2007).

74. These data are maintained by the Center for Systemic Peace and the Center for Global Policy at George Mason University and are available at www.systemicpeace.org/ polity/polity4.htm. 
executive ${ }^{75}$ Countries within one standard deviation of the sample mean for the constraints measure were assigned to the medium-constraints category, and the rest were assigned to either the strong-constraints or the weakconstraints group. Figure 3 shows the distribution of average constraints on the executive for our sample as well as the cutoffs for the different categories. Appendix table A1 shows the category in which each country was classified. The weak- and medium-constraints countries are found mainly in Asia and Latin America; most OECD countries are in the strong-constraints category.

To verify that our results are not driven by the specific cutoffs used in creating the weak-, medium-, and strong-constraints groups, we also look at the interaction of a quadratic function of the average constraints on the executive with the CBI dummy. We show that the results obtained using this approach are similar to those estimated using the dummies for weak, medium, and strong constraints.

In addition, we check the robustness of our results using different measures of institutions. In particular, we use the rule-of-law and the controlof-corruption indices constructed by Daniel Kaufmann, Aart Kraay, and Massimo Mastruzzi for the period 1996-2005. ${ }^{76}$ These indices are reported on a scale from -2.5 to 2.5 and are based on subjective perceptions reported by experts from the public sector, the private sector, and nongovernmental organizations. ${ }^{77}$ The classification of countries on these variables, following the same one-standard-deviation rule described above, is reported in appendix table A1. Broadly speaking, the classifications under the three institutional variables are similar. The most notable exception is Singapore, which is classified as having weak constraints on the executive, but strong institutions in terms of both the rule-of-law and control-of-corruption indices.

75. We use the average of constraints on the executive over 1972-2004 rather than its value at the beginning of the period or its year-to-year variation, because the average value of this variable appears to provide a better and less noisy measure of how constrained politicians are in a given country. The changes in this variable from year to year are subject to potential miscodings, which are averaged out when we consider the average constraints on the executive over a reasonable period of time.

76. Kaufmann, Kraay, and Mastruzzi (2007). One advantage of these indices is that they measure institutional quality around the time of CBI for most countries.

77. The rule-of-law question asks respondents the extent to which they have confidence in and abide by the rules of society, and in particular the quality of contract enforcement, the police, and the courts, as well as the likelihood of crime and violence; the control-of-corruption question asks the extent to which respondents perceive public power as exercised for private gain, including both petty and grand forms of corruption as well as capture of the state by elites and private interests (Kaufmann, Kraay, and Mastruzzi, 2007, p. 4). 
Figure 3. Distribution of Countries by Average Executive Constraints Score

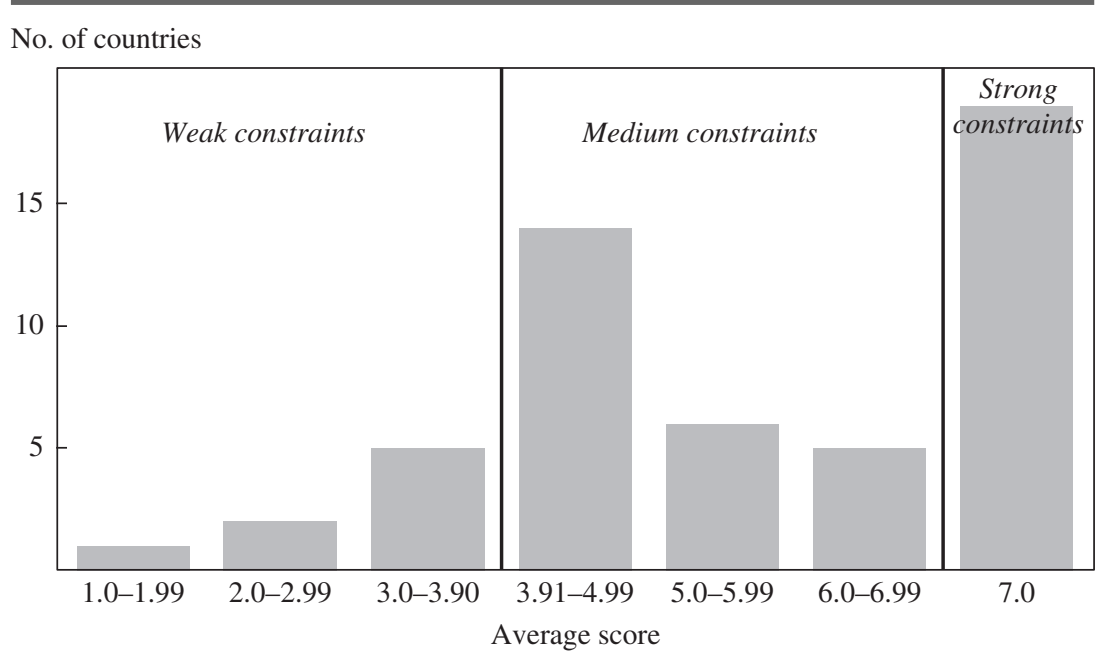

Source: Authors' calculations using data from Polity IV.

Our main dependent variable, inflation, was obtained from the International Financial Statistics (IFS) of the International Monetary Fund and is defined as the annual percentage change in the consumer price index. ${ }^{78}$ Figures B1, B2, and B3 in appendix B plot the inflation data over time as well as the date of CBI for all the countries in our sample. Figure B1 focuses on the eight countries categorized as having weak constraints on the executive, figure B2 on the twenty-five medium-constraints countries, and figure $\mathrm{B} 3$ on the nineteen countries with strong constraints. To isolate changes in inflation in individual countries, in all three figures the average of normalized world inflation is subtracted from each country's normalized inflation rate; thus a value of zero indicates that the country's inflation rate is at the world average. ${ }^{79}$

Figure B1 presents a mixed picture with respect to the association between inflation and CBI in countries with the weakest constraints. In China and Guyana a decline in inflation is seen following the introduction

78. The inflation data reported for Qatar by IFS show an unusual spike in 1998 and 1999. Rather than verify and, where necessary, modify the IMF data for every country, we use the data exactly as reported. However, all our results are robust to excluding Qatar from the sample.

79. Normalized inflation is defined as inflation/(1+ inflation); see equation 11 in the next section. 
of CBI, whereas in Guatemala and Nepal inflation drifts upward over time, and the introduction of CBI in 2002 in both countries appears to have had no effect on this process. Figure B2 shows several cases of significant disinflation concurrent with the introduction of CBI. This happens in Colombia and Argentina, as discussed in the introduction, but it also seems to occur in Turkey and Uruguay. In a number of countries, such as Bolivia, Chile, and Greece, inflation starts declining before CBI. Finally, figure B3 shows no case where $\mathrm{CBI}$ is followed by a large fall in inflation.

Comparison of figures B1 and B2 shows that in contrast to our theoretical model, inflation is generally higher in medium-constraints countries than in weak-constraints countries. We do not have an explanation for this pattern. It may reflect the fact that in countries with weak constraints, politicians have access to other instruments for achieving their political objectives and do not need to rely primarily on monetary policy, which may be a relatively blunt instrument for achieving clientelistic objectives or self-enrichment.

Our data on government expenditure as a percentage of GDP were obtained from the International Monetary Fund's World Economic Outlook. ${ }^{80}$ In our robustness checks we also use additional macroeconomic variables to control for other time-varying determinants of inflation. We use the logarithm of GDP per capita (in constant prices, using the chain series from the Penn World Tables 6.2). Also, to control for the extent to which fixed exchange rate regimes might have provided an anchor for inflation and limited the discretionary use of monetary policy, we use an index of exchange rate flexibility constructed by Carmen Reinhart and Rogoff. ${ }^{81}$ This index takes values between one and six, with higher values corresponding to more-flexible exchange rate regimes. The index is reported on an annual basis and covers the period 1972-2001.

\section{Central Bank Independence and Inflation}

In this section we present our main empirical results concerning the relationship between CBI and inflation. Throughout, the left-hand-side variable is defined as

$$
y_{c, t}=\frac{\text { inflation }_{c, t}}{1+\text { inflation }_{c, t}},
$$

80. Government expenditure corresponds to "Total Expenditure and Net Lending by the General Government" (variable GGTENL in World Economic Outlook).

81. Reinhart and Rogoff (2004). 
where inflation ${ }_{c, t}$ denotes the inflation rate (for example, 0.1 for 10 percent inflation) for country $c$ in year $t$. This transformation is useful, since otherwise hyperinflationary episodes entirely dominate the analysis. An alternative would have been to use the logarithm of inflation, but this is not possible when there are cases of zero inflation. Moreover, using logarithms would shift the outlier problem to cases in which inflation is very low. With a slight abuse of terminology, we refer to $y_{c, t}$ as inflation rather than as normalized inflation.

It should be noted throughout that changes in CBI are neither randomly assigned nor exogenous, so the empirical work we present here is intended to uncover robust correlations between central banking reform and contemporaneous or subsequent declines in inflation. As noted in the introduction, $\mathrm{CBI}$ is often adopted as part of a package of anti-inflation policies, and this can be seen in figures $\mathrm{B} 1$ and $\mathrm{B} 2$ in appendix $\mathrm{B}$, which reveal a number of instances in which inflation starts declining a few years before CBI. This is indicative of a pattern in which other anti-inflation measures are adopted simultaneously with or just before the introduction of CBI.

\section{The Main Effect of Central Bank Independence on Inflation}

Our general estimating equation for the results reported in table 1 is

$$
y_{c, t}=\sum_{j=1}^{k} \zeta_{j} y_{c, t-j}+\phi_{0} x_{c, t}+\sum_{j=1}^{k} \phi_{j} x_{c, t-j}+\delta_{c}+\omega_{t}+\varepsilon_{c, t} .
$$

Here the first summation includes lags of inflation and helps us control for potential serial correlation in this variable. The variable of interest is the dummy for CBI, described in the previous section and denoted by $x_{c, t}$. Since CBI may have delayed effects, we sometimes also control for lags of $\mathrm{CBI}$, as shown by the second summation. For simplicity, the same number of lags is used for inflation as for CBI. In addition, all regressions include $\delta_{c}$, which stands for a full set of country dummies, and $\omega_{t}$, which is a full set of year dummies. The error term $\varepsilon_{c, t}$ captures all omitted influences. Since $\mathrm{CBI}$ is not randomly assigned, this disturbance term may be correlated with some of the right-hand-side variables. It is therefore important to interpret the estimates we report as conditional correlations rather than causal effects. $\varepsilon_{c, t}$ may also have residual serial correlation, and to control for this we report throughout standard errors that are fully robust for arbitrary serial correlation at the country level (that is, clustered at the country level) ${ }^{82}$

82. See Wooldridge (2002). 
Columns 1-1 through 1-3 of table 1 examine the whole sample of countries. Columns 1-4 through 1-6 repeat the same regressions but focus on the sample of countries that changed their CBI during the sample period, and thus rely only on differences in the timing of CBI to identify its effect on inflation. Column 1-1 includes only the contemporaneous CBI dummy, $x_{c, t}$. The estimate of $\phi_{0}$ is -0.036 , with a (robust) standard error of 0.034 . Thus, in this first specification, the effect of CBI on inflation is negative, but this effect is not statistically significant at the 10 percent level, and the coefficient is rather small. This estimate implies that CBI is associated with a reduction in the annual inflation rate by 9 percentage points at the sample mean inflation rate of 58 percent. $^{83}$

The specification in column 1-1 does not control for persistence in inflation, however. Since inflation is a highly serially correlated variable, doing so can have major effects on the estimates. Column 1-2 therefore includes five lags of inflation but still includes only the contemporaneous CBI dummy. When these lags are included, one can distinguish between the short- and the long-run effects of CBI. The short-run effect is still given by $\phi_{0}$, whereas the long-run effect is $\frac{\phi_{0}}{1-\sum_{j=1}^{k} \zeta_{j}}$.

Column 1-2 reports both of these effects, together with the p-value for the statistical significance of the long-run effect. It shows that neither the shortrun nor the long-run effect is significant. For example, the long-run effect is about double the impact of CBI on inflation suggested in column 1-1, but it falls short of conventional levels of significance $(p=0.13)$. The lags of inflation themselves are highly significant. The results in the first two columns therefore show that despite the preponderance of theory and some evidence that $\mathrm{CBI}$ is important in practice, in this broad sample of countries the effect of CBI on inflation is modest and not statistically significant.

Column 1-3 also includes the five lags of the CBI dummy. In this case, however, the long-run effect is given by $\frac{\sum_{j=0}^{k} \phi_{j}}{1-\sum_{j=1}^{k} \zeta_{j}}$. In this specification the short-run effect is -0.031 (suggesting that CBI decreases inflation by

83. To calculate the economic magnitude of the coefficient estimates, we use average annual inflation over our sample period. If instead we use median annual inflation ( 8 percent instead of 58 percent), $\phi_{0}$ is even smaller and suggests that CBI reduces inflation by 4 percentage points. Throughout, the economic magnitudes implied by median inflation are about 60 percent smaller than those implied by mean inflation. 
Table 1. OLS Fixed-Effects Regressions of Inflation on Central Bank Independence ${ }^{a}$

\begin{tabular}{|c|c|c|c|c|c|c|}
\hline \multirow[b]{2}{*}{ Variable } & \multicolumn{3}{|c|}{ Full sample (52 countries) } & \multicolumn{3}{|c|}{$\begin{array}{c}\text { Countries with change } \\
\text { in CBI only (40 countries) }\end{array}$} \\
\hline & $1-1$ & $1-2$ & $1-3$ & $1-4$ & $1-5$ & $1-6$ \\
\hline $\begin{array}{l}\text { CBI dummy, short-run } \\
\text { effect }\end{array}$ & $\begin{array}{c}-0.036 \\
(0.034)\end{array}$ & $\begin{array}{l}-0.019 \\
(0.012)\end{array}$ & $\begin{array}{l}-0.031 \\
(0.022)\end{array}$ & $\begin{array}{c}-0.063 \\
(0.030)\end{array}$ & $\begin{array}{c}-0.028 \\
(0.013)\end{array}$ & $\begin{array}{c}-0.040 \\
(0.023)\end{array}$ \\
\hline $\begin{array}{l}\text { CBI dummy, long-run } \\
\text { effect }\end{array}$ & & -0.079 & -0.087 & & -0.119 & -0.164 \\
\hline p-value, long-run effect & & {$[0.129]$} & {$[0.126]$} & & {$[0.051]$} & [0.021] \\
\hline $\begin{array}{l}\text { p-value, five lags of } \\
\text { inflation }=0\end{array}$ & & {$[0.000]$} & {$[0.000]$} & & {$[0.000]$} & {$[0.000]$} \\
\hline $\begin{array}{l}\text { p-value, current and } \\
\text { five lags of CBI } \\
\text { dummy }=0\end{array}$ & & & {$[0.826]$} & & & {$[0.072]$} \\
\hline No. of observations & 1,670 & 1,500 & 1,500 & 1,300 & 1,172 & 1,172 \\
\hline Adjusted $R^{2}$ & 0.50 & 0.83 & 0.83 & 0.47 & 0.84 & 0.84 \\
\hline
\end{tabular}

Source: Authors' regressions.

a. The dependent variable is inflation/ $(1+$ inflation $)$, using inflation data from International Monetary Fund, International Financial Statistics. The sample period is 1972-2005. Each column reports a single ordinary least squares regression using unbalanced panel data with one observation per year, per country and including country and year fixed effects. Robust standard errors, adjusted for clustering by country, are in parentheses.

b. Takes a value of one in every year after a substantial reform to the country's central bank laws leading to more independence is introduced.

8 percentage points) and is again insignificant. The long-run effect is estimated to be -0.087 (suggesting that CBI decreases inflation by 22 percentage points) but is also insignificant.

Column 1-4 reestimates the basic model reported in column 1-1 using the smaller subsample of countries that underwent a change in CBI. The estimated effect is now -0.063 , with a standard error of 0.030 , and is thus now significant, as are the results in columns 1-5 and 1-6, which repeat the regressions in columns 1-2 and 1-3, respectively, using the smaller subsample. Both the short- and the long-run effects are negative, and the estimated effects are larger. The basic finding of table 1, then, is of some weak evidence that CBI does reduce inflation, especially when one looks only at the sample of countries that changed their CBI over the period.

\section{Central Bank Independence, Political Constraints, and Inflation}

Why does CBI not have a quantitatively more significant effect on inflation? The answer we will propose is based on our motivating theory, namely, that CBI will have a strong effect on inflation only in societies with intermediate levels of constraints on politicians. Let $S_{c}, M_{c}$, and $W_{c}$ be 
dummy variables denoting a strong-, a medium-, or a weak-constraints country, respectively. Including interactions with these dummies, the general estimating equation becomes

$$
\begin{aligned}
y_{c, t}= & \sum_{j=1}^{k} \zeta_{j} y_{c, t-j}+\phi_{0}^{H} S_{c} x_{c, t}+\phi_{0}^{M} M_{c} x_{c, t}+\phi_{0}^{L} W_{c} x_{c, t} \\
& +\sum_{j=1}^{k} \phi_{j}^{H} S_{c} x_{c, t-j}+\sum_{j=1}^{k} \phi_{j}^{M} M_{c} x_{c, t-j}+\sum_{j=1}^{k} \phi_{j}^{L} W_{c} x_{c, t-j} \\
& +\mathbf{Z}_{c, t}^{\prime} \boldsymbol{v}+\delta_{c}+\omega_{t}+\varepsilon_{c, t} .
\end{aligned}
$$

This equation implies that $\phi_{0}^{S}$ measures the short-run effect of CBI on countries with strong constraints on the executive, whereas with the full set of lags included,

$$
\text { long-run effect }{ }^{s}=\frac{\sum_{j=0}^{k} \phi_{j}^{s}}{1-\sum_{j=1}^{k} \zeta_{j}}
$$

corresponds to the long-run effect for these countries. The short-run and the long-run effects for medium- and weak-constraints countries are defined analogously. Equation 13 also includes a vector of country- and timevarying covariates $\mathbf{Z}_{c, t}$ (with a vector of coefficients denoted by $\boldsymbol{v}$ ). These covariates will be included in the robustness checks reported in table 7 .

Table 2 reports the results of estimating equation 13 on our base sample, with constraints measured in terms of the average constraints on the executive from the Polity IV data as described above. The first three columns use data for the whole sample. Column 2-1 is again the most parsimonious specification, omitting any lags of inflation or of the CBI dummy. The estimates suggest that CBI has no effect on inflation in weak- and strongconstraints countries but has a marginally significant effect of -0.071 (standard error of 0.044) in the sample of medium-constraints countries. This effect is twice the size of the estimate in column 1-1, showing that almost all of the effect in table 1 is due to the impact of CBI on inflation in countries with intermediate constraints. Moreover, the $\mathrm{p}$-values at the bottom of the table indicate that we can reject the null hypothesis that the impact of CBI in the medium-constraints group is equal to that in the weak- or the strong-constraints groups.

Column 2-2 shows similar results when the lags of inflation are included, and again the effect of CBI on inflation is statistically significant at about the 7 percent level. However, in this case, even though the long-run effect 


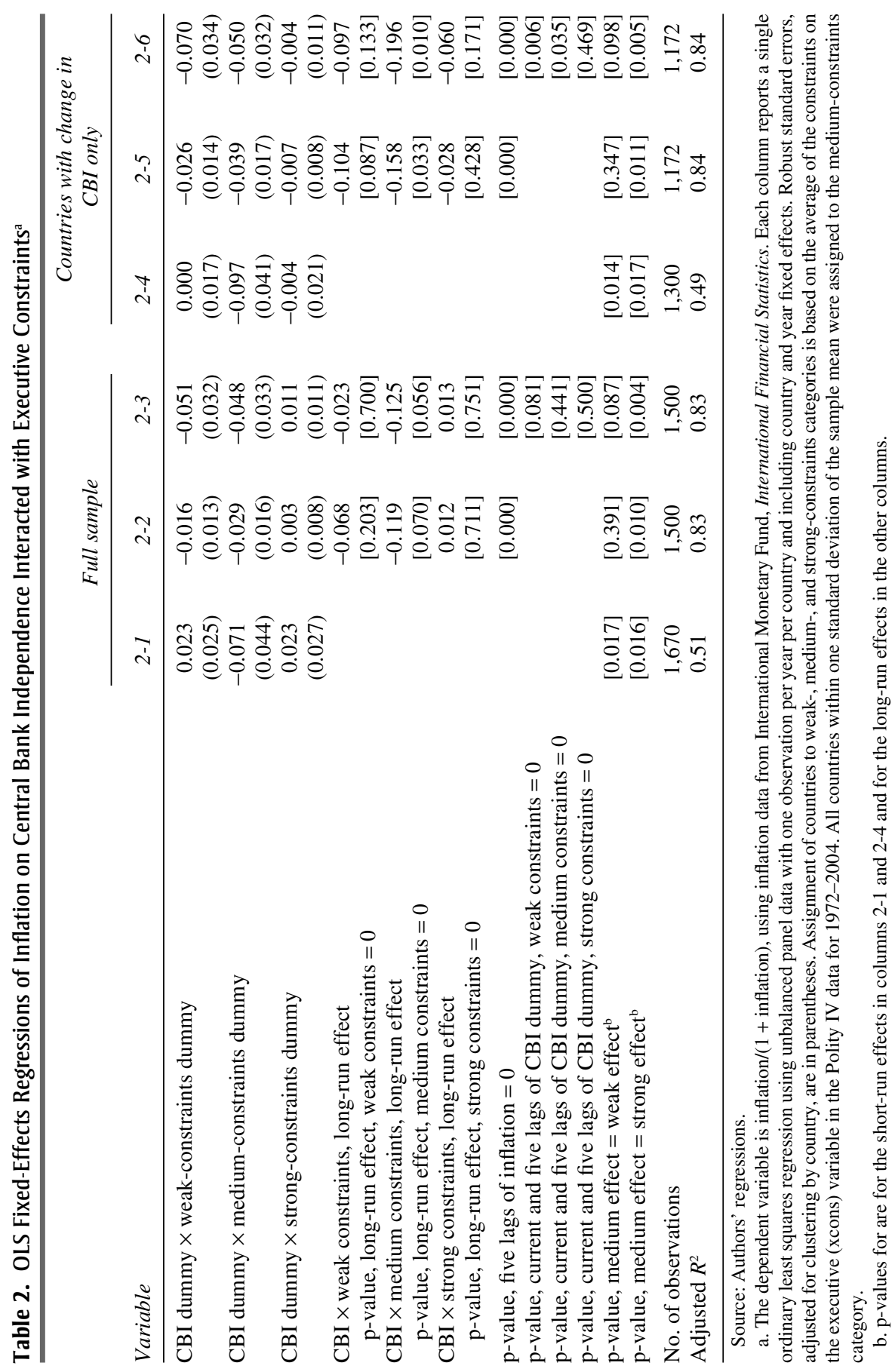


in the medium-constraints group is almost twice as large as for the weakconstraints group, we can no longer reject the null hypothesis that they are equal. (But we continue to reject the null hypothesis that the effect is the same in strong- as in medium-constraints countries.)

Column 2-3 reports the specification that includes the lags of CBI as well as the lags of inflation. Now the long-run effect in the sample of countries with intermediate constraints is larger, at -0.125 , and is significant at about the 6 percent level. The effects in countries with strong or weak constraints continue to be insignificant. In this specification we can reject at the 10 percent level the null hypothesis that the effect of CBI is the same in the medium- and weak-constraints countries (and we continue to reject, at the 1 percent level, the null hypothesis that it is the same in the strongand medium-constraints countries).

Columns 2-4 through 2-6 estimate the same models for the sample of countries that experienced a change in CBI. The effects of CBI in the medium-constraints countries are now quantitatively larger and more significant. The short-run effect in column 2-4, -0.097 , is significant and implies that $\mathrm{CBI}$ is associated with a decline in inflation of 24 percentage points for this group of countries. ${ }^{84} \mathrm{We}$ continue to reject the null hypotheses that this effect is the same as that for strong- or weak-constraints countries. In columns 2-5 and 2-6, once we include lags of the CBI dummy and inflation, the short-run effect becomes smaller and less significant, but the long-run effects are statistically and economically significant. For example, the effect in column 2-6, -0.196 , implies that CBI reduces inflation by 49 percentage points. As in the first three columns, there is no evidence that $\mathrm{CBI}$ influences inflation in countries with strong constraints. However, the results reported in these columns show some evidence that CBI might have a negative long-run effect on inflation in weak-constraints countries, although this effect is smaller than that for medium-constraints countries.

We conclude from this evidence that the conditional correlations between the introduction of CBI and changes in inflation are broadly consistent with the ideas suggested in the theoretical discussion above. In particular, CBI appears to be followed by a decline in inflation in countries with intermediate constraints on politicians, but there is no evidence of a negative effect of CBI on inflation in strong-constraints countries. In weak-constraints countries there is typically no effect of CBI on inflation, although some specifications show negative but (usually) less significant effects. Although

84. If we use median inflation to calculate the magnitude of the coefficient, the coefficient implies that CBI reduces inflation by 11 percentage points. 
we can reject the null hypothesis that the effect of CBI on inflation differs between strong- and medium-constraints countries, we can reject the same hypothesis in only some of the specifications for medium- and weakconstraints countries.

\section{Robustness}

Tables 3 through 7 investigate the robustness of the results in tables 1 and 2. Table 3 replicates columns 2-1, 2-3, 2-4, and 2-6 of table 2 but replaces the Polity IV executive constraints measure with the rule-of-law and control-of-corruption indices constructed by Kaufmann, Kraay, and Mastruzzi. ${ }^{85}$ The results in columns 3-1 through 3-4, based on the full sample, are similar to those in columns 1-1 through 1-3 of table 1 and do not show statistically significant effects of CBI. The results in columns 3-5 through 3-8, which focus on the sample of countries that experienced a change in CBI, are more encouraging. They are broadly similar to those in columns 2-4 through 2-6 of table 2. Columns 3-5 and 3-7 show evidence of a statistically significant short-run effect of CBI on inflation only in countries with institutions of medium strength, whether using the rule-of-law index (column 3-5) or the control-of-corruption index (column 3-7). These coefficients are similar in magnitude to those reported in column 2-4 of table 2. Columns 3-6 and 3-8, on the other hand, show evidence of a negative and statistically significant long-run effect of CBI on inflation in both the medium- and the weak-institutions countries. These results again show that the effects in the medium- and strong-institutions countries are statistically different, but we cannot reject the null hypothesis that the effects in the weak- and the medium-institutions countries are equal. Overall, the results using the alternative measures of institutions are generally consistent with those reported in table 2, although with these measures the differences between the weak and the medium categories are less pronounced.

An econometric problem in the estimation of equation 13 is that it includes both fixed effects and lagged dependent variables. In the presence of the latter, the key regressor $x_{c, t}$ (and its lags) will be mechanically correlated with $\varepsilon_{c, s}$ for $s<t$, so that the standard fixed-effects estimator, used in table 2, is inconsistent. ${ }^{86}$ However, it can be shown that the fixed-effects estimator becomes consistent as the number of time periods in the sample increases (that is, as $T \rightarrow \infty$ ). Even though our sample covers a relatively large number of time periods, this source of inconsistency might still be

85. Kaufmann, Kraay, and Mastruzzi (2007).

86. See, for example, Wooldridge (2002, ch. 11). 
important depending on how close to a unit root the inflation dynamics are. The most common way of ensuring consistency in this case is to use the generalized method of moments (GMM) estimator developed by Manuel Arellano and Stephen Bond. ${ }^{87}$ This involves differencing equation 13 to eliminate fixed effects, so that we have

$$
\begin{aligned}
\Delta y_{c, t} & =\sum_{j=1}^{k} \zeta_{j} \Delta y_{c, t-j}+\phi_{0}^{H} S_{c} \Delta x_{c, t}+\phi_{0}^{M} M_{c} \Delta x_{c, t}+\phi_{0}^{L} W_{c} \Delta x_{c, t} \\
& +\sum_{j=1}^{k} \phi_{j}^{H} S_{c} \Delta x_{c, t-j}+\sum_{j=1}^{k} \phi_{j}^{M} M_{c} \Delta x_{c, t-j}+\sum_{j=1}^{k} \phi_{j}^{L} W_{c} \Delta x_{c, t-j} \\
& +\Delta \omega_{t}+\Delta \varepsilon_{c, t},
\end{aligned}
$$

and then using lags of $y_{c, t}$ and $x_{c, t}$ to instrument for the differenced terms (here $\Delta y_{c, t}=y_{c, t}-y_{c, t-1}$ and so on). These lags will be valid instruments to solve the endogeneity problem resulting from the mechanical correlation between $x_{c, t}$ and the error term if there is no additional serial correlation in $\varepsilon_{c, t}$ (so that there is no second-order serial correlation in $\Delta \varepsilon_{c, t}$ ), which can be tested. Table 4 reports the results of estimating equation 14 on the same samples and specifications as in columns 2-2, 2-3, 2-5, and 2-6 of table 2. (Here and throughout the rest of the paper, $S_{c}, M_{c}$, and $W_{c}$ are again based on the Polity IV executive constraints variable.) The results are similar to those of table 2. In particular, the interactions between the mediumconstraints dummy and CBI are still negative, and the estimates are almost all statistically more significant than in table 2 . There is no evidence of a negative effect of CBI on inflation in strong-constraints countries. The results in table 4 also show some evidence of a negative effect of CBI in weak-constraints countries once we focus on the sample of countries that changed their CBI, in columns 4-3 and 4-4. Nevertheless, these results should be interpreted with caution: although the tests for serial correlation cannot reject the null hypothesis of no second-order correlation in the differenced residuals, the Sargan overidentification tests reject the null hypothesis in all columns, which implies that different lags estimate different magnitudes for the coefficients of CBI and lagged inflation (which is often a problem when using this GMM procedure with large $T$ ).

Table 5 investigates an alternative to the use of the three dummy variables $S_{c}, M_{c}$, and $W_{c}$ for strong-, medium-, and weak-constraints countries to capture the nonlinear effects of this variable, namely, the use of a quadratic term in the average of constraints on the executive interacted with the CBI 


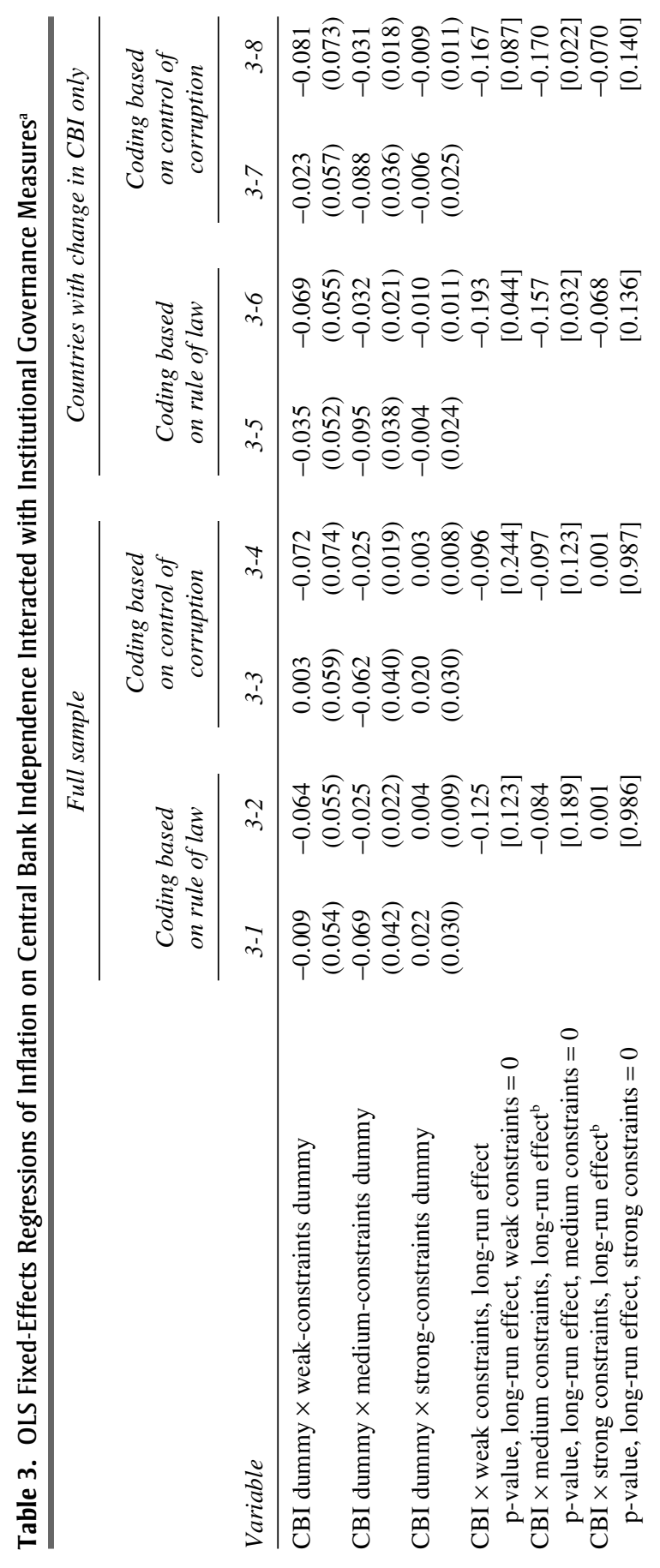




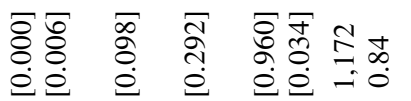

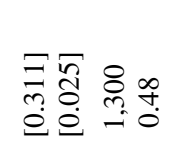

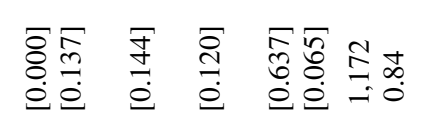

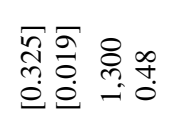

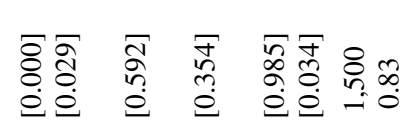

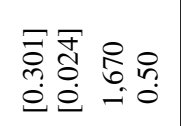

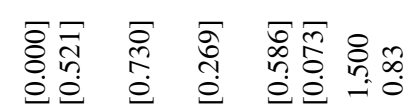

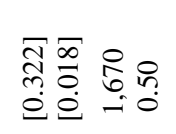

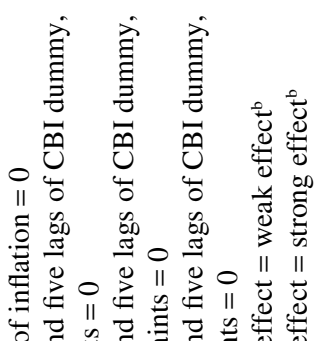

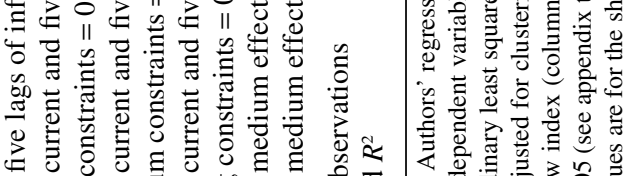

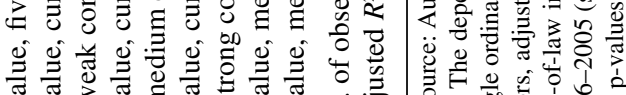

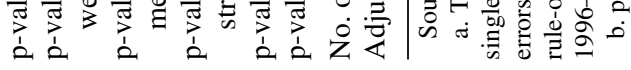


Table 4. Arellano-Bond GMM Regressions of Inflation on Central Bank Independence Interacted with Executive Constraints ${ }^{\mathrm{a}}$

\begin{tabular}{|c|c|c|c|c|}
\hline \multirow[b]{2}{*}{ Variable } & \multicolumn{2}{|c|}{ Full sample } & \multicolumn{2}{|c|}{$\begin{array}{l}\text { Countries with } \\
\text { change in } \\
\text { CBI only }\end{array}$} \\
\hline & $4-1$ & $4-2$ & $4-3$ & $4-4$ \\
\hline $\begin{array}{l}\text { CBI dummy } \times \text { weak- } \\
\text { constraints dummy }\end{array}$ & $\begin{array}{l}-0.010 \\
(0.040)\end{array}$ & $\begin{array}{c}-0.059 \\
(0.048)\end{array}$ & $\begin{array}{r}-0.050 \\
(0.024)\end{array}$ & $\begin{array}{c}-0.091 \\
(0.042)\end{array}$ \\
\hline $\begin{array}{l}\text { CBI dummy } \times \text { medium- } \\
\text { constraints dummy }\end{array}$ & $\begin{array}{l}-0.046 \\
(0.027)\end{array}$ & $\begin{array}{l}-0.060 \\
(0.037)\end{array}$ & $\begin{array}{r}-0.053 \\
(0.021)\end{array}$ & $\begin{array}{c}-0.063 \\
(0.032)\end{array}$ \\
\hline $\begin{array}{l}\text { CBI dummy } \times \text { strong- } \\
\text { constraints dummy }\end{array}$ & $\begin{array}{c}0.032 \\
(0.018)\end{array}$ & $\begin{array}{c}0.034 \\
(0.015)\end{array}$ & $\begin{array}{c}0.010 \\
(0.015)\end{array}$ & $\begin{array}{c}0.012 \\
(0.013)\end{array}$ \\
\hline $\begin{array}{l}\mathrm{CBI} \times \text { weak constraints, } \\
\text { long-run effect }\end{array}$ & -0.039 & -0.049 & -0.203 & -0.203 \\
\hline $\begin{array}{l}\text { p-value, long-run effect, } \\
\text { weak constraints }=0\end{array}$ & {$[0.804]$} & {$[0.725]$} & [0.043] & [0.035] \\
\hline $\begin{array}{l}\mathrm{CBI} \times \text { medium constraints, } \\
\text { long-run effect }\end{array}$ & -0.181 & -0.191 & -0.217 & -0.273 \\
\hline $\begin{array}{l}\mathrm{p} \text {-value, long-run effect, } \\
\text { medium constraints }=0\end{array}$ & {$[0.068]$} & {$[0.063]$} & [0.034] & [0.011] \\
\hline $\begin{array}{l}\mathrm{CBI} \times \text { strong constraints, } \\
\text { long-run effect }\end{array}$ & 0.129 & 0.111 & 0.040 & -0.014 \\
\hline $\begin{array}{l}\text { p-value, long-run effect, } \\
\text { strong constraints }=0\end{array}$ & {$[0.072]$} & {$[0.186]$} & [0.480] & [0.830] \\
\hline $\mathrm{p}$-value, five lags of inflation $=0$ & {$[0.000]$} & {$[0.000]$} & {$[0.000]$} & [0.000] \\
\hline $\begin{array}{l}\text { p-value, current and five lags } \\
\text { of CBI dummy, } \\
\text { weak constraints }=0\end{array}$ & & {$[0.042]$} & & [0.005] \\
\hline $\begin{array}{l}\text { p-value, current and five lags } \\
\text { of CBI dummy, } \\
\text { medium constraints }=0\end{array}$ & & {$[0.541]$} & & [0.074] \\
\hline $\begin{array}{l}\text { p-value, current and five lags } \\
\text { of CBI dummy, } \\
\text { strong constraints =0 }\end{array}$ & & {$[0.210]$} & & [0.326] \\
\hline $\begin{array}{l}\text { p-value, medium effect }= \\
\text { weak effect }^{\mathrm{b}}\end{array}$ & {$[0.387]$} & {$[0.236]$} & {$[0.890]$} & [0.445] \\
\hline $\begin{array}{l}\text { p-value, medium effect }= \\
\text { strong effect }^{\mathrm{b}}\end{array}$ & {$[0.001]$} & {$[0.000]$} & {$[0.003]$} & [0.001] \\
\hline Sargan test & {$[0.00]$} & {$[0.00]$} & {$[0.00]$} & {$[0.00]$} \\
\hline Second-order serial correlation & {$[0.59]$} & {$[0.45]$} & {$[0.99]$} & {$[0.85]$} \\
\hline No. of observations & 1,358 & 1,358 & 1,060 & 1,060 \\
\hline
\end{tabular}

Source: Authors' regressions.

a. The dependent variable is inflation/( $1+$ inflation $)$, using inflation data from International Monetary Fund, International Financial Statistics. Each column reports a single regression using unbalanced panel data with one observation per year per country and including year dummies. Robust standard errors are in parentheses. The GMM (Arellano-Bond) estimation method uses all available lags of inflation as instruments.

b. p-values in all columns are for the long-run effects. 


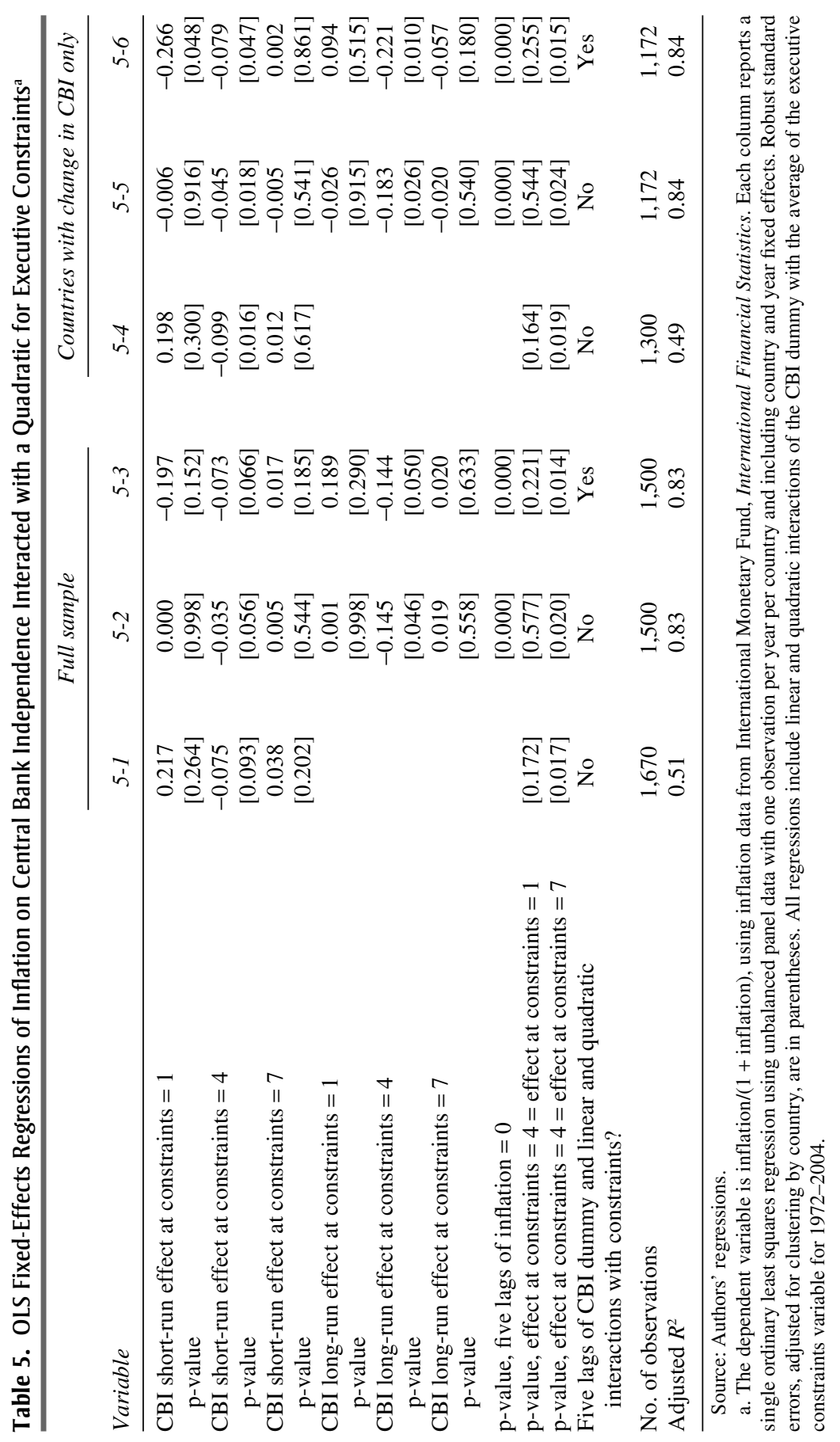


dummy. The coefficients reported evaluate the quadratic at levels 1,4 , and 7 of constraints on the executive. The results are broadly similar to those in table 2. The short- and the long-run effects of CBI on inflation are always negative and significant for countries with medium constraints. There is no evidence of a significant effect of CBI in countries with strong or weak constraints. However, we can reject the hypothesis that the effects are equal only when comparing the strong- and the medium-constraints groups. Overall, these results suggest that the specific way of parameterizing the nonlinearity in the exact cutoffs between weak and medium, and medium and strong, constraints does not matter greatly to our results.

Table 6 reports the results of a simple falsification exercise. Each regression this time includes the interaction of each of the executive constraints dummies with both the contemporaneous CBI and its five-year lead. To the extent that inflation was already declining in some countries before central bank reform, this lead variable will capture the decline. When this is the case, we cannot have much confidence that CBI is in fact a major factor in the decline in inflation. The table shows that the contemporaneous effect of CBI in countries with intermediate constraints is still significant. The coefficient on the five-year lead is never negative for this group and is typically very small. Hence the negative association between CBI and inflation in this group of countries is not driven mainly by a secular decline in inflation. For strong-constraints countries, the lead of CBI is likewise never significant and is typically very small. For weak-constraints countries there is some evidence of an upward trend in inflation preceding CBI. This suggests that in some of these cases CBI may have been introduced in the midst of episodes of particularly high inflation.

Finally, table 7 reports results from a range of other robustness checks. The top panel focuses on the full sample and reports results of specifications corresponding to columns 2-1 and 2-3 in table 2. In the bottom panel the sample is restricted to countries that changed their CBI during the sample period, and specifications corresponding to columns 2-4 and 2-6 of table 2 are reported. Columns 7-1 and 7-2 in both panels report the robustness of the results to including potential time-varying determinants of inflation. In particular, we include five lags of the logarithm of GDP per capita and five lags of the exchange rate flexibility index constructed by Reinhart and Rogoff, described above. ${ }^{88}$ Although the negative effect of CBI on inflation is not significant in the full sample, the results in the bottom panel show a pattern similar to that depicted in table 2 , with a negative

88. Reinhart and Rogoff (2004). 
Table 6. Regressions of Inflation on Five-Year Lead of Central Bank Independence Interacted with Executive Constraints ${ }^{\mathrm{a}}$

\begin{tabular}{|c|c|c|c|c|}
\hline \multirow[b]{2}{*}{ Variable } & \multicolumn{2}{|c|}{ Full sample } & \multicolumn{2}{|c|}{$\begin{array}{l}\text { Countries with } \\
\text { change in CBI only }\end{array}$} \\
\hline & $6-1$ & $6-2$ & $6-3$ & $6-4$ \\
\hline $\begin{array}{l}\text { CBI dummy } \times \text { weak-constraints } \\
\text { dummy }\end{array}$ & $\begin{array}{r}-0.007 \\
(0.017)\end{array}$ & $\begin{array}{r}-0.044 \\
(0.020)\end{array}$ & $\begin{array}{r}-0.013 \\
(0.017)\end{array}$ & $\begin{array}{l}-0.048 \\
(0.019)\end{array}$ \\
\hline $\begin{array}{l}\text { CBI dummy } \times \text { medium-constraints } \\
\text { dummy }\end{array}$ & $\begin{array}{r}-0.119 \\
(0.056)\end{array}$ & $\begin{array}{l}-0.035 \\
(0.020)\end{array}$ & $\begin{array}{r}-0.132 \\
(0.050)\end{array}$ & $\begin{array}{c}-0.042 \\
(0.020)\end{array}$ \\
\hline $\begin{array}{l}\text { CBI dummy } \times \text { strong-constraints } \\
\text { dummy }\end{array}$ & $\begin{array}{c}0.032 \\
(0.020)\end{array}$ & $\begin{array}{c}0.006 \\
(0.005)\end{array}$ & $\begin{array}{c}0.023 \\
(0.019)\end{array}$ & $\begin{array}{c}0.002 \\
(0.006)\end{array}$ \\
\hline $\begin{array}{l}\text { CBI dummy, } t+5 \times \text { weak- } \\
\text { constraints dummy }\end{array}$ & $\begin{array}{l}0.052 \\
(0.024)\end{array}$ & $\begin{array}{c}0.030 \\
(0.015)\end{array}$ & $\begin{array}{c}0.032 \\
(0.029)\end{array}$ & $\begin{array}{c}0.022 \\
(0.014)\end{array}$ \\
\hline $\begin{array}{l}\text { CBI dummy, } t+5 \times \text { medium- } \\
\text { constraints dummy }\end{array}$ & $\begin{array}{c}0.083 \\
(0.042)\end{array}$ & $\begin{array}{l}0.016 \\
(0.010)\end{array}$ & $\begin{array}{c}0.070 \\
(0.046)\end{array}$ & $\begin{array}{c}0.012 \\
(0.010)\end{array}$ \\
\hline $\begin{array}{l}\text { CBI dummy, } t+5 \times \text { strong- } \\
\text { constraints dummy }\end{array}$ & $\begin{array}{c}-0.001 \\
(0.019)\end{array}$ & $\begin{array}{c}0.002 \\
(0.007)\end{array}$ & $\begin{array}{c}-0.018 \\
(0.024)\end{array}$ & $\begin{array}{l}-0.006 \\
(0.008)\end{array}$ \\
\hline $\mathrm{p}$-value, five lags of inflation $=0$ & & {$[0.000]$} & & [0.000] \\
\hline No. of observations & 1,514 & 1,344 & 1,180 & 1,052 \\
\hline Adjusted $R^{2}$ & 0.54 & 0.83 & 0.51 & 0.84 \\
\hline
\end{tabular}

Source: Authors' regressions.

a. The dependent variable is inflation/ $(1+$ inflation $)$, using inflation data from International Monetary Fund, International Financial Statistics. Each column reports a single ordinary least squares regression using unbalanced panel data with one observation per year per country and including country and year fixed effects. Robust standard errors, adjusted for clustering by country, are in parentheses.

and statistically significant long-run effect of CBI only in the group with intermediate constraints on the executive. The results in columns 7-3 and 7-4 include a quadratic time trend interacted with regional dummies to control for differing trends in inflation across world regions. These additional controls have little effect on the estimates. In column 7-3 in the top panel, the estimate of the impact of $\mathrm{CBI}$ in medium-constraints countries is -0.065 , with a standard error of 0.044 , which is similar to that reported in column 2-1 of table 2. The long-run effect in column 7-4, however, is smaller and less significant than that in column 2-2. Nevertheless, the results in the bottom panel for columns 7-3 and 7-4 show that in the sample of countries that changed CBI, once we control for differences in regional trends, the results are again similar to those in table 2.

In columns 7-5 and 7-6 we exclude the Western European countries from the sample entirely. This robustness check is motivated by the concern that policy dynamics and the effect of CBI on inflation might be different in Western Europe than in the rest of the world. The results, however, are again similar to the baseline estimates. 


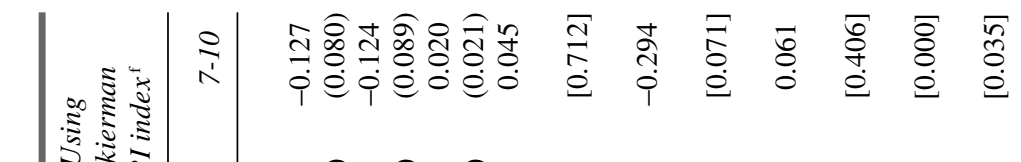

$$
\begin{aligned}
& \text { है }
\end{aligned}
$$

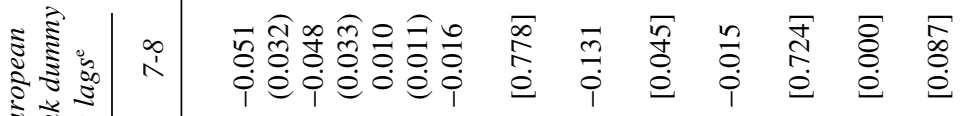

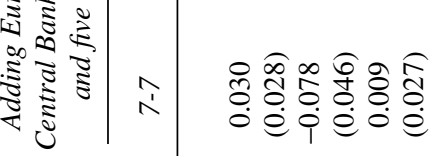

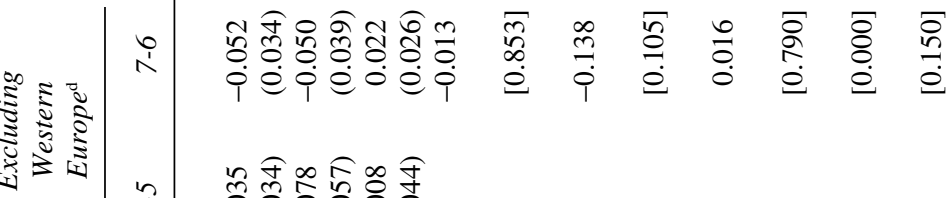

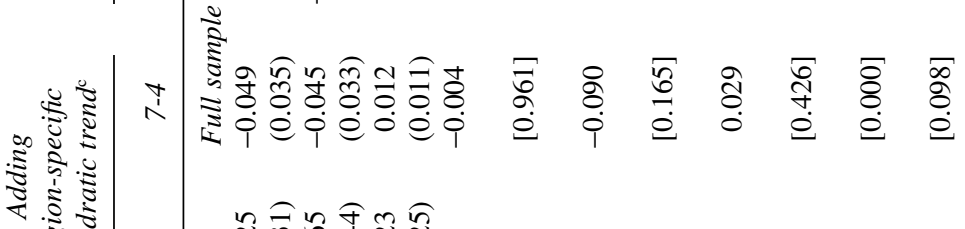

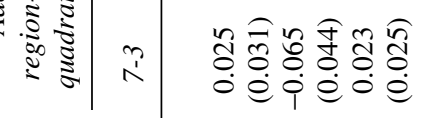

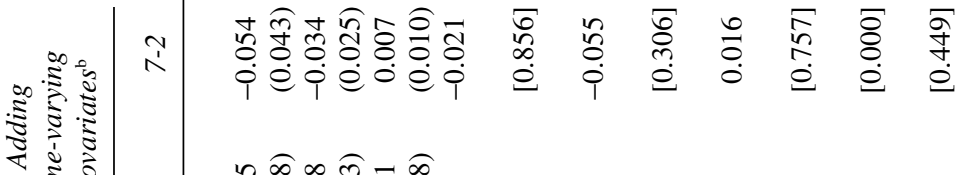

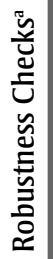

$$
\begin{aligned}
& \text { 它 }
\end{aligned}
$$

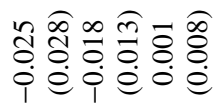

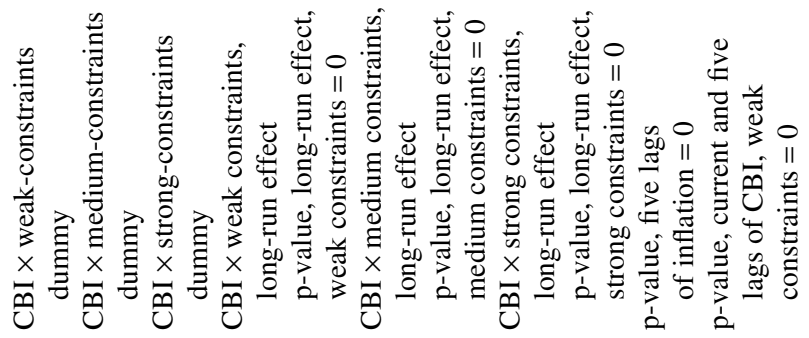




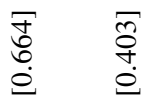

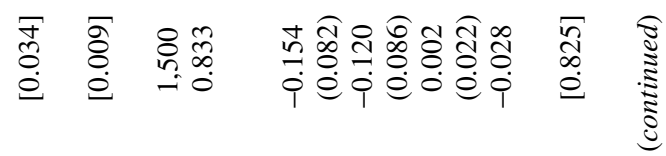

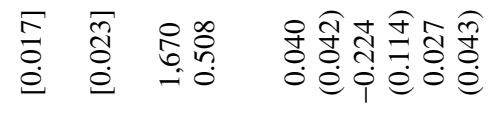

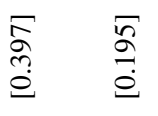

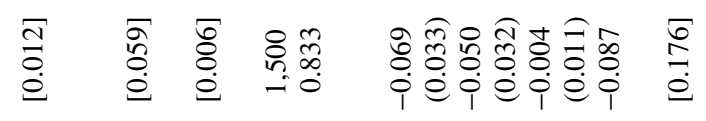

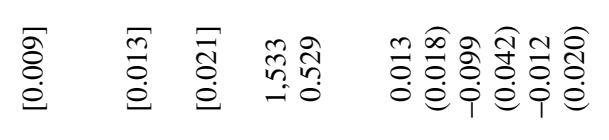

商

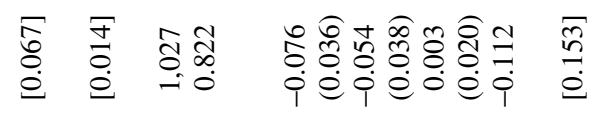

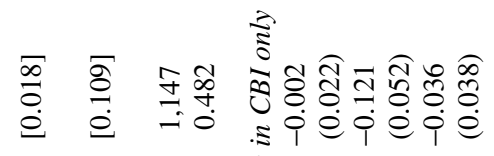

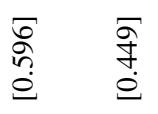

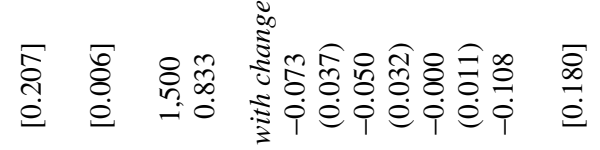

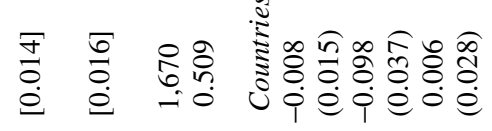

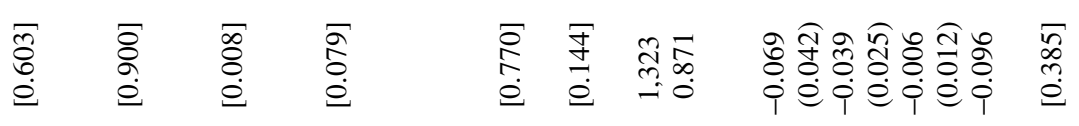

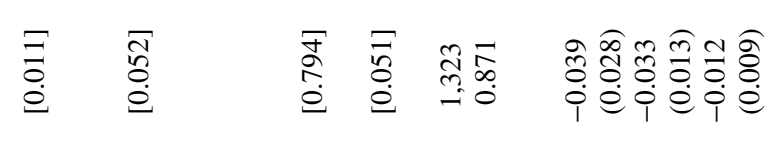

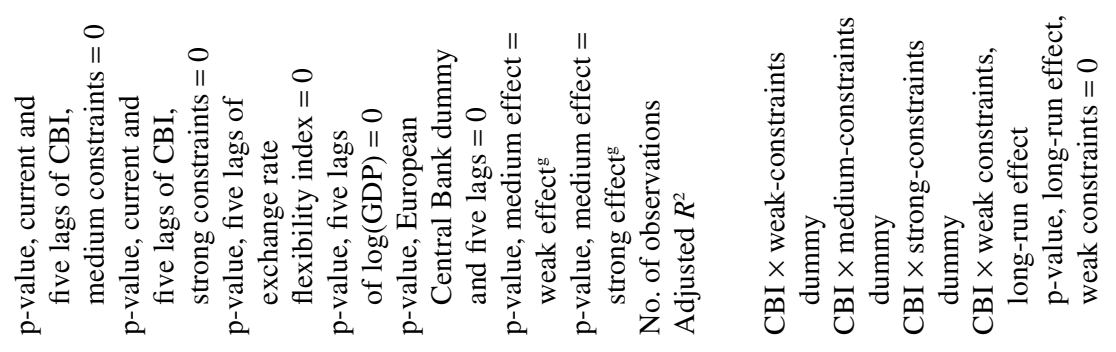




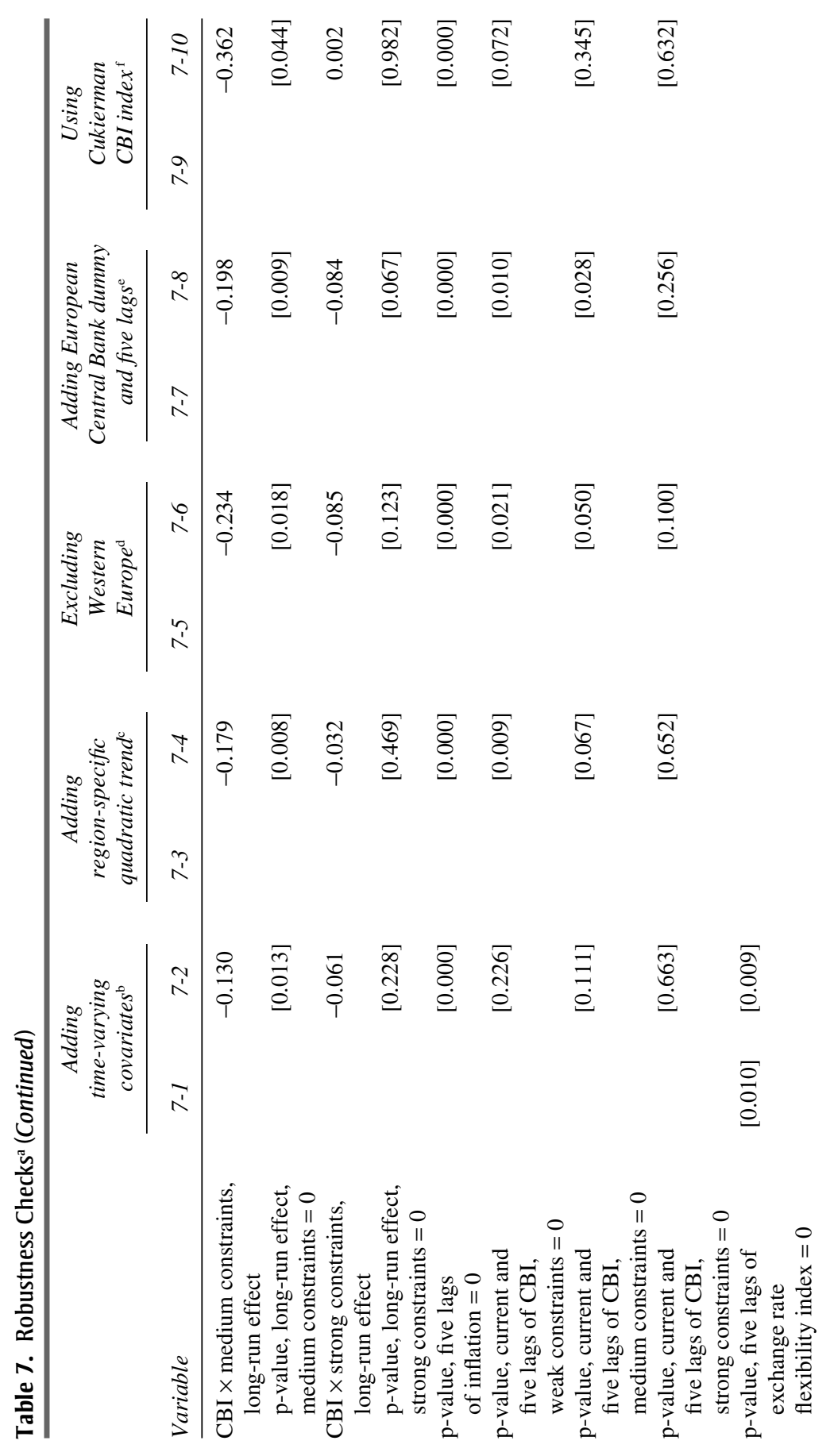




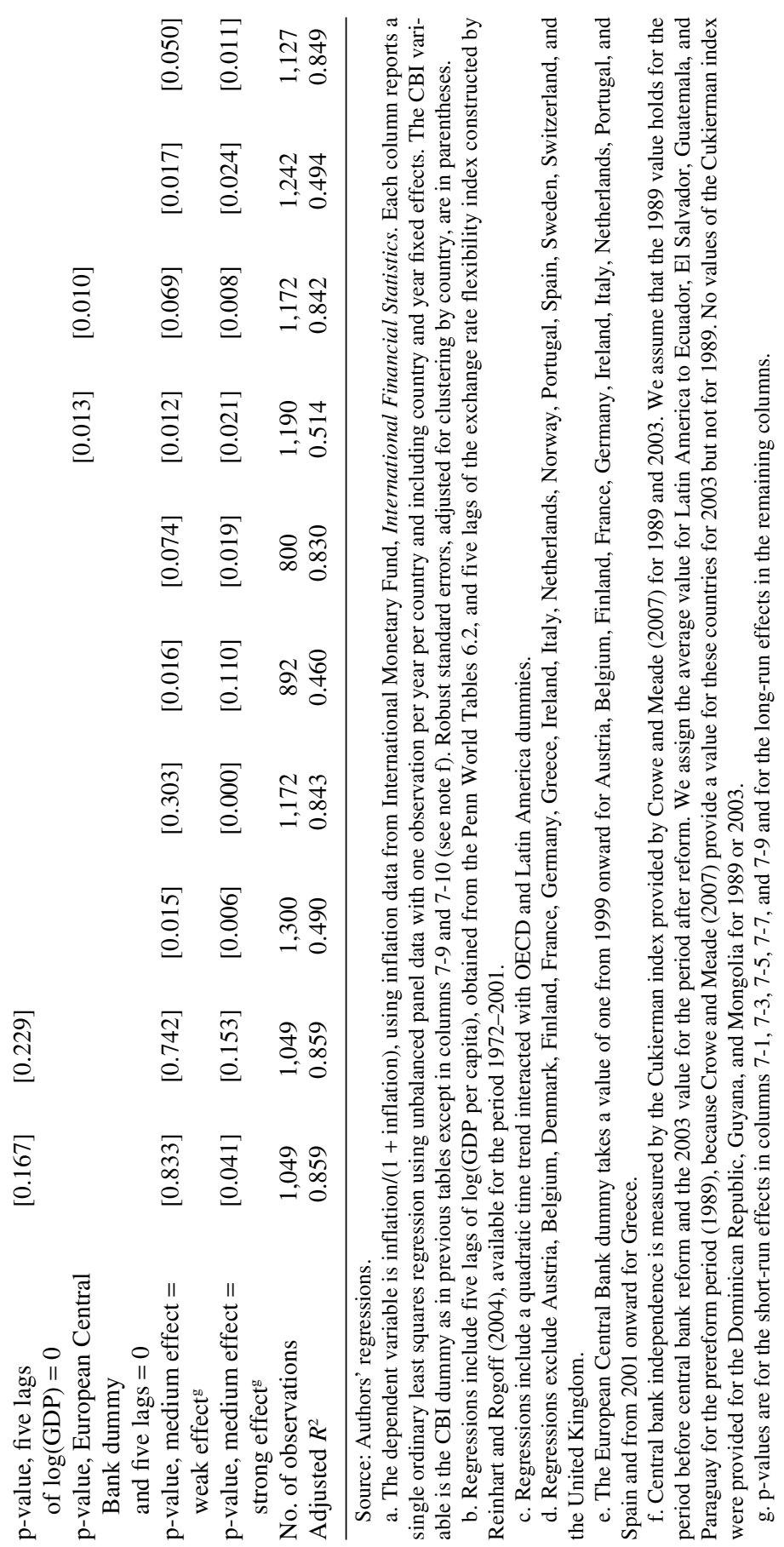


Columns 7-7 and 7-8 include an additional dummy for the introduction of the European Central Bank, or for the country in question joining the European monetary union after the European Central Bank was established. Again there is little change from the results in table 2.

Finally, columns 7-9 and 7-10 show the robustness of our results to using the CBI index constructed by Cukierman rather than the CBI dummy. Despite the concerns discussed above related to the coding and interpretation of this index, it still constitutes a useful check on our measure of CBI and on our results. The results using this index are again similar to those reported in table 2: only the interaction between the medium-constraints dummy and the Cukierman CBI index is negative and statistically significant. ${ }^{89}$ Interestingly, in columns 7-5 through 7-10 for both panels we can now reject at the 10 percent level the null hypothesis that the effects in the intermediate-constraints group are equal to those in the weak-constraints group as well as in the strong-constraints group.

We also examined the robustness of the results reported in table 2 to the type of CBI that different countries implemented. To do this we ran the same regressions as in table 2 but included a dummy for goal independence of the CBI. This dummy takes a value of one for countries where CBI reform defined inflation as the unique objective of monetary policy, and zero elsewhere. This is a useful robustness check against the possibility that CBI may have very different effects where the central banker is truly conservative, with price stability the unique objective (as with the German Bundesbank), than where CBI has multiple objectives (as with the U.S. Federal Reserve). The results (not reported here) using the goal independence dummy are analogous to those in table 2 and suggest a similar pattern, with a negative effect of goal independence on inflation found only for countries with intermediate constraints on the executive. We also briefly investigated whether changes in the dynamics and persistence of inflation in the mid-1980s, documented for example by Haroon Mumtaz and Paolo Surico and by James Stock and Mark Watson, ${ }^{90}$ might be responsible for our results. As a crude control for this possibility, we interacted the lags of inflation with a dummy for the

89. The coefficient in column 7-9 in the bottom panel, -0.224 , implies that an increase of one standard deviation in the index is associated with a decrease of 11 percentage points in the inflation rate in countries with intermediate constraints. The coefficient in column 7-10, on the other hand, suggests that an increase of one standard deviation in the CBI index decreases inflation by 18 percentage points in the long run.

90. Mumtaz and Surico (2006); Stock and Watson (2007). 
period 1972-90 and a dummy for 1991-2005. The results (again not reported here) exhibited a pattern similar to that in table 2, with a negative effect of CBI found only in countries with intermediate constraints on the executive, although the statistical significance of some of the estimates became weaker.

\section{The Seesaw Effect}

Here we investigate the implications of CBI reform for other dimensions of policy. In particular, we look at whether CBI is followed by an increase in government expenditure as a percentage of GDP in countries with intermediate political constraints. Our basic econometric model is again equation 13, but now the dependent variable measures fiscal policy. Table 8 reports the different effects of CBI in strong-, medium-, and weak-constraints countries on government expenditure as a percentage of GDP. No evidence is found that introducing CBI in countries with strong or weak constraints has any impact on government expenditure relative to GDP in either the short or the long run. However, in medium-constraints countries, where CBI was found above to be associated with declines in inflation, CBI also appears to be associated with increases in government expenditure. Both the short- and the long-run effects are positive for these countries in all specifications, and in columns 8-2, 8-3, and 8-5 these effects are statistically significant. In column 2 the estimated $\phi_{0}^{M}$ is 0.011 , with a standard error of 0.004 , which suggests an immediate increase in government expenditure equivalent to just above 1 percent of GDP. The long-run effect of 0.050 is also significant and corresponds to a 5-percent-of-GDP increase in government expenditure in the long run in medium-constraints countries that have introduced CBI.

Table 9 shows that the broad pattern is similar when we use the ArellanoBond GMM estimator as in table 4. In this case the evidence consistent with the seesaw effect is somewhat stronger, although now we also find some positive long-run effect of CBI on government expenditure in weakconstraints countries (see, for example, column 9-2). Finally, table 10 reports results of a falsification exercise similar to that in table 6 . Here we again include a five-year lead of the CBI dummy to check whether the estimates in table 8 might be capturing a secular upward trend in government expenditure in countries with intermediate constraints. The results show no evidence of such a pattern. The interaction between the medium-constraints dummy and the five-year lead of the CBI dummy is never significantly different from zero. 


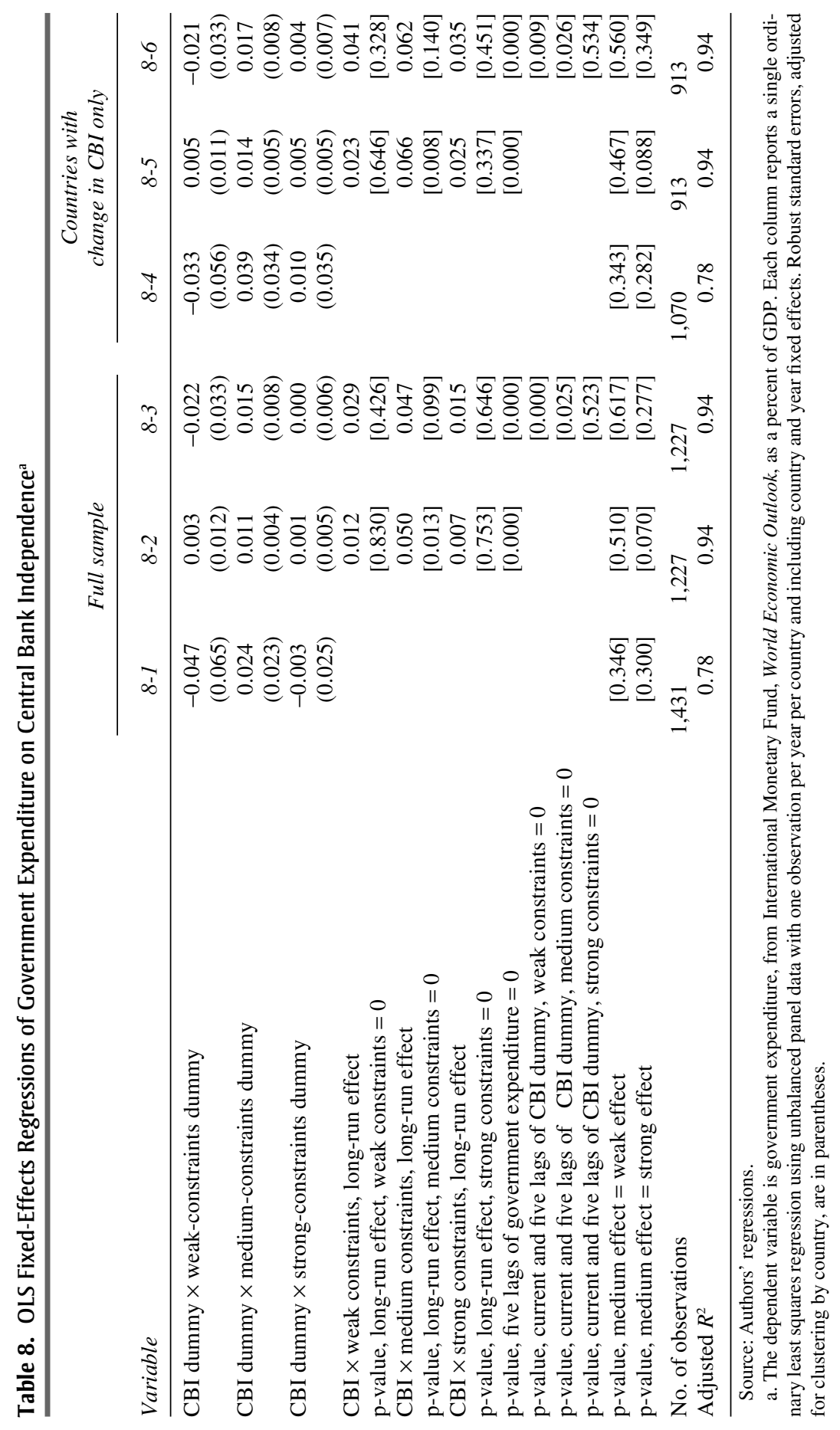


Table 9. Arellano-Bond GMM Regressions of Government Expenditure on Central Bank Independence Interacted with Executive Constraints ${ }^{a}$

\begin{tabular}{|c|c|c|c|c|}
\hline \multirow[b]{2}{*}{ Variable } & \multicolumn{2}{|c|}{ Full sample } & \multicolumn{2}{|c|}{$\begin{array}{l}\text { Countries with } \\
\text { change in CBI only }\end{array}$} \\
\hline & $9-1$ & $9-2$ & $9-3$ & $9-4$ \\
\hline $\begin{array}{l}\text { CBI dummy } \times \text { weak-constraints } \\
\text { dummy }\end{array}$ & $\begin{array}{c}0.017 \\
(0.010)\end{array}$ & $\begin{array}{l}-0.008 \\
(0.027)\end{array}$ & $\begin{array}{c}0.008 \\
(0.007)\end{array}$ & $\begin{array}{l}-0.018 \\
(0.026)\end{array}$ \\
\hline $\begin{array}{l}\text { CBI dummy } \times \text { medium-constraints } \\
\text { dummy }\end{array}$ & $\begin{array}{c}0.022 \\
(0.008)\end{array}$ & $\begin{array}{c}0.020 \\
(0.008)\end{array}$ & $\begin{array}{c}0.017 \\
(0.006)\end{array}$ & $\begin{array}{c}0.019 \\
(0.008)\end{array}$ \\
\hline $\begin{array}{l}\text { CBI dummy } \times \text { strong-constraints } \\
\text { dummy }\end{array}$ & $\begin{array}{l}0.003 \\
(0.005)\end{array}$ & $\begin{array}{l}-0.001 \\
(0.007)\end{array}$ & $\begin{array}{c}-0.002 \\
(0.005)\end{array}$ & $\begin{array}{l}-0.004 \\
(0.008)\end{array}$ \\
\hline $\begin{array}{l}\mathrm{CBI} \times \text { weak constraints, } \\
\text { long-run effect }\end{array}$ & 0.079 & 0.119 & 0.035 & 0.050 \\
\hline $\begin{array}{l}\text { p-value, long-run effect, } \\
\text { weak constraints }=0\end{array}$ & {$[0.069]$} & {$[0.008]$} & {$[0.242]$} & [0.111] \\
\hline $\begin{array}{l}\mathrm{CBI} \times \text { medium constraints, } \\
\text { long-run effect }\end{array}$ & 0.105 & 0.111 & 0.075 & 0.063 \\
\hline $\begin{array}{l}\text { p-value, long-run effect, } \\
\text { medium constraints }=0\end{array}$ & {$[0.002]$} & {$[0.016]$} & {$[0.003]$} & {$[0.160]$} \\
\hline $\begin{array}{l}\text { CBI } \times \text { strong constraints, } \\
\text { long-run effect }\end{array}$ & 0.013 & 0.027 & -0.010 & -0.006 \\
\hline $\begin{array}{l}\text { p-value, long-run effect, } \\
\text { strong constraints }=0\end{array}$ & {$[0.577]$} & [0.385] & [0.633] & [0.871] \\
\hline $\begin{array}{l}\text { p-value, five lags of government } \\
\text { expenditure }=0\end{array}$ & {$[0.000]$} & {$[0.000]$} & {$[0.000]$} & {$[0.000]$} \\
\hline $\begin{array}{l}\text { p-value, current and five lags } \\
\text { of CBI dummy, } \\
\text { weak constraints }=0\end{array}$ & & {$[0.000]$} & & [0.036] \\
\hline $\begin{array}{l}\text { p-value, current and five lags } \\
\text { of CBI dummy, medium } \\
\text { constraints }=0\end{array}$ & & {$[0.024]$} & & [0.003] \\
\hline $\begin{array}{l}\text { p-value, current and five lags } \\
\text { of CBI dummy, strong } \\
\text { constraints }=0\end{array}$ & & {$[0.487]$} & & [0.206] \\
\hline $\begin{array}{l}\text { p-value, medium } \\
\text { effect }=\text { weak effect }^{\mathrm{b}}\end{array}$ & {$[0.629]$} & {$[0.855]$} & [0.381] & {$[0.707]$} \\
\hline $\begin{array}{l}\text { p-value, medium } \\
\text { effect }=\text { strong effect }^{\mathrm{b}}\end{array}$ & {$[0.000]$} & {$[0.004]$} & {$[0.000]$} & {$[0.004]$} \\
\hline Sargan test & {$[0.00]$} & {$[0.00]$} & {$[0.00]$} & {$[0.00]$} \\
\hline Second-order serial correlation & {$[0.41]$} & {$[0.40]$} & {$[0.25]$} & {$[0.25]$} \\
\hline No. of observations & 1,137 & 1,137 & 848 & 848 \\
\hline
\end{tabular}

Source: Authors' regressions.

a. The dependent variable is general government expenditure, from International Monetary Fund, World Economic Outlook. Each column reports a single regression using unbalanced panel data with one observation per year per country and including year dummies. Robust standard errors are in parentheses. The GMM (Arellano-Bond) estimation method uses all available lags of government expenditure as instruments.

b. p-values in all columns are for the long-run effects. 
Table 10. Regressions of Government Expenditure on Five-Year Lead of Central Bank Independence Interacted with Executive Constraints ${ }^{\mathrm{a}}$

\begin{tabular}{|c|c|c|c|c|}
\hline \multirow[b]{2}{*}{ Variable } & \multicolumn{2}{|c|}{ Full sample } & \multicolumn{2}{|c|}{$\begin{array}{c}\text { Countries with } \\
\text { change in CBI only }\end{array}$} \\
\hline & $10-1$ & $10-2$ & $10-3$ & $10-4$ \\
\hline CBI dummy $\times$ weak-constraints dummy & $\begin{array}{c}0.061 \\
(0.035)\end{array}$ & $\begin{array}{c}0.018 \\
(0.007)\end{array}$ & $\begin{array}{c}0.069 \\
(0.039)\end{array}$ & $\begin{array}{c}0.018 \\
(0.008)\end{array}$ \\
\hline CBI dummy $\times$ medium-constraints dummy & $\begin{array}{c}0.008 \\
(0.016)\end{array}$ & $\begin{array}{c}0.013 \\
(0.004)\end{array}$ & $\begin{array}{c}0.028 \\
(0.023)\end{array}$ & $\begin{array}{c}0.017 \\
(0.005)\end{array}$ \\
\hline CBI dummy $\times$ strong-constraints dummy & $\begin{array}{l}-0.021 \\
(0.018)\end{array}$ & $\begin{array}{c}-0.004 \\
(0.004)\end{array}$ & $\begin{array}{l}-0.011 \\
(0.025)\end{array}$ & $\begin{array}{l}-0.001 \\
(0.004)\end{array}$ \\
\hline $\begin{array}{l}\text { CBI dummy } \times \text { weak-constraints dummy, } \\
\qquad t+5\end{array}$ & $\begin{array}{l}-0.140 \\
(0.094)\end{array}$ & $\begin{array}{l}-0.027 \\
(0.021)\end{array}$ & $\begin{array}{l}-0.111 \\
(0.079)\end{array}$ & $\begin{array}{c}-0.019 \\
(0.018)\end{array}$ \\
\hline $\begin{array}{l}\text { CBI dummy } \times \text { medium-constraints dummy, } \\
t+5\end{array}$ & $\begin{array}{c}0.015 \\
(0.018)\end{array}$ & $\begin{array}{c}-0.003 \\
(0.009)\end{array}$ & $\begin{array}{c}0.033 \\
(0.028)\end{array}$ & $\begin{array}{c}0.001 \\
(0.012)\end{array}$ \\
\hline $\begin{array}{l}\text { CBI dummy } \times \text { strong-constraints dummy, } \\
t+5\end{array}$ & $\begin{array}{c}0.025 \\
(0.021)\end{array}$ & $\begin{array}{c}0.005 \\
(0.007)\end{array}$ & $\begin{array}{c}0.052 \\
(0.032)\end{array}$ & $\begin{array}{c}0.011 \\
(0.010)\end{array}$ \\
\hline $\begin{array}{l}\mathrm{p} \text {-value, five lags of government } \\
\text { expenditure }=0\end{array}$ & & {$[0.000]$} & & {$[0.000]$} \\
\hline No. of observations & 1,284 & 1,080 & 959 & 802 \\
\hline Adjusted $R^{2}$ & 0.80 & 0.93 & 0.79 & 0.94 \\
\hline
\end{tabular}

Source: Authors' regressions.

a. The dependent variable is general government expenditure, from International Monetary Fund, World Economic Outlook, as a percent of GDP. Each column reports a single ordinary least squares regression using unbalanced panel data with one observation per year per country and including country and year fixed effects. Robust standard errors, adjusted for clustering by country, are in parentheses.

We also investigated whether CBI is associated with a change in the government budget balance (again measured as a fraction of GDP). These results (not reported here) reveal no significant effect. One reason might be that governments in medium-constraints countries, which do show a significant increase in spending, may have also raised revenue. Alternatively, government balances may have improved automatically because these governments held nominal debt and benefited from the decline in interest rates associated with reduced inflation. Counteracting this, however, they are also likely to have experienced a reduction in the inflation tax.

We conclude that there is some suggestive evidence consistent with the seesaw pattern, in that in some of the cases where CBI reduces inflation, there may also be an increase in government expenditure as a share of GDP. Nevertheless, this result is not always robust, and further investigation is necessary before reaching a firm conclusion. 


\section{Conclusions}

We have argued that in order to understand when policy reform will be effective, one must understand the political context that leads to distortionary policies in the first place. Although such a claim would seem natural to those steeped in the study of political economy, it appears not to have influenced either the design of policy reform in the past or the recent wave of revisionist research on the failures of reform. Rather, scholars have taken some recent instances of failure to imply that the reforms themselves were misconceived because of second-best problems. We believe that a much more fruitful approach is to study the political economy constraints that interact with both the implementation and the effects of reform.

To develop this perspective, we constructed a simple political economy model of policy distortions and showed that when such distortions arise as a result of the political equilibrium, strong forces exerted by those actors initially benefiting from the distortions may negate the effects of the reform. The model illustrates in a simple way that both the extent of distortionary policy and the effects of reform will generally depend on political institutions, for example on various measures of the constraints on political officeholders. The first major insight of the model is that policy reform may not be effective when constraints are so weak that reform can be undermined, or when constraints are sufficiently strong that policy is unlikely to have been highly distortionary to start with. Rather, it is at intermediate values of constraints that policy reform might be most effective. The second important lesson from the model is that with multiple policy instruments, reform may lead to a seesaw effect, whereby effective or partially effective reform in one dimension leads to more-intensive use of other distortionary instruments.

The paper also provides empirical evidence consistent with these patterns in the context of CBI. Our evidence suggests that CBI is associated with significant declines in inflation in countries with medium constraints, but with no decline, or smaller declines, in countries with strong or weak constraints. There is also some evidence that, consistent with the seesaw effect, countries where CBI is associated with reduced inflation also experience an increase in government expenditure. This might partly reflect the use of an alternative policy instrument to achieve goals that high inflation was previously being used for.

Do these results imply that policy reform can never work? We do not think this is the correct conclusion, for two reasons. First, our evidence is 
consistent with the view that targeted reforms, such as anti-inflation programs and CBI, can be effective. Second, the evidence is difficult to reconcile with a naive approach that assumes that politicians adopt reforms for well-meaning reasons or because they have decided that their old policies were inappropriate. In this light, if reforms fail to be fully effective, it must be at least partly because of the constraints imposed by existing political economy factors. In particular, when reforms are promoted by international organizations and imposed on reluctant leaders, they are less likely to be effective or, at the very least, need to be designed much more carefully to ensure their effectiveness. Otherwise our model and the empirical results suggest that de jure reform may not translate into de facto reform, and when it does, other dimensions of policy may deteriorate.

The general message of our paper is that the analysis of policy reform should start with an understanding of the political economy constraints that lead to distortionary policies in the first place. This type of political economy analysis might ultimately be useful both in predicting when reforms are likely to be effective and in understanding how reforms can be better designed to reduce the risk of backlash. Although we are currently too far from a satisfactory theoretical or empirical understanding to be able to design policy reforms that are robust to such challenges, this paper and others in this vein should help make the case that an analysis of the political economic roots of distortionary policies must be part of any debate on the effectiveness and design of reforms.

ACKNOWLEDG M ENTS We are grateful to Ioannis Tokatlidis for help in constructing the data, to Marco Arnone for sending us his data, and to Alberto Alesina and David Romer for detailed comments. We are also grateful to seminar participants at the Canadian Institute for Advanced Research, the macro lunch at the Massachusetts Institute of Technology, and the Brookings Papers conference, and to Marios Angeletos, Timothy Besley, Olivier Blanchard, Leopoldo Fergusson, Torsten Persson, and Guido Tabellini for comments and suggestions. Finally, we thank Jeffry Frieden for several very helpful conversations and Lawrence Broz for guidance to the literature. 
Table A1. Classification of Countries by Strength of Executive Constraints and Institutions

\begin{tabular}{|c|c|c|c|}
\hline Country & $\begin{array}{c}\text { Coding based } \\
\text { on executive } \\
\text { constraints }^{\mathrm{a}}\end{array}$ & $\begin{array}{l}\text { Coding } \\
\text { based on } \\
\text { rule of law }{ }^{\mathrm{b}}\end{array}$ & $\begin{array}{c}\text { Coding based } \\
\text { on control of } \\
\text { corruption }^{\mathrm{b}}\end{array}$ \\
\hline Argentina & Medium & Medium & Medium \\
\hline Australia & Strong & Strong & Strong \\
\hline Austria & Strong & Strong & Strong \\
\hline Belgium & Strong & Medium & Medium \\
\hline Bolivia & Medium & Medium & Weak \\
\hline Brazil & Medium & Medium & Medium \\
\hline Canada & Strong & Strong & Strong \\
\hline Chile & Medium & Medium & Medium \\
\hline China & Weak & Medium & Medium \\
\hline Colombia & Medium & Weak & Medium \\
\hline Costa Rica & Strong & Medium & Medium \\
\hline Denmark & Strong & Strong & Strong \\
\hline Dominican Republic & Medium & Weak & Medium \\
\hline Ecuador & Medium & Weak & Weak \\
\hline El Salvador & Medium & Weak & Medium \\
\hline Finland & Strong & Strong & Strong \\
\hline France & Medium & Medium & Medium \\
\hline Germany & Strong & Strong & Strong \\
\hline Greece & Medium & Medium & Medium \\
\hline Guatemala & Weak & Weak & Weak \\
\hline Guyana & Weak & Medium & Medium \\
\hline Honduras & Medium & Weak & Weak \\
\hline India & Medium & Medium & Medium \\
\hline Indonesia & Weak & Weak & Weak \\
\hline Ireland & Strong & Strong & Medium \\
\hline Israel & Strong & Medium & Medium \\
\hline Italy & Strong & Medium & Medium \\
\hline Japan & Strong & Medium & Medium \\
\hline Korea & Medium & Medium & Medium \\
\hline Malaysia & Medium & Medium & Medium \\
\hline Mexico & Medium & Medium & Medium \\
\hline Mongolia & Medium & Medium & Medium \\
\hline Nepal & Weak & Medium & Medium \\
\hline Netherlands & Strong & Strong & Strong \\
\hline New Zealand & Strong & Strong & Strong \\
\hline Nicaragua & Medium & Weak & Weak \\
\hline Norway & Strong & Strong & Strong \\
\hline Pakistan & Medium & Weak & Weak \\
\hline Paraguay & Weak & Weak & Weak \\
\hline Peru & Medium & Weak & Medium \\
\hline Philippines & Medium & Medium & Medium \\
\hline Portugal & Medium & Medium & Medium \\
\hline Qatar & Weak & Medium & $\begin{array}{l}\text { Medium } \\
\text { (continued) }\end{array}$ \\
\hline
\end{tabular}


Table A1. Classification of Countries by Strength of Executive Constraints and Institutions (Continued)

\begin{tabular}{|c|c|c|c|}
\hline Country & $\begin{array}{c}\text { Coding based } \\
\text { on executive } \\
\text { constraints }^{\mathrm{a}}\end{array}$ & $\begin{array}{c}\text { Coding } \\
\text { based on } \\
\text { rule of law } w^{\mathrm{b}}\end{array}$ & $\begin{array}{c}\text { Coding based } \\
\text { on control of } \\
\text { corruption }^{\mathrm{b}}\end{array}$ \\
\hline Singapore & Weak & Strong & Strong \\
\hline Spain & Medium & Medium & Medium \\
\hline Sweden & Strong & Strong & Strong \\
\hline Switzerland & Strong & Strong & Strong \\
\hline Turkey & Medium & Medium & Medium \\
\hline United Kingdom & Strong & Strong & Strong \\
\hline United States & Strong & Strong & Medium \\
\hline Uruguay & Medium & Medium & Medium \\
\hline Venezuela & Medium & Weak & Weak \\
\hline
\end{tabular}

Sources: Authors' determinations based on sources indicated.

a. From Polity IV dataset.

b. From Kaufmann, Kraay, and Mastruzzi (2007) data. 


\section{APPENDIX A}

Figure B1. Difference from Average Normalized World Inflation for Countries with Weak Executive Constraints, 1972-2005

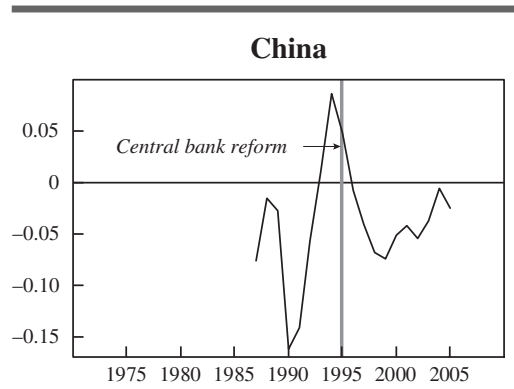

\section{Guyana}

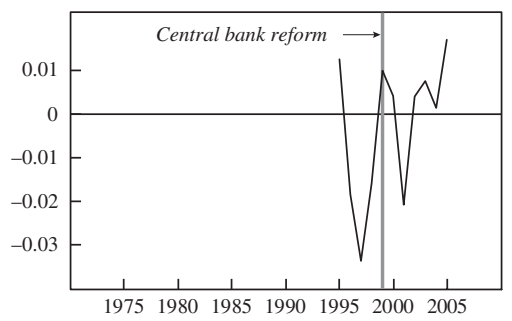

Nepal

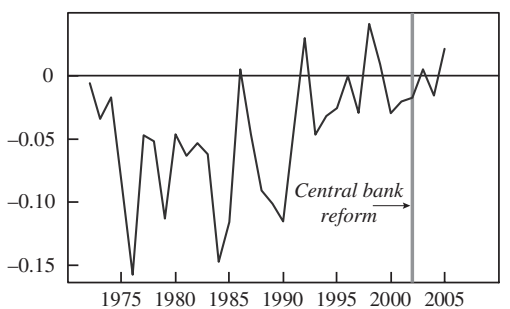

Qatar

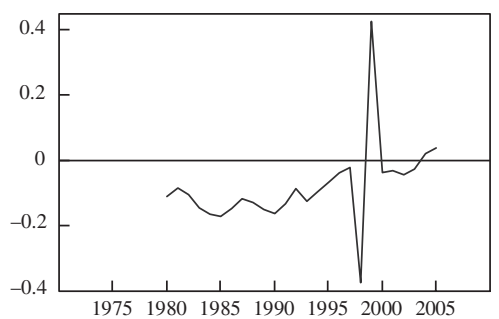

Guatemala

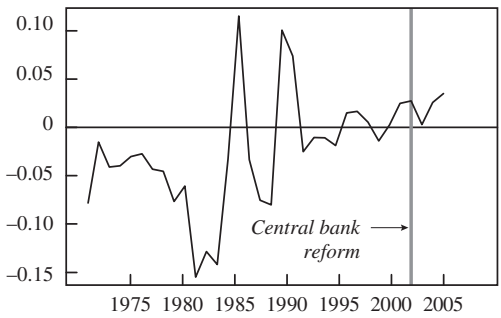

Indonesia

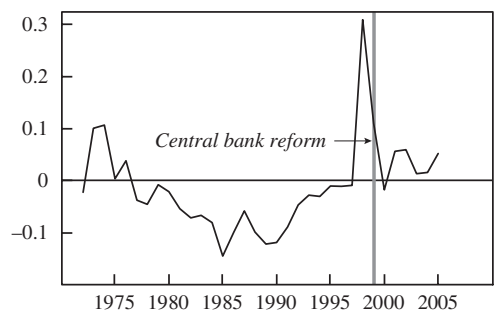

Paraguay

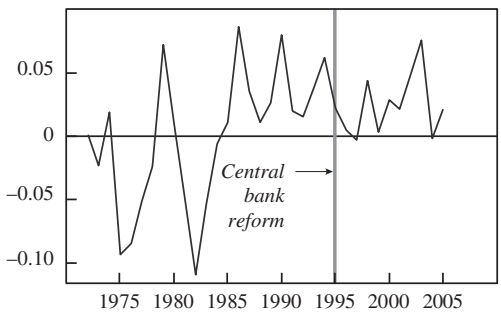

Singapore

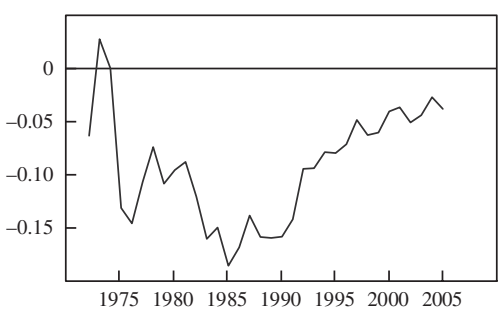

Sources: International Monetary Fund, International Financial Statistics; Jácome and Vásquez (2005).

a. Figures show difference between normalized inflation, defined as $100 \times$ [inflation/ $(1+$ inflation $)]$, in the indicated country and the world average. See text and appendix table A1 for details. 
Figure B2. Difference from Average Normalized World Inflation for Countries with Medium Executive Constraints, 1972-2005

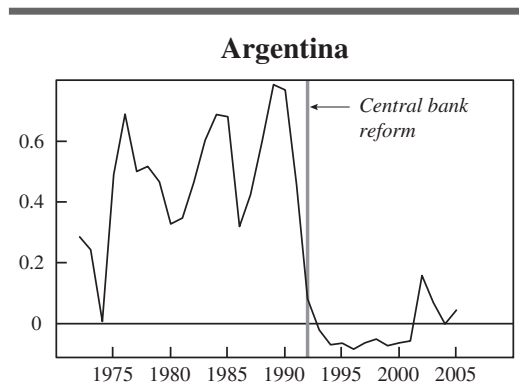

\section{Bolivia}

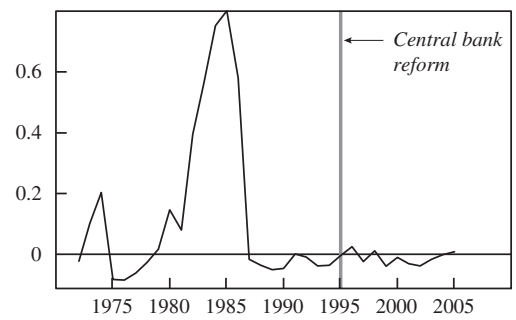

Brazil

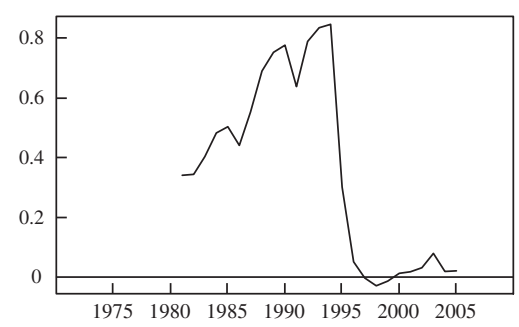

Chile

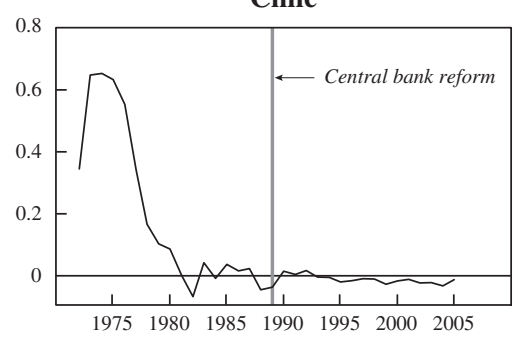

Colombia

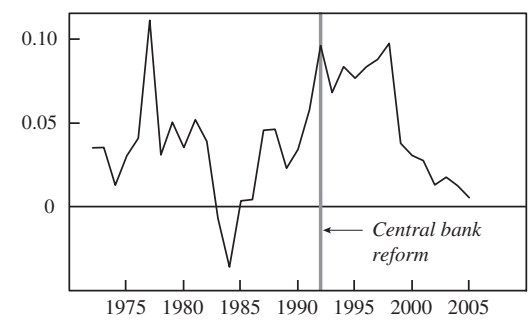

Dominican Republic

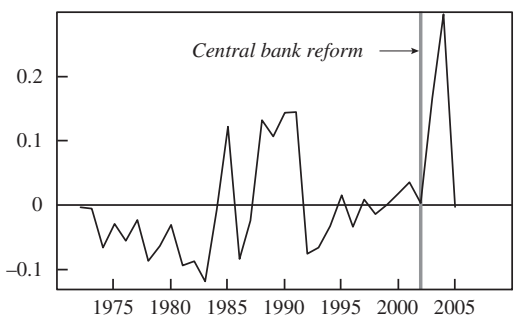

Ecuador

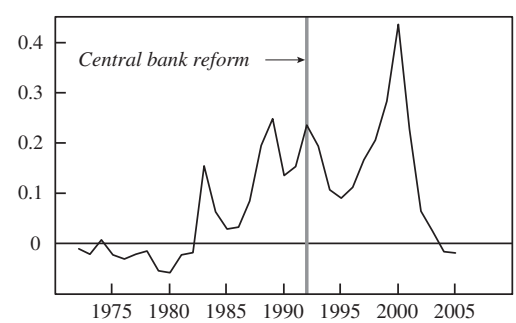

El Salvador

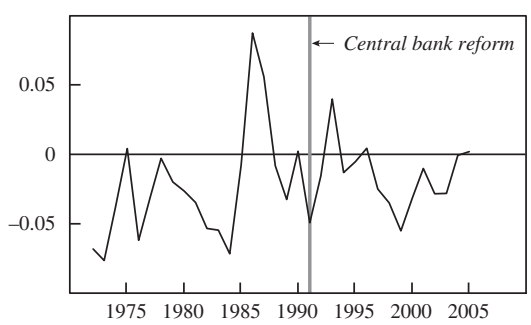


Figure B2. Difference from Average Normalized World Inflation for Countries with Medium Executive Constraints, 1972-2005 (Continued)

\section{France}

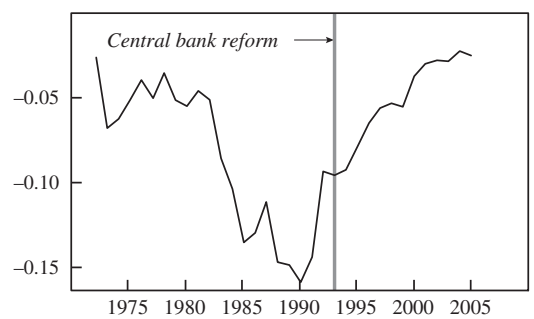

Honduras

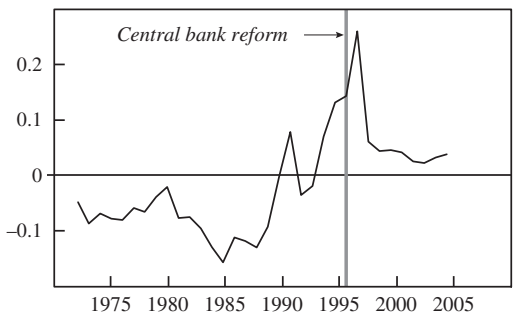

Korea

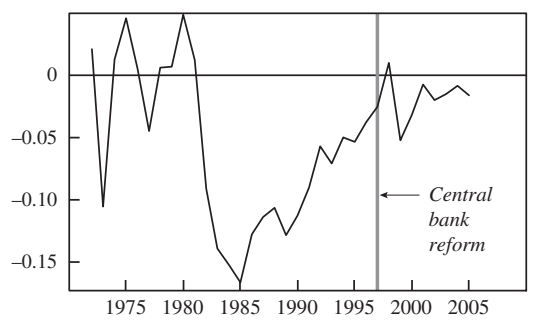

Mexico

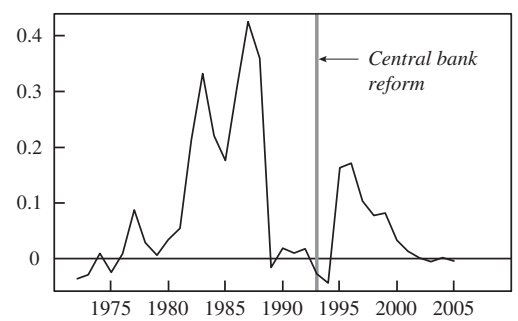

Greece

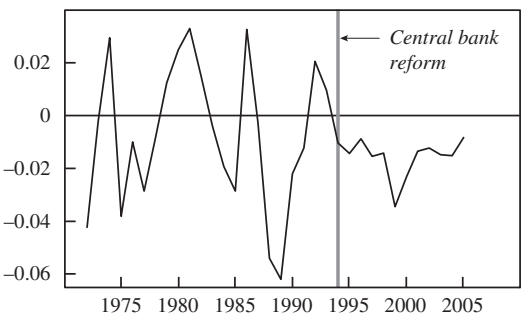

India

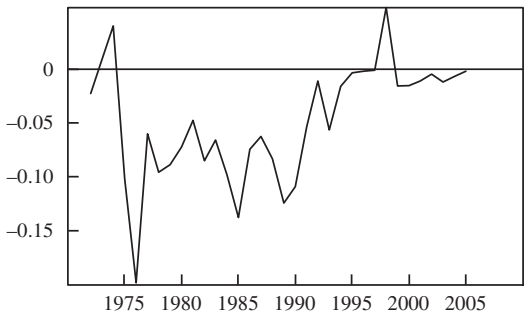

Malaysia

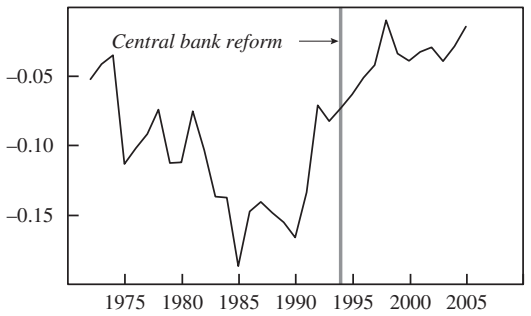

Mongolia

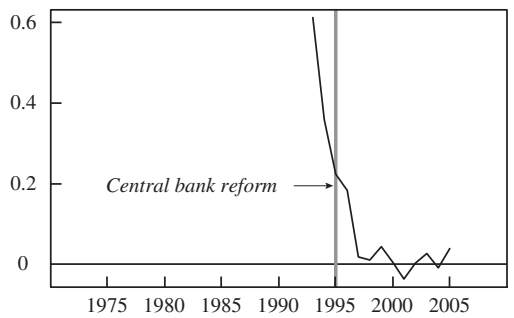

(continued) 
Figure B2. Difference from Average Normalized World Inflation for Countries with Medium Executive Constraints, 1972-2005 (Continued)

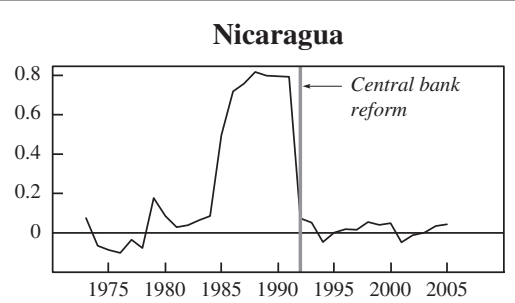

\section{Pakistan}

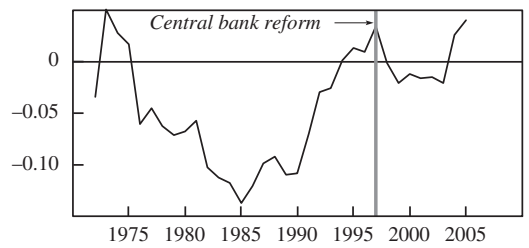

Peru

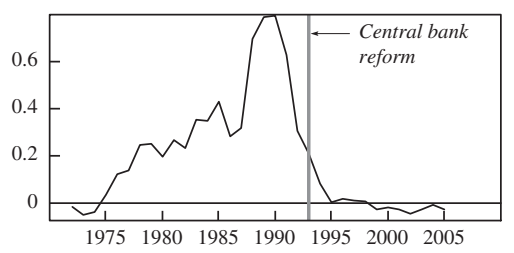

Philippines

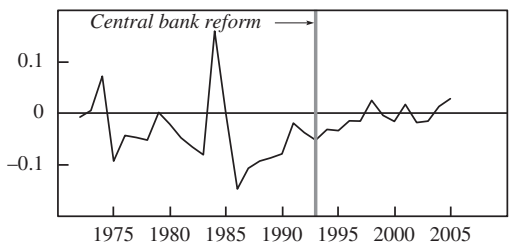

Portugal

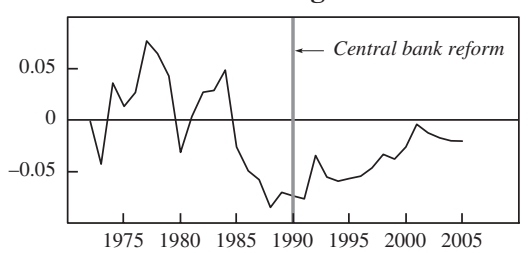

Spain

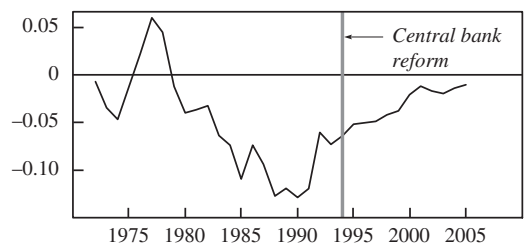

Turkey

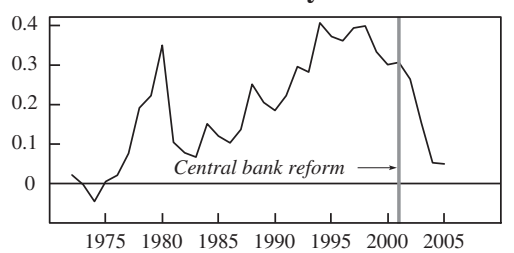

\section{Uruguay}

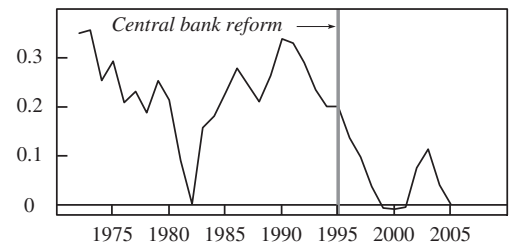

\section{Venezuela}

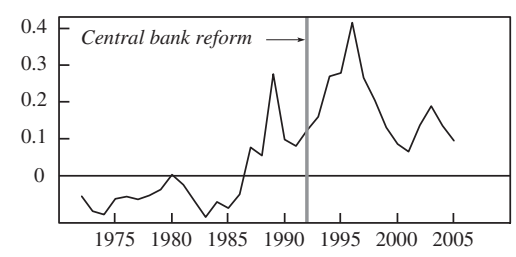

Sources: International Monetary Fund, International Financial Statistics; Jácome and Vásquez (2005).

a. Figures show difference between normalized inflation, defined as $100 \times$ [inflation/ $(1+$ inflation $)$, in the indicated country and the world average. See text and appendix table A1 for details. 
Figure B3. Difference from Average Normalized World Inflation for Countries with Strong Executive Constraints, 1972-2005
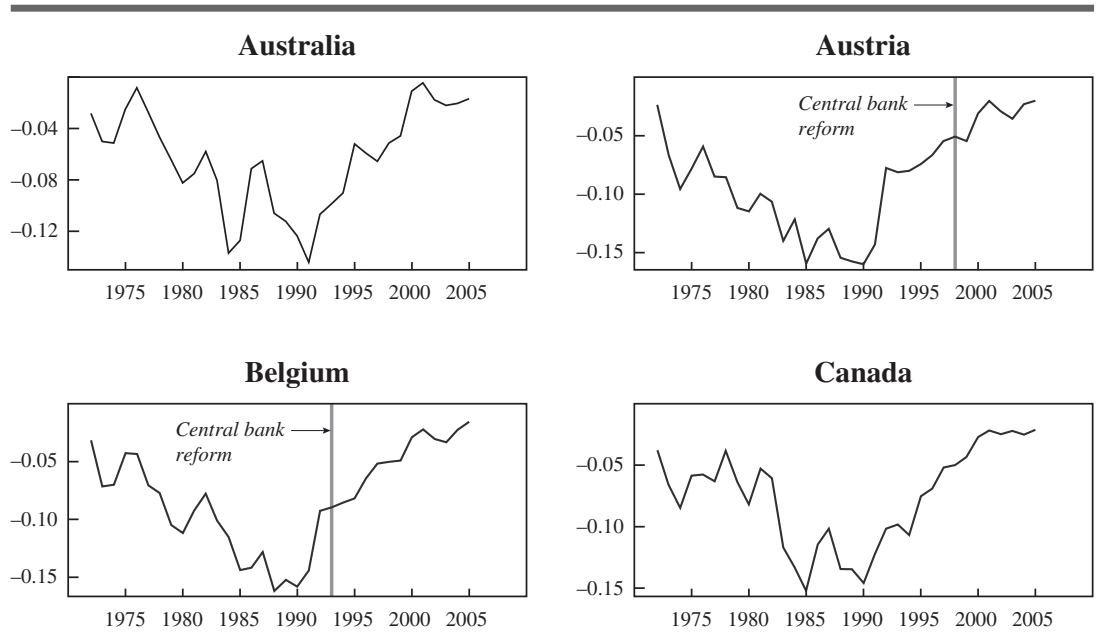

\section{Costa Rica}

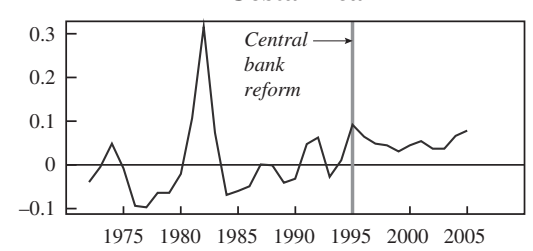

Denmark

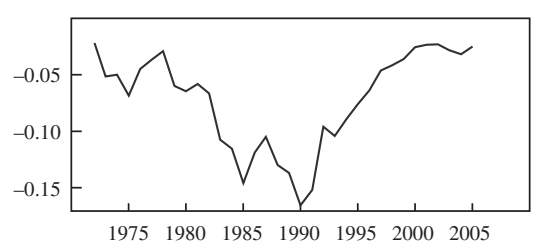

Finland

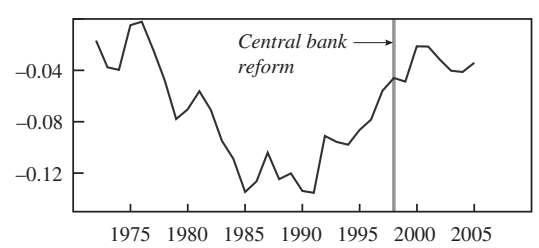

Germany

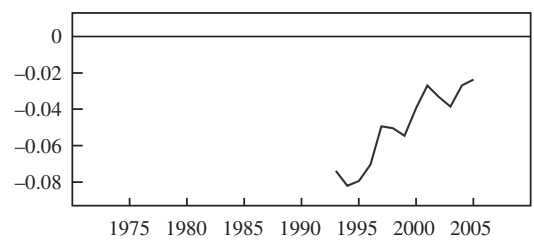

Ireland

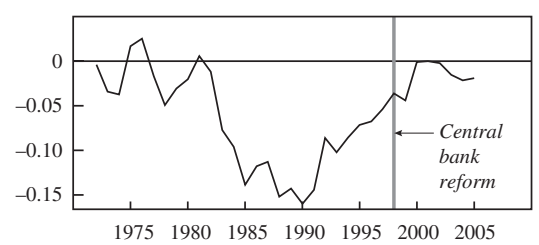

Israel

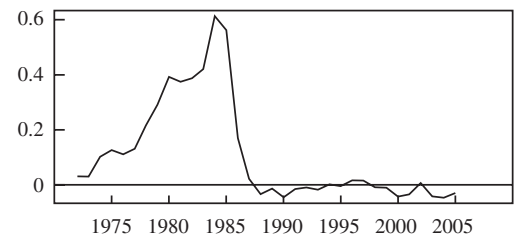

(continued) 
Figure B3. Difference from Average Normalized World Inflation for Countries with Strong Executive Constraints, 1972-2005 (Continued)
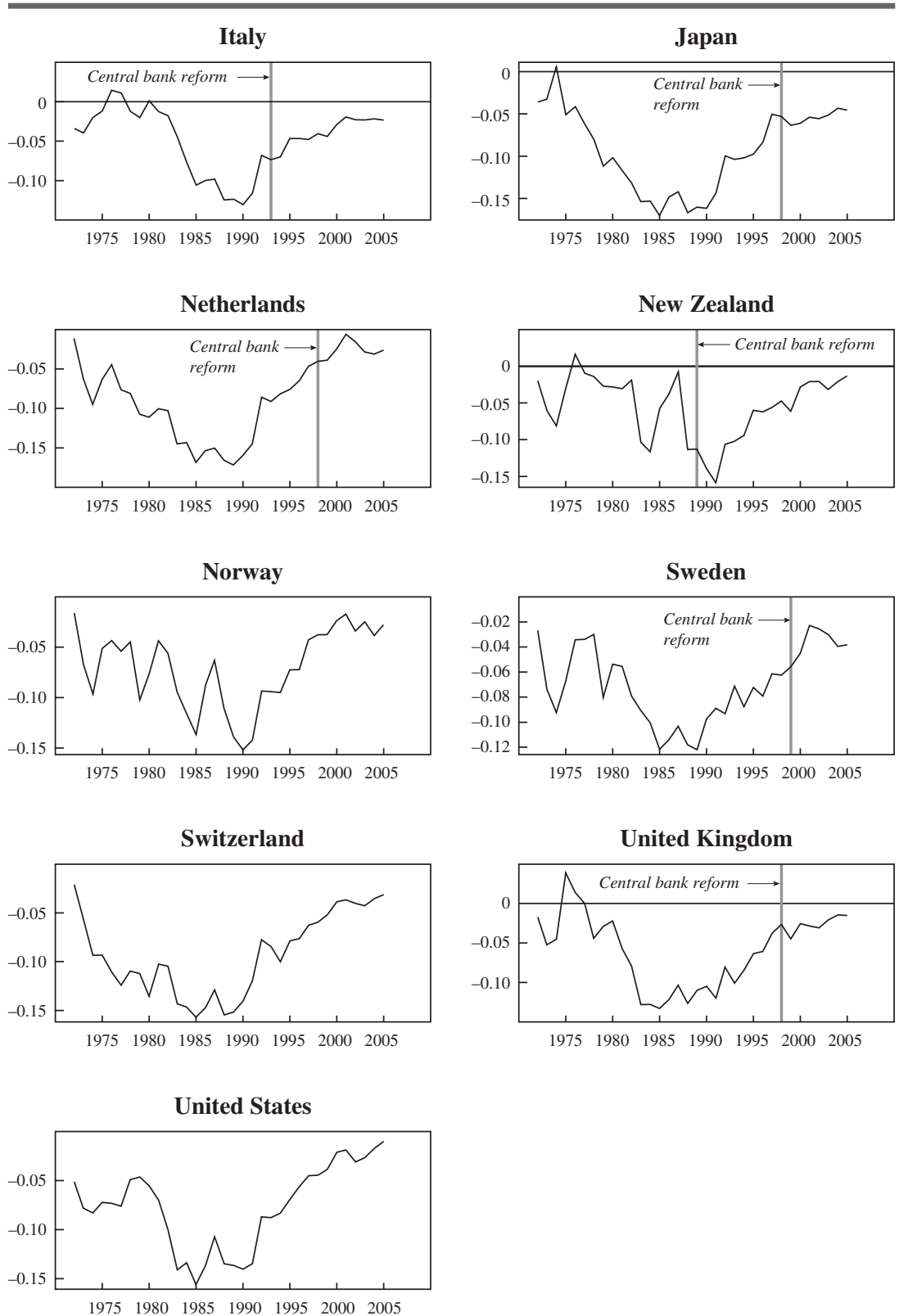

Sources: International Monetary Fund, International Financial Statistics; Jácome and Vásquez (2005). a. Figures show difference between normalized inflation, defined as $100 \times$ [inflation/ $(1+$ inflation $)$ ], in the indicated country and the world average. See text and appendix table A1 for details. 


\section{References}

Acemoglu, Daron. 2006. "A Simple Model of Inefficient Institutions." Scandinavian Journal of Economics 108, no. 4: 515-46.

Acemoglu, Daron, Simon Johnson, and James A. Robinson. 2005. "The Rise of Europe: Atlantic Trade, Institutional Change, and Economic Growth." American Economic Review 95, no. 3: 546-79.

Acemoglu, Daron, James A. Robinson, and Thierry Verdier. 2004. "Kleptocracy and Divide-and-Rule: A Model of Personal Rule." Journal of the European Economic Association 2, no. 2-3: 162-92.

Acemoglu, Daron, Simon Johnson, James A. Robinson, and Yunyong Thaicharoen. 2003. "Institutional Causes, Macroeconomic Symptoms: Volatility, Crises and Growth." Journal of Monetary Economics 50, no. 1: 49-123.

Alesina, Alberto. 1988. "Macroeconomics and Politics." NBER Macroeconomics Annual 3: 13-52.

Alesina, Alberto, and Allan Drazen. 1991. "Why Are Stabilizations Delayed?" American Economic Review 81, no. 5: 1170-88.

Alesina, Alberto, and Lawrence H. Summers. 1993. "Central Bank Independence and Macroeconomic Performance: Some Comparative Evidence.” Journal of Money, Credit and Banking 25, no. 2: 151-62.

Arellano, Manuel, and Stephen R. Bond. 1991. "Some Tests of Specification for Panel Data: Monte Carlo Evidence and an Application to Employment Equations." Review of Economic Studies 58, no. 2: 277-97.

Arnone, Marco, Bernard J. Laurens, and Jean-François Segalotto. 2006. "The Measurement of Central Bank Autonomy: Survey of Models, Indicators, and Empirical Evidence." IMF Working Paper WP/06/227. Washington: International Monetary Fund.

Arnone, Marco, Bernard J. Laurens, Jean-François Segalotto, and Martin Sommer. 2007. "Central Bank Autonomy: Lessons from Global Trends." IMF Working Paper WP/07/88. Washington: International Monetary Fund.

Aufricht, Hans. 1967. Central Banking Legislation: A Collection of Central Bank, Monetary, and Banking Laws. International Monetary Fund Monograph Series. Washington.

Banaian, King, Richard C. K. Burdekin, and Thomas D. Willett. 1998. "Reconsidering the Principal Components of Central Bank Independence: The More the Merrier?" Public Choice 97, no. 1-2: 1-12.

Barro, Robert J., and David B. Gordon. 1983. "A Positive Theory of Monetary Policy in a Natural Rate Model." Journal of Political Economy 91, no. 4: 589-610.

Bates, Robert H., and Anne O. Krueger, eds. 1993. Political and Economic Interactions in Economic Policy Reform: Evidence from Eight Countries. Oxford, U.K.: Blackwell.

Beck, Thorsten, George Clarke, Alberto Groff, Philip Keefer, and Patrick Walsh. 2001. "New Tools in Comparative Political Economy: The Database of Political Institutions." World Bank Economic Review 15, no. 1: 165-76. 
Bekaert, Geert, Campbell R. Harvey, and Christian Lundblad. 2005. "Does Financial Liberalization Spur Growth?” Journal of Financial Economics 77, no. 1: 3-55.

Boycko, Maxim, Andrei Shleifer, and Robert W. Vishny. 1996. "A Theory of Privatisation." Economic Journal 106, no. 435: 309-19.

Burnside, Craig, and David Dollar. 2000. “Aid, Policies, and Growth.” American Economic Review 90, no. 4: 847-68.

Cabrera Galvis, Mauricio, and Jose Antonio Ocampo. 1980. "Precios Internacionales, Tipo de Cambio e Inflación.” In Inflación y Política Económica, edited by Mauricio Cabrera Galvis. Bogotá: Asociación Bancaria de Colombia.

Campillo, Marta, and Jeffrey A. Miron. 1997. "Why Does Inflation Differ across Countries?" In Reducing Inflation: Motivation and Strategy, edited by Christina D. Romer and David H. Romer. University of Chicago Press.

Carrasquilla, Alberto. 1999. Estabilidad y Gradualismo: Ensayos sobre Economía Colombiana. Santafé de Bogotá: TM Editores.

Coate, Stephen T., and Stephen E. Morris. 2006. "Policy Conditionality." In Globalization and the Nation State: The Impact of the IMF and World Bank, edited by Gustav Ranis, James Vreeland, and Stephen Kosack. Routledge.

Collier, David, and Ruth Berins Collier. 1991. Shaping the Political Arena: Critical Junctures, the Labor Movement, and Regime Dynamics in Latin America. Princeton University Press.

Crowe, Christopher, and Ellen E. Meade. 2007. "The Evolution of Central Bank Governance around the World." Journal of Economic Perspectives 21, no. 4: 69-90.

Cukierman, Alex. 1992. Central Bank Strategy, Credibility and Independence: Theory and Evidence. MIT Press.

Cukierman, Alex, Geoffrey Miller, and Bilin Neyapti. 2002. "Central Bank Reform, Liberalization and Inflation in Transition Economies: An International Perspective." Journal of Monetary Economics 49, no. 2: 237-64.

Cukierman, Alex, Steven B. Webb, and Bilin Neyapti. 1992. "Measuring the Independence of Central Banks and Its Effect on Policy Outcomes." World Bank Economic Review 6, no. 3: 353-98.

Daunfeldt, Sven-Olov, and Xavier de Luna. 2003. "Central Bank Independence and Price Stability: Evidence from 23 OECD-Countries.” Working paper. Umeå University.

Dávila Ladrón de Guevara, Andrés, Rodolfo Escobedo, Adriana Gavina, and Mauricio Vargas. 2000. "El Ejército Colombiano durante el Período Samper: Paradojas de un Proceso Tendencialmente Crítico." Colombia Internacional 49/50: 148-77.

Dewatripont, Mathias, and Gérard Roland. 1997. "Transition as a Process of Large Scale Institutional Change." In Advances in Economics and Econometrics: Theories and Applications: The Seventh World Congress, edited by David M. Kreps and Kenneth Wallis. Cambridge University Press.

Dollar, David, and Jakob Svensson. 2000. "What Explains the Success or Failure of Structural Adjustment Programmes?” Economic Journal 110, no. 466: 894-917. 
Drazen, Allan. 2000. Political Economy in Macroeconomics. Princeton University Press.

Easterly, William. 2005. "National Policies and Economic Growth: A Reappraisal." In The Handbook of Economic Growth, edited by Philippe Aghion and Steve Durlauf. Amsterdam: North Holland.

Easterly, William, Ross Levine, and David Roodman. 2004. "Aid, Policies, and Growth: Comment." American Economic Review 94, no. 3: 774-80.

Echeverry, Juan Carlos. 2002. Las Claves del Futuro: Economía y Conflicto en Colombia. Bogotá: Editorial Oveja Negra.

Eijffinger, Sylvester C. W., and Jakob de Haan. 1996. "The Political Economy of Central-Bank Independence.” Princeton University Department of Economics International Finance Section.

Fernandez, Raquel, and Dani Rodrik. 1991. "Resistance to Reform: Status Quo Bias in the Presence of Individual Specific Uncertainty." American Economic Review 81, no. 5: 1146-55.

Forder, James. 1998. "The Case for an Independent European Central Bank: A Reassessment of Evidence and Sources." European Journal of Political Economy 14, no. 1: 53-71.

Galiani, Sebastián, Paul Gertler, and Ernesto Schargrodsky. 2005. "Water for Life: The Impact of the Privatization of Water Service on Child Mortality." Journal of Political Economy 113, no. 1: 83-120.

Gibson, Edward L. 1997. "The Populist Road to Market Reform: Policy and Electoral Coalitions in Mexico and Argentina." World Politics 49, no. 3: 339-70.

Grilli, Vittorio, Donato Masciandaro, and Guido Tabellini. 1991. "Political and Monetary Institutions and Public Financial Policies in the Industrial Countries." Economic Policy 13: 341-92.

Grossman, Gene M., and Elhanan Helpman. 1994. "Protection for Sale." American Economic Review 84, no. 4: 833-50.

Gutiérrez, Eva. 2003. "Inflation Performance and Constitutional Central Bank Independence: Evidence from Latin America and the Caribbean." IMF Working Paper WP/03/53. Washington: International Monetary Fund.

Henisz, Witold J. 2000. "The Institutional Environment for Economic Growth." Economics and Politics 12, no. 1: 1-31.

Jácome, Luis I. 2001. "Legal Central Bank Independence and Inflation in Latin America during the 1990s." IMF Working Paper WP/01/212. Washington: International Monetary Fund.

Jácome, Luis I., and Francisco Vázquez. 2005. “Any Link between Legal Central Bank Independence and Inflation? Evidence from Latin America and the Caribbean." IMF Working Paper WP/05/75. Washington: International Monetary Fund.

Jaramillo, Juan Carlos, Roberto Steiner, and Natalia Salazar. 1999. "La Economía Política de la Política Cambiaria en Colombia.” Coyuntura Económica 29, no. 2.

Kaufmann, Daniel, Aart Kraay, and Massimo Mastruzzi. 2007. "Governance Matters VI: Aggregate and Individual Governance Indicators 1996-2006." World Bank Policy Research Working Paper 4280. Washington: World Bank. 
Keefer, Philip, and David Stasavage. 2002. "Checks and Balances, Private Information, and the Credibility of Monetary Commitments." International Organization 56, no. 4: 751-74.

— 2003. "The Limits of Delegation: Veto Players, Central Bank Independence, and the Credibility of Monetary Policy." American Political Science Review 97, no. 3: 407-23.

Killick, Tony. 1978. Development Economics in Action: A Study of Economic Policies in Ghana. London: Heinemann.

King, Michael. 2001a. “The Bank of Canada's Pursuit of Price Stability: Reputation as an Alternative to Independence." Central Banking 12, no. 1: 68-78.

- 2001b. "Contrasting Approaches to Central Bank Independence: Australia and New Zealand." Central Banking 12, no. 2: 58-68.

La Porta, Rafael, and Florencio Lopez-de-Silanes. 1999. "The Benefits of Privatization: Evidence from Mexico." Quarterly Journal of Economics 114, no. 4: 1193-1242.

Levitsky, Steven. 2003. Transforming Labor-Based Parties in Latin America: Argentine Peronism in Comparative Perspective. Cambridge University Press.

Mangano, Gabriel. 1998. "Measuring Central Bank Independence: A Tale of Subjectivity and of Its Consequences." Oxford Economic Papers 50, no. 3: 468-92.

Maxfield, Sylvia. 1997. Gatekeepers of Growth: The International Political Economy of Central Banking in Developing Countries. Princeton University Press.

McNamara, Kathleen. 2002. "Rational Fictions: Central Bank Independence and the Social Logic of Delegation.” West European Politics 25, no. 1: 47-76.

Mehlum, Halvar, Karl-Ove Moene, and Ragnar Torvik. 2006. "Institutions and the Resource Curse.” Economic Journal 116, no. 508: 1-20.

Mukand, Sharun, and Dani Rodrik. 2005. "In Search of the Holy Grail: Policy Convergence, Experimentation, and Economic Performance." American Economic Review 95, no. 1: 374-83.

Mumtaz, Haroon, and Paolo Surico. 2006. "Evolving International Inflation Dynamics: World and Country Specific Factors.” Working paper. London: Bank of England.

North, Douglass C., and Barry R. Weingast. 1989. "Constitutions and Commitment: The Evolution of Institutions Governing Public Choice in Seventeenth Century England." Journal of Economic History 49, no. 4: 803-32.

Oatley, Thomas. 1999. "Central Bank Independence and Inflation: Corporatism, Partisanship, and Alternative Indices of Central Bank Independence." Public Choice 98, no. 3/4: 399-413.

Panagiotidis, Theodore, and Afrioditi Triampella. 2006. "Central Bank Independence and Inflation: The Case of Greece." Revista de Economía del Rosario 9, no. 1: 95-109.

Persson, Torsten, Gerard Roland, and Guido Tabellini. 1997. "Separation of Powers and Political Accountability." Quarterly Journal of Economics 112, no. 4: $1163-1202$. 
Polillo, Simone, and Mauro Guillén. 2005. "Globalization Pressures and the State: The Worldwide Spread of Central Bank Independence." American Journal of Sociology 110, no. 6: 1764-1802.

Reinhart, Carmen, and Kenneth S. Rogoff. 2004. "The Modern History of Exchange Rate Arrangements: A Reinterpretation." Quarterly Journal of Economics 119, no. 1: 1-48.

Reyes, Alvaro, Stéfano Farné, Luis Angel Rodríguez, Angela Forero, and Emilio A. Carrasco. 1998. "Empleo, Productividad e Ingresos: Colombia 1990-1996." Documento de Trabajo 66. Lima: Organización Internacional del Trabajo, ETM Países Andinos.

Roberts, Kenneth M. 1995. "Neoliberalism and the Transformation of Populism in Latin America: The Peruvian Case." World Politics 48, no. 1: 82-116.

- 2008. Changing Course: Parties, Populism and Political Representation in Latin America's Neoliberal Era. Cambridge University Press.

Rodrik, Dani. 1996. "Understanding Economic Policy Reform.” Journal of Economic Literature 34, no. 1: 9-41.

2005. "Growth Strategies.” In The Handbook of Economic Growth, edited by Philippe Aghion and Steve Durlauf. Amsterdam: Elsevier.

Rogoff, Kenneth S. 1985. "The Optimal Degree of Commitment to an Intermediate Monetary Target." Quarterly Journal of Economics 100, no. 4: 1169-89.

Shleifer, Andrei, and Robert Vishny. 1994. "Politicians and Firms." Quarterly Journal of Economics 109, no. 4: 995-1025.

Sierra Montoya, Jorge Emilio. 2004. 50 Protagonistas de la Economía Colombiana. Bogotá: Universidad Jorge Tadeo Lozano.

Slok, Torsten. 2002. "Money Demand in Mongolia: A Panel Data Analysis." IMF Staff Papers 49, no. 1: 128-36.

Stigler, George. 1971. "The Theory of Economic Regulation." Bell Journal of Economics and Management Science 2, no. 1: 3-21.

. 1972. "Economic Competition and Political Competition." Public Choice 13, no. 1: 91-106.

Stiglitz, Joseph E. 2002. Globalization and its Discontents. W. W. Norton.

Stock, James, and Mark Watson. 2007. "Why Has U.S. Inflation Become Harder to Forecast?" Journal of Money, Credit and Banking (Supplement) 39: 3-33.

van de Walle, Nicolas. 1993. "The Politics of Nonreform in the Cameroon." In Hemmed In: Responses to Africa's Economic Decline, edited by Thomas M. Callaghy and John Ravenhill. Columbia University Press.

- 2001. African Economies and the Politics of Permanent Crisis, 1979-1999. Cambridge University Press.

Velasco, Andrés. 2005. "Why Doesn't Latin America Grow More, and What Can We Do about It?" Harvard University, Kennedy School of Government.

Williamson, John. 1990. "The Progress of Policy Reform in Latin America." Policy Analyses in International Economics 28. Washington: Institute for International Economics.

Wooldridge, Jeffery M. 2002. Econometric Analysis of Cross Section and Panel Data. MIT Press. 



\section{Comments and Discussion}

\section{COMMENT BY}

ALBERTO ALESINA This paper by Daron Acemoglu and his coauthors addresses an important topic. In general terms, the question is when and how policy reforms are successful or unsuccessful. More specifically, the paper focuses on central bank independence (CBI), and its goal is to shed some light on the inconclusive results in the literature regarding the benefits of CBI on inflation. I will focus relatively briefly on the authors' model and more extensively on the empirical evidence. I conclude that the model is not especially appropriate for studying this issue and that the empirical evidence is not robust.

THE MODEL. What models have been used in the literature to study the pros and cons of CBI? The first was the model of time inconsistency and inflation bias developed by Finn Kydland and Edward Prescott and later extended by Robert Barro and David Gordon. ${ }^{1}$ The source of inflation in all these models is an interplay between wage setting behavior and the incentive of the central bank to "surprise" the economy with an inflation shock to reduce unemployment. Kenneth Rogoff pointed out how an inflation-averse and independent central banker can improve on the tradeoff between rules and discretion. ${ }^{2}$

A second approach emphasizes the political influences on monetary policy, in particular, political business cycles, both "opportunistic" and "partisan." CBI can limit the inefficient fluctuations of inflation created by

1. Finn E. Kydland and Edward C. Prescott, "Rules Rather Than Discretion: The Inconsistency of Optimal Plans," Journal of Political Economy 85, no. 3 (1977): 473-91; Robert Barro and David Gordon, "Rules, Discretion, and Reputation in a Model of Monetary Policy," Journal of Monetary Economics 12, no. 1 (1983): 101-21.

2. Kenneth Rogoff, "The Optimal Degree of Commitment to an Intermediate Monetary Target," Quarterly Journal of Economics 100, no. 4 (1985): 1169-89. 
political cycles. In this model the source of inflation is monetary policy that is excessively loose because of political influences. Alesina, Gerald Cohen, and Nouriel Roubini discuss this approach in detail. ${ }^{3}$

The third type of model focuses on biases toward fiscal deficit and the pressure on central banks to accommodate such deficits. ${ }^{4}$ In this context CBI is part of a package that ensures fiscal responsibility and avoids all excessive use of the inflation tax. Fiscal deficits are the source of inflation in this model.

The model of this paper is quite different. There is a lobby pushing for inflation, but the general public is against inflation. Not much is said in the paper about which lobby that would be in reality, nor does the paper explain why the lobby benefits from inflation. This is a good model for other issues, such as trade protection or regulation of certain sectors. And in fact, similar models have been widely used to discuss how policies that are inefficient for society as a whole are adopted to favor a specific, narrowly defined constituency. But this is not a good model for explaining why countries find themselves in a high-inflation equilibrium. Inflation is almost universally the result of some form of macroeconomic imbalance, not the effect of a small organized lobby pushing for it. The implications in terms of which governments are more likely to be successful and which will undertake reforms are different. The authors mention in passing that the model is meant to be illustrative, but I am not at all sure how their empirical implications would generalize to a more aggregate model of inflation along the lines sketched above.

An additional issue concerns the endogeneity of central bank reform. Many authors share the same problem that this paper has, ${ }^{5}$ namely, the assumption that central bank laws are considered an exogenous variable, an issue first raised by Adam Posen. ${ }^{6}$ However, I feel that this shortcoming is especially serious for this paper. In fact, it discusses interactions between political regimes and central bank reforms and the role of lobbies in pushing for more or less inflationary policies. The same political vari-

3. Alberto Alesina, Gerald Cohen, and Nouriel Roubini, Political Cycles and the Macroeconomy (MIT Press, November 1997).

4. For an extended discussion, see Torsten Persson and Guido Tabellini, Political Economics: Explaining Economic Policy (MIT Press, 2002).

5. For example, Alberto Alesina and Lawrence Summers, "Central Bank Independence and Macroeconomic Performance: Some Comparative Evidence," Journal of Money, Credit and Banking 25 (May 1993): 151-62.

6. Adam Posen, "Declarations Are Not Enough: Financial Sector Sources of Central Bank Independence,” NBER Macroeconomic Annual 10 (1995): 253-74. 
ables that make it more or less likely that a central bank reform will be successful are at the root of the question of whether central bank reform is adopted in the first place.

THE EMPIRICAL EVIDENCE. Here I will focus on some sensitivity analysis of the paper's two key tables, table 2 and table $4 .^{7}$ First of all, the results as presented in the paper are not especially strong. The theory has implications for the differences between coefficients for three groups of countries defined in terms of the strength of executive constraints. In many cases, as the authors acknowledge, these coefficients, although different from zero, are not statistically different from each other.

My first sensitivity test examined to what extent the results were driven by the Latin American countries, since this is a region that has experienced much inflation and several central bank reforms. I found that, in table 2, dropping Argentina makes all the relevant coefficients insignificant in the full sample; similar patterns hold for table 4 . The results are thus very sensitive to dropping one country.

Then I examined the groupings. The authors define their country groups as follows: the intermediate group includes all the countries within one standard deviation of the mean of their constraints index, and the strong and weak groups include those more than one standard deviation above and below the mean, respectively. The problem is that the distribution of countries is very asymmetric: 36.5 percent of the countries are bunched at the top of the distribution, with an index value of seven. Thus, the authors' distribution is as follows:

—-strong constraints (index of 7): 36.5 percent of the countries

-intermediate constraints (index between 3.92 and 6.99): 48 percent

—weak constraints (index between 0 and 3.2): 15.5 percent (that is, a handful of countries).

The results hold only if the weak-constraints group is restricted to a very small set of countries. I tried two alternative groupings that seem more reasonable: ${ }^{8}$

—strong constraints: 36.5 percent

—weak constraints: 36.5 percent

-intermediate constraints: the rest,

7. I thank the authors for providing their data and codes, which made it very easy to replicate and examine their results.

8. Note that, because of the bunching at the top, one cannot quite split the sample evenly into thirds. 
and

—strong constraints: 36.5 percent

-intermediate and weak constraints: split 50-50 between the remaining countries.

With either grouping, the results of the paper disappear: the weakconstraints group has a negative and significant coefficient, and the middle group has an insignificant and often positive coefficient. Thus even moving a handful of countries from the middle group to the weak group changes the results. Therefore the strategy of looking at the interaction of a quadratic function of the executive constraint variable with the CBI variable does not guarantee robustness to the grouping classification, contrary to the authors' claims. ${ }^{9}$

In conclusion, investigating the success of policy reforms in alternative institutional settings is a very good idea, but the paper does not use the most appropriate model to address the issue at hand, and thus it derives implications that may not be plausible. Moreover, the empirical evidence is not robust.

\section{COMMENT BY}

DAVID ROMER The thesis of this paper by Daron Acemoglu, Simon Johnson, Pablo Querubín, and James Robinson is simple but important. There has been a vast amount of work on the political economy of poor policies. Yet when it comes to thinking about the effects of policy reform, economists and policymakers too often still adopt the perspective of a benevolent social planner and assume that reforms will be implemented as intended. The basic insight of the paper is that in thinking about the effects of reform, it is a first-order mistake to overlook the forces that gave rise to the need for reform in the first place. Considering those forces can critically change what one should expect. Often the change is particularly stark: if a country is following poor policies because the rule of law is not respected, reforms that consist of passing new laws are unlikely to change anything at all. These core ideas more than repay the effort of reading the paper.

THE THEORY. The authors develop their thesis both theoretically and empirically, focusing on how central bank independence affects inflation.

9. The results of all these sensitivity tests are available from the author upon request. 
The main result of their theoretical model is that central bank reform is unlikely to reduce inflation much either in countries with unconstrained leaders (because the reform will be ineffective) or in countries with highly constrained leaders (because inflation will already be low). The largest effect is likely to occur in countries with moderate levels of constraints on their leaders.

I have three main comments about the theory. First, it appears that nothing critical hinges on the paper's assumption that excessive inflation is the result of special-interest lobbying. For example, suppose inflation arises instead from dynamic inconsistency or the political business cycle. Central bank reform would be unlikely to reduce inflation if power in fact remained in the hands of politicians, but would be likely to do so if the reform genuinely put control of monetary policy in the hands of an independent central bank. The same is true if - to mention my favorite theory of high inflation-inflation occurs because politicians understand the short-run benefits of demand stimulus but not the costs of inflation or the difficulty of bringing it down. The fact that the theoretical results do not rest on a specific view of the source of excessive inflation has the advantage that the theory is not tied to the debatable view that inflation is the result of redistributive efforts. But it has the disadvantage of reducing the ability of tests based on the theory to discriminate among competing views of the reasons for poor policies.

Second, the prediction of an inverted U-shaped relationship between constraints on politicians and the effects of central bank reform on inflation seems unlikely to be robust. There are two competing effects. On the one hand, when constraints on politicians are weaker, the prereform situation is worse, so the room for improvement is greater. On the other, when constraints are stronger, the extent to which nominal reforms are likely to have force is greater. This suggests that the overall effect can go either way, but it does not suggest a strong reason for expecting an inverted U-shaped relationship in particular. It is not difficult to find changes in functional forms or other assumptions of the model that alter the prediction of an inverted U-shaped relationship. To give a simple example, just dropping the assumption in the paper's model that inflation cannot be negative changes the relationship from an inverted $\mathrm{U}$ to monotonically increasing.

Third, a prediction that is likely to be more robust is that if one controls for initial inflation, the amount that central bank reform reduces inflation will be monotonically increasing in the strength of political constraints. Controlling for initial inflation eliminates one of the two competing effects, and so leaves only the fact that nominal reforms are likely to have more force when politicians are more constrained. 
The paper's model is not well suited to analyzing this issue, for two reasons. First, the prereform level of inflation is completely determined by the extent of constraints, so once one controls for initial inflation there is no remaining variation in political constraints. Second, the model's assumption that inflation cannot be negative means that inflation is sometimes at a corner solution. This is important to the model's implications, but it seems quite unrealistic and complicates the analysis.

I therefore consider a modest variation on the paper's model. First, I replace the paper's social welfare function with a conventional quadratic one,

$$
u(\pi)=-\frac{b}{2} \pi^{2}, b>0,
$$

where I have normalized the socially optimal level of inflation to zero. Second, I assume that the lobbyists' preferred inflation rate (or, more generally, the inflation rate that would prevail in the absence of constraints on politicians) varies across countries. Specifically, I assume that in the lobbyists' utility function, $w(\pi, t)=\alpha \pi-\frac{\beta}{2} \pi^{2}-t$ (the paper's equation 3 ), $\alpha$ may be heterogeneous. And third, I model central bank reform as an increase in the social cost of departures of inflation from its optimal level-that is, as an increase in $b$. Thus, I interpret central bank reform as an increased emphasis in the conventional (noncorrupted) policymaking arena on reaching the optimal level of inflation. The rest of the model is the same as the paper's. The politician maximizes $\lambda u(\pi)+(1-\lambda) t$, where $\lambda$ measures the strength of constraints on politicians and $t$ is the transfer from the lobby, and the lobby makes a take-it-or-leave-it offer to the politician.

Analyzing the model along the lines of the paper yields an expression for equilibrium inflation:

$$
\pi=\frac{\alpha}{\beta+\frac{\lambda}{1-\lambda} b} .
$$

This expression has two implications. First, it shows that my variant of the authors' model captures their idea that reform does not affect inflation if political constraints are either very low or very high. When $\lambda$ is zero (politicians are unconstrained), inflation equals lobbyists' preferred level of $\alpha / \beta$ regardless of how much weight is given to achieving low inflation in the conventional policymaking process $(b)$. And when $\lambda$ is one (politi- 
cians are completely constrained), lobbyists have no influence, and so inflation is zero for any level of $b$. More generally, equation $7^{\prime}$ implies the inverted U-shaped relationship that the authors' emphasize.

The second implication of equation $7^{\prime}$ is that

$$
\frac{\partial \pi}{\partial b}=-\left(\frac{\lambda}{1-\lambda}\right)\left(\frac{1}{\beta+\frac{\lambda}{1-\lambda} b}\right) \pi .
$$

That is, at a given level of inflation, the amount by which inflation falls in response to central bank reform is monotonically increasing in the strength of political constraints. The intuition is exactly that described above: trying to correct a bad outcome through some kind of nominal reform is more effective when the rule of law is stronger.

THE EMPIRICAL WORK. Let me now turn to the empirical findings. One of the most interesting aspects of the results is the absence of a strong correlation between increases in central bank independence and decreases in inflation. This is most easily seen in the figures in appendix B, which are a marvelous feature of the paper. Over the paper's sample period, forty countries increased the independence of their central bank. But in thirty-four of those countries, inflation relative to the world average either showed no clear change from its behavior before the reform or, in a number of cases, rose modestly but clearly. In only six countries was inflation following the reform clearly lower than one would have expected based on its prior behavior. This is hardly a stunning endorsement of the anti-inflationary power of central bank independence.

One can also see from these figures why the authors obtain their result about the relationship between political constraints and the behavior of inflation following central bank reform. The six countries where inflation clearly fell following reform are Argentina, Mongolia, Nicaragua, Peru, Turkey, and Uruguay; all six are in the middle group in terms of political constraints. Since only slightly more than half of the forty countries that implemented reform are in this group, this pattern would be very unlikely to occur by chance.

Looking at these correlations is interesting, and the finding that increases in central bank independence are associated with falls in inflation only in countries with intermediate levels of political constraints is intriguing. At the same time, I do not think one should get overly excited about this result, for three reasons.

First, as the authors emphasize, in most specifications the effect is only moderately statistically significant. 
Second, there is considerable room for improvement on the authors' measure of political constraints. The authors employ the average of the Polity IV measure of constraints on the executive over their full sample period, 1972-2004. This means that if a country reformed its central bank in, say, 1992, the authors' measure puts as much weight on political constraints twenty years before the reform, and ten years after the reform, as at the time of the reform. If another country had its reform in 2002, the paper's measure for this country goes back thirty years rather than twenty.

I think it is clear that, conceptually, one would like to know how constrained politicians were at the time of the reform. The extent of constraints at some point decades earlier or a decade later should not matter. What should matter for whether reform puts genuine control over monetary policy in the hands of a legally independent central bank is whether the rule of law is respected when the reform takes place. Because the Polity IV measure is not perfect, its lagged values surely convey some information about current constraints given its current value. But this hardly makes a case for the paper's approach of treating each year identically.

Putting much more weight on the measure of constraints near the time of the central bank reform changes one's views of many of the reforms. Consider the countries that the authors classify as having an intermediate level of constraints. Four of these countries (Bolivia, Spain, Turkey, and Uruguay) achieved the highest possible level of constraints a full decade before their reforms and kept them at that level through the end of the sample, and four more (Ecuador, Greece, Mongolia, and Portugal) attained the highest possible rating at least three years before their reforms and maintained it well afterward. In addition, Chile had an essentially unconstrained executive for fifteen years before its reform (although the constraints jumped to the highest possible level in the year of the reform), and Peru had a very low level of constraints from the year before its reform through six years afterward. Thus, a more appropriate measure of the constraints relevant to the effects of central bank reform would look quite different from the authors' measure. ${ }^{1}$

1. The results based on an alternative measure of political constraints reported in table 3 of the paper are not reassuring in this regard, for two reasons. First, this measure also does not systematically attempt to measure constraints around the times of central bank reforms. Second, the results with this measure suggest that central bank reform reduces inflation by at least as much under weak political constraints as under moderate constraints, which contradicts one of the paper's main hypotheses. 
Third, the paper looks only at the model's predictions about changes in inflation in response to changes in central bank independence, while the model makes a rich set of predictions about the level of inflation and how it responds to changes in both central bank independence and political constraints. For example, as I described, the model makes predictions about the strength of political constraints and the fall in inflation following central bank reform controlling for initial inflation. And it appears that at least one of the model's major predictions about those additional dimensions fails. The model predicts that with weak political constraints, inflation will be high both before and after central bank reform. But as the authors mention, this is not what the data show: in the eight countries in the weakconstraints group, inflation has been generally below the world average in seven.

Thus, as with many other valuable papers, this paper's contribution lies more in raising issues than in resolving them. The paper does not come close to settling the issue of how the political economy forces that give rise to poor policies affect the consequences of policy reform. But it makes a compelling case that those effects are likely to be large and important.

GENERAL DISCUSSION Gregory Mankiw wondered how best to take political economy constraints into consideration when doing policy analysis. If all outcomes are assumed to be the result of political constraints, analyzing the welfare implications of alternative policies becomes a purely academic exercise. This paper seemed to propose a compromise: sometimes policy can be altered to improve overall welfare, but other times it is determined by politics. Mankiw was not sure how helpful this perspective would be in practice.

Justin Wolfers suggested that some of the data used in the paper may be unreliable. For example, the data from Zimbabwe indicate that the central bank is independent, which, practically speaking, is probably not the case. The lesson to draw from this paper may be not that central bank reform is futile when political institutions are weak, but rather that central bank reform is futile when institutions are weak and the reforms are not actually being implemented. Conversely, some countries, such as Australia, have de facto central bank independence before they formalize it in law, so the formal policy change appears to have little effect. This should not lead one to conclude that central bank independence is ineffectual in such countries, however. 
Michael Woodford questioned the relationship between constraints on the executive and the effect of policy reform on inflation. In countries with strong constraints, changes in central bank law might simply be less correlated with other important monetary policy changes. For example, the paper cites as pertinent policy changes the 1999 Riksbank Law in Sweden and the 1998 Bank of England Act in the United Kingdom. In fact, the most important anti-inflationary policy changes in both countries probably occurred in 1992, following the crisis in the European fixed exchange rate regime. Likewise, the 1998 Bank Act in the Netherlands is cited as an important policy change, but probably the most important anti-inflationary actions were those taken following the Maastricht Treaty at the beginning of the 1990s. The paper does not list any major reform in the United States during the sample period because there were no changes to the Federal Reserve Act; however, there was an important change in the character of U.S. monetary policy with the accession of Paul Volcker as Federal Reserve chairman at the beginning of the 1980s.

Benjamin Friedman raised another issue that appears in the literature on central bank independence, namely, the correlation between independence and the country's sacrifice ratio, a measure of the output cost of lowering inflation. If central bank independence delivered lower inflation by anchoring inflation expectations, this would imply that if some supply shock were to cause inflation to increase unexpectedly, a country that has an independent central bank should be able to return to low inflation at lower cost than one that does not. However, it turns out that the correlation goes in the other direction: countries with more independent central banks tend to have worse sacrifice ratios. This casts doubt on the notion that the relationship between central bank independence and low inflation is causal, and it suggests that these phenomena may be jointly caused by some third variable. Therefore Friedman proposed that the authors look at the relationship between the variables they examine and the countries' sacrifice ratios to see what this implies about their model.

Edward Glaeser also recommended that the authors examine the interaction between central bank independence and other country-level variables. The observed correlation between central bank independence and constraints on the executive may be caused by a third variable that jointly determines both, such as GDP.

Gary Becker observed that shifts in political power often facilitate policy changes. Examining such power shifts, in addition to the legal reforms studied in the paper, might be useful. Olivier Blanchard noted that the reasons for central bank reform are important in influencing outcomes and are 
missing from the paper's argument. Some countries adopt central bank independence because of pressure from international organizations or from other countries. Christopher Sims added that, in some instances, central bank independence is simply a bad idea that economists have forced onto a complicated and unfavorable political environment. Without the institutions and fiscal policies necessary for an independent central bank to be effective, central bank reform can become little more than an excuse for the legislature to abdicate responsibility for inflation. 
